
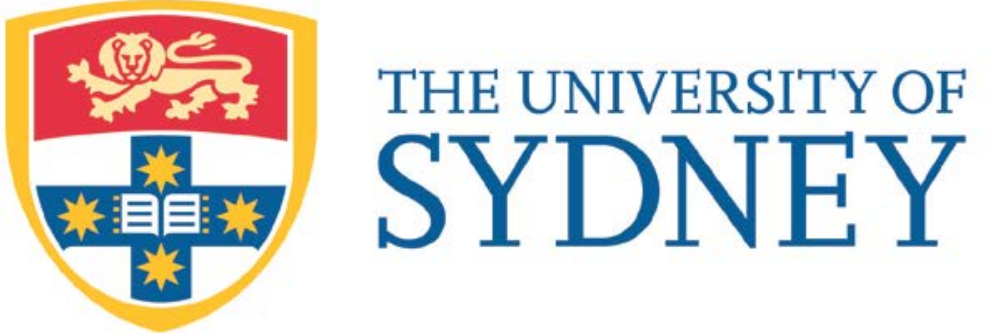

Economics Working Paper Series

$2016-16$

\title{
Avoiding Convictions: Regression \\ Discontinuity Evidence on Court Deferrals for First-Time Drug Offenders
}

Michael Mueller-Smith and Kevin T. Schnepel

November 2016 


\title{
Avoiding Convictions: Regression Discontinuity Evidence on Court Deferrals for First-Time Drug Offenders
}

\author{
Michael Mueller-Smith* Kevin T. Schnepel ${ }^{\dagger}$
}

Draft date: November 30, 2016

\begin{abstract}
This paper studies the causal impact of court deferrals, a legal strategy to help defendants avoid a felony conviction record, on the future criminal and labor market outcomes of first-time felony drug offenders. To accomplish this, we exploit two natural experiments in Harris County, Texas, in which defendants appearing in court one day versus the next experienced abruptly different likelihoods of deferral. In 1994 deferral rates dropped by 34 percentage points the day following the implementation of a penal code reform; in 2007 deferral rates increased by 22 percentage points the day after the unexpected failure of a ballot initiative to expand the county jail. Using administrative data and local polynomial regression discontinuity methods, we find robust evidence consistent across both experiments that regimes with expanded use of court deferrals generated substantially lower rates of reoffending and unemployment over a five-year follow-up period. Additional analysis delves further into the timing, nature and incidence of these impacts. Together our results suggest that increasing the use of deferral programs may be an attractive and feasible option for a jurisdiction seeking to reduce the fiscal cost and community impact of its criminal justice system.
\end{abstract}

Keywords: felony records, criminal justice, drug offenders, recidivism, labor market

\section{JEL classification codes: J24, K14, K42}

\footnotetext{
*mgms@umich.edu, Department of Economics, University of Michigan

${ }^{\dagger}$ kevin.schnepel@sydney.edu.au, School of Economics, The University of Sydney

Acknowledgements: We thank Martha Bailey, Steve Billings, John Bound, Charlie Brown, Jennifer Doleac, Ben Hansen, Aurelie Ouss, Becky Pettit, David Phillips, Jeffrey Smith, and Glen Waddell for helpful comments and suggestions; conference participants at the 2015 Southern Economic Association Annual Meetings, 2016 NBER Summer Institute, the 8th Transatlantic Workshop on the Economics of Crime and the 11th Annual Conference on Empirical Legal Studies; and seminar participants at Cornell University, Clemson University, Rutgers University, University of Chicago Crime Lab New York, University of Oregon, University of Texas at Austin, University of Virginia, and Victoria University Wellington. We also thank Christopher King and Greg Kumpton at the Ray Marshall Center. This research was supported in part by NICHD center and training grants to the Population Studies Center at the University of Michigan (R24 HD041028 and T32 HD007339).
} 
Beginning in the 1970s with "The War on Drugs," the United States embarked on a sustained period of harsh, punitive sanctioning for drug offenses. ${ }^{1}$ In many states, drug offenses were elevated from misdemeanors to felonies and commonly punished with incarceration. The impacts of these changes are widespread; nearly 10 percent of the U.S. adult population (and 33 percent of African-American adult males) now carry a felony conviction ${ }^{2}$ and the number of individuals in prisons and jails for drug offenses increased from around 40,000 in 1980 to nearly 500,000 in $2014 .^{3}$

New proposals have emerged to roll back these stringent drug policies as local jurisdictions confront dire budget and overcrowding challenges. At the federal level, the Fair Sentencing Act of 2010 (Public Law 111-220) and the Sentencing Reform \& Corrections Act of 2015 (Senate Bill 2123) reduce criminal sanctions for certain types of drug offenders and include provisions to allow more judicial discretion when sentencing low-level drug offenders. A similar shift has also been observed at the state and local level with more than 30 states passing laws decreasing sanctions for drug offenses since 2009 (Subramanian and Moreno 2014).

One example of this trend is the emerging use of agreements that allow defendants to avoid a criminal felony conviction through completing a probationary period without incident, such as a deferred prosecution or a deferred adjudication of guilt, ${ }^{4}$ which we colloquially refer to as court deferrals. ${ }^{5}$ In contrast to the establishment of specialized drug courts and treatment programs, this approach requires fewer public resources since the deferral programs typically rely on established community supervision programs (e.g. probation) and can be rapidly implemented.

Despite the increasing prevalence of deferral programs in the criminal justice system, little is known about their causal impact on defendants' future behavior. ${ }^{6}$ Growing research on the

${ }^{1}$ In 1971, President Richard Nixon labeled drug abuse "America's public enemy number one" and called for an "all-out offensive" (Subramanian and Moreno 2014).

${ }^{2}$ These estimates are based on a combination of current work by Shannon et al. (2016) and our calculations of the fraction of felony sentences which are drug-related from the State Court Processing Statistics (United States Department of Justice, Office of Justice Programs and Bureau of Justice Statistics 2014).

${ }^{3}$ See The Sentencing Project (2014) for details on the estimated drug offender population in incarceration.

${ }^{4}$ Also known as "probation before judgment," "deferred disposition," or "deferred sentence" depending on the local jurisdiction.

${ }^{5}$ At the extreme end, some jurisdictions have explored court diversions that fully eliminate any form of prosecution as well as correctional supervision for specific low-risk offenses. Programs of this nature are outside the scope of this project.

${ }^{6}$ Chiricos, Barrick, Bales and Bontrager (2007) find that two-year recidivism rates among offenders with a court deferral agreement are significantly lower compared with convicted offenders using data from Florida. While 
impact of felony convictions (Raphael 2014, Lovenheim and Owens 2014, Finlay 2009, Pager 2008, 2003), ${ }^{7}$ as well as criminal sanctions (Mueller-Smith 2015, Aizer and Doyle 2015, Di Tella and Schargrodsky 2013), suggest that these programs could affect a wide array of outcomes. ${ }^{8}$

To the best of our knowledge, this study provides the first quasi-experimental empirical evidence on the effect of changes in the use of court deferrals on recidivism and labor market outcomes. ${ }^{9}$ We exploit two natural experiments in Harris County, Texas (TX), which dramatically altered the provision of deferral agreements to drug offenders. The first follows a TX penal code reform in 1994 which discontinuously decreased court deferrals for first-time felony drug offenders, while the second tracks the fallout from an unexpected failure of a 2007 ballot initiative intended to expand local county jails but which instead resulted in an immediate increase in the deferral rate. In both contexts, marginal defendants who did not receive a deferral were convicted of a drug felony offense.

What is particularly attractive about these policy shifts from a research perspective is that each was implemented quite rapidly such that defendants charged or disposed one day versus the next experienced distinctly different court verdicts and sanctions but do not differ across any observable predetermined characteristics. Additionally, through studying two experiments that together exhibit both increasing and decreasing rates of deferrals for drug offenders, we can be more confident that our estimates are not simply capturing other unobserved changes contemporaneous with the discontinuities.

Because of the immediate nature of these changes, we use a regression discontinuity (RD) research design to demonstrate that court deferral (and consequently conviction) rates change sharply across the thresholds and present reduced form evidence on how these changes affect

the authors control for offender and county characteristics, estimates may suffer from bias since variation in conviction status is endogenous.

${ }^{7}$ Uggen, Vuolo, Lageson, Ruhland and Whitham (2014) find smaller effects on employment opportunities of low-level arrest records using a similar audit design as Pager (2003), suggesting that employers would respond to a difference between an arrest and a felony conviction when evaluating applicants.

${ }^{8}$ Also relevant to our study, Green and Winik (2010) focus on a sample of drug felony defendants and exploits the random assignment to judges differing in severity. This study does not find significant differences in recidivism among offenders incarcerated or offenders sentenced to probationary supervision relative to those not receiving either of those sanctions.

${ }^{9}$ Additionally, we provide the first causal evidence (to our knowledge) on the effect of a felony conviction record that does not rely on an audit or correspondence design, which we believe is a strong contribution to the criminal record literature as well. 
future criminal justice and labor market outcomes. ${ }^{10}$ Our results are documented graphically and through formal statistical tests. The common finding across these two quasi-experiments is that court deferrals substantially improve outcomes for drug offenders over a five-year follow-up period. We observe statistically significant and economically meaningful changes in recidivism, driven mainly by changes in drug possession and property offenses, as well as in employment and earnings, with the strongest effects observed for the 2007 sample. An evaluation of the joint determination of future behavior suggests these outcomes are interdependent. Our effects appear to be driven by young, African-American men with a misdemeanor record, a group that exhibits the highest likelihood of future interaction with the criminal justice system during the five-year follow-up period.

We do not find evidence of any significant discontinuities in observable demographic characteristics, prior criminal histories, or the density of the criminal caseload. These results support our argument that these two natural experiments present valid contexts for the use of a RD methodology. We conduct a number of robustness tests to verify that our results do not rely on any specific implementation design or functional form in addition to a variety of placebo exercises to validate these findings.

We contribute to a large literature investigating the impact of criminal sanctions on reoffending and other outcomes. Our results are consistent with recent evidence suggesting that punitive sanctions and criminal records may have a scarring effect on individuals (Mueller-Smith 2015, Aizer and Doyle 2015, Di Tella and Schargrodsky 2013, Shapiro and Chen 2007), which could operate directly through transmission of criminal capital among peers while incarcerated (Bayer et al. 2009, Ouss 2011, Stevenson 2015) or due to penalties in the labor market (Raphael 2014, Finlay 2009, Pager 2008, 2003). Our results are also consistent with a potential labeling effect within the criminal justice system wherein those with a felony record are treated differently by police, prosecutors, or judges in future criminal justice interactions. ${ }^{11}$

\footnotetext{
${ }^{10}$ Appendix A presents fully replicated results using a research design rooted in time series econometrics that relaxes the assumption of independence between observations along our running variable.

${ }^{11}$ For instance, certain types of prior convictions can trigger aggravated (elevated) charges upon reoffense which results in more severe and potentially more certain future convictions. Additionally, defendants under varying forms of supervision may face differing probabilities of arrest conditional on criminal activity. We are not aware of any empirical evidence that confirms this to be the case however.
} 
Our findings suggest that these scarring and criminogenic mechanisms outweigh any decrease in reoffending through specific deterrence or incapacitation. This is perhaps surprising given recent research to the contrary. Hansen (2015) shows compelling evidence that stricter penalties applied to drunk drivers in Washington reduced future reoffending. Many other studies document a decrease in reoffending from increasing incarceration rates through an incapacitation effect (Buonanno and Raphael 2013, Barbarino and Mastrobuoni 2014, Johnson and Raphael 2012, Owens 2009, Kuziemko and Levitt 2004, Levitt 1996). One explanation to reconcile these conflicting results is that the outcomes for different types of offenders are more or less affected by various mechanisms. Through focusing on first-time drug offenders, we may be examining a population that, on average, does not exhibit a strong specific deterrence response to prior punishments. Moreover, incapacitation may exert a smaller influence on reoffending for this population relative to other types of criminals due to the typically short length of incarceration and lower overall rate of offending. ${ }^{12}$

One may also expect aggregate changes in drug crime activity around the discontinuities we study as a result of a general deterrence effect. Such changes would imply a change in the number and composition of offenders around our threshold dates and would be a threat to our identification strategy. Several recent studies find evidence of general deterrence (Helland and Tabarrok 2007, Drago et al. 2009, Abrams 2012); however, we do not find any clear indication that general deterrence operates in the context of either of our natural experiments. There are no changes in the number of first-time felony drug charges or in the characteristics of the defendants across the two discontinuities. This is consistent with another body of evidence that fails to observe general deterrence responses among young offenders reaching the age of maturity (Lee and McCrary 2016), and with results suggesting that drug offenders are more present-oriented (low discount factors and short time horizons) and, therefore, less responsive to changes in expected punishment than other types of offenders (Mastrobuoni and Rivers 2016). ${ }^{13}$

\footnotetext{
${ }^{12}$ Kuziemko and Levitt (2004) find a small aggregate response of crime to the dramatic increase in incarceration rates for drug-related offenses in the U.S. during the 1980s and 1990s and suggest that this was not due to a lack of incapacitation but instead because incarcerating drug offenders displaced other types of offenders from prisons who exhibited similar levels of incapacitation resulting in a small net impact. While this and other studies find incapacitation effects for drug offenders, our focus on first-time offenders may imply lower levels of prevented crime from incapacitation.

${ }^{13}$ It is possible that the two discontinuities we exploit were not salient to potential offenders which is why we do not observe discontinuous changes in caseload composition. This is particularly true for the 2007 experiment
} 
Overall, our results suggest that greater use of court deferrals for first-time drug felony offenders will lead to long-term reductions in criminal offending and improvements in labor market outcomes. A potential concern with this conclusion is that individuals without any criminal involvement may suffer through statistical discrimination. For instance, an employer averse to hiring former offenders who no longer observes the prior criminal activity of job applicants may decrease his propensity to hire individuals who are part of high-offending demographic groups. Agan and Starr (2016) and Doleac and Hansen (2016) find decreases in employment outcomes for young black males following the implementation of "Ban-the-Box" policies, which restrict questions about felony convictions on employment applications. While we are not able to test for such effects given our research design, we believe this mechanism might be stunted in this context given evidence that employers are less averse to hiring former drug offenders relative to other types of felons (Holzer et al. 2007). In this case, court deferrals would permit drug offenders to avoid being pooled with more undesirable convicts without imposing much harm on the non-offending population.

The remainder of the paper is structured as follows: Section 1 describes the two sharp changes in criminal sanctions for drug offenders in Harris County, TX; Section 2 describes the administrative data sets used; Section 3 outlines our regression discontinuity empirical strategy; Section 4 presents and discusses our results and provides evidence supporting our identification assumptions; and, Section 5 includes concluding remarks.

which did not arise due to any official change in policy. Because the 1994 changes were publicly enacted in early 1993 and could be fully anticipated by would-be criminal offenders, it is more surprising that no general deterrence response is observed for that time period. 


\section{History and Background on the Two Natural Experiments}

\subsection{Penal Code Reform}

In 1993 the Texas Legislature enacted its most sweeping sentencing reform in the history of the state. ${ }^{14}$ It was motivated in large part in response to major overcrowding in its prisons and county jails dating back to the 1970s and 1980s and introduced several measures to limit the state's dependence on incarceration. ${ }^{15}$ The new sentencing regime applied only to defendants who had committed their offenses on or after September 1, 1994, ${ }^{16,17,18}$ and since prosecutors were required to file charges within 48 hours of arrest there was limited ability to manipulate who was charged when. ${ }^{19}$

While the new legislation was intended to relieve the burden of overcrowding, it had the unanticipated consequence of dramatically increasing conviction rates and discouraging the use of court deferrals. The rate of first-time drug offenders receiving a deferral plummeted from over 50 percent to less than 20 percent after the new policies went into effect (Figure 5).

The main determinant of this drop was the lost ability of assistant district attorneys to use the threat of incarceration as leverage to enforce the terms of court deferrals. The new sentencing regime required probation before incarceration for most first-time felony drug offenders which meant that a second round of probation would have to be given to those who violated a deferral

\footnotetext{
${ }^{14}$ Two pieces of legislation accomplished this overhaul: Senate Bill 1067 reclassified most non-violent felony crimes as "state jail felonies," a newly created offense level below a $3^{\text {rd }}$ degree felony; and, Senate Bill 532 created "state jails," correctional institutions set up specifically for individuals who had been convicted of state jail felonies.

${ }^{15}$ Individuals convicted of a state jail felony would still be considered as having a felony record by the state but would be subject to different sentencing guidelines. These new guidelines limited the maximum incarceration sentence to two years and required a probated (conditional) incarceration sentence for defendants without prior state jail felony convictions.

${ }^{16}$ In practice, it appears that the courts used the charging date rather than the offending date as the key variable for determining which code applied.

${ }^{17}$ Offenses occurring prior to September 1, 1994, but not disposed until after this cutoff date were not grandfathered into the new policy regime.

${ }^{18}$ Additional provisions in the penal reform specific to only violent offenders (which are beyond the scope of this study) went into effect a year earlier on September 1, 1993.

${ }^{19}$ In our empirical estimation, we drop individuals charged on August 31, 1994 and September 1, 1994 to avoid any issues with sorting within the 48 hour threshold.
} 
agreement. This precise issue was raised in October 1993 during a simulated plea bargaining exercise between prosecutors and defense attorneys, yet no action was taken to amend the statutory language before the changes were implemented (Fabelo 1997). The majority of the would-be court deferrals were instead given formal felony convictions. For those charged just after the new regime went into effect, it was very unlikely they would be able to escape a permanent felony conviction record.

\subsection{The 2007 Failed Jail Expansion Ballot Initiative.}

Overcrowding in prisons and jails remained an important concern across Texas during the 2000s, especially in the Harris County Jail. This local jail-which houses inmates with shorter sentences and serves several other functions including pre-trial detention and holding for local inmates waiting to be transferred to the state prison system-had up to 1,900 inmates sleeping on mattresses on the floor by 2005 (Hughes 2005). To address overcrowding, the county sought to expand the jail capacity by 2,500 beds with $\$ 195$ million to be raised through county bonds for construction of a new jail facility. ${ }^{20}$

A local campaign against the jail expansion and an unexpectedly large voter turnout on November 6, 2007 led to a narrow and unexpected defeat of the initiative by a vote of 50.6 to 49.4 percent. This outcome was particularly surprising given that all of the other local bonds were approved, and a $\$ 1$ billion state-wide bond to expand state prison capacity was overwhelmingly approved (58.2 to 41.8$)$.

The local campaign against the jail expansion proposition suggested that the intended location of the new jail would be bad for local economic development and that existing infrastructure could be more efficiently used with less reliance on incarceration. Some commentators explicitly placed the responsibility of the overcrowding problem on the courts in Harris County, suggesting that they depended too heavily on incarceration at the cost of taxpayer funds. ${ }^{21}$

\footnotetext{
${ }^{20}$ The proposed jail expansion (Proposition 3) was part of a broader bond package being put to local voters in 2007 in response to the county's fast growing population. Together Harris County and the Port of Houston Authority added six local bond propositions to the November 6, 2007 election ballot at combined total of $\$ 880$ million in potential bonds. The projects included upgrading roads and parks, expanding capacity at the port, building a new forensic lab and constructing a new family law center.

${ }^{21}$ See the following articles for discussions at the time of the election: Snyder (2007), Grits for Breakfast (2007b),
} 
Most Harris County criminal courts took notice of the results and responded immediately after the election. In the days, weeks and months following, guilty verdicts dropped from around 65 percent to 40 percent with most of these cases shifting into court deferrals (Figure 5). A small fraction of cases even appear to have had their charges altogether dismissed as a result of the election (Figure 5). With the drop in guilty rates, incarceration rates decreased and were replaced by community-supervised probation (Figure 6).

These changes accomplished two goals for the courts. First, they were able to show that they were responding to their pre-election critics, an important task given that both the district attorney and the criminal court judges are publicly elected officials in Harris County. And second, it immediately reduced the inflow of inmates into the jail system which would help alleviate the

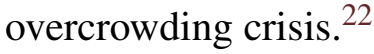

\section{Data Sources and Sample Restrictions}

In order to empirically evaluate the effect of these large shifts in sanctions, this paper utilizes several sources of administrative data including: criminal court records from the Harris County District Clerk, jail booking and spell data from Harris County Sheriff's Department, and state incarceration data from the Texas Department of Criminal Justice. ${ }^{23}$ To evaluate the impact of these different sanctions on labor market outcomes, we also link offenders to administrative earnings and employment data. Quarterly unemployment insurance wage records for Texas between 1994 and 2016 were accessed through a data sharing agreement with the Texas Workforce Commission.

The criminal court record database contains felony and misdemeanor charges and court outcomes for all adults between 1980 and 2013 regardless of the final verdict. ${ }^{24}$ The Harris and Grits for Breakfast (2007a).

${ }^{22}$ In spite of this, by the summer of 2008 the Harris County Jail had to transport an additional 1,130 inmates to Louisiana in order to stay in compliance with the Texas Commission on Jail Standards. With this addition, total annual costs for incarcerating inmates outside Harris County reached \$24 million (Peterson 2008).

${ }^{23} \mathrm{We}$ also use information from the Computerized Criminal History Database, provided by the Texas Department of Public Safety, which tracks state-wide convictions in Texas from the mid-1970s up to the present to support our findings using county court records and to check for potential biases caused by offenders moving out of Harris County as a result of the court verdict.

${ }^{24}$ Cases sealed to the public by order of the court, which account for less than half of a percentage point of the 
County Jail booking data provides an opportunity to observe arrests that did not progress to court charges as well as any time spent in the jail between 1980 through 2013 . We link these two Harris County data sets using a unique county identifier tied to an individual's fingerprint known as the SPN. We match the state-level data capturing all state prison or state jail incarceration spells between 1978 and 2013 to the county records using a defendant's full name and date of birth. ${ }^{25}$ Wage and employment records were matched to the criminal justice records using a social security number. ${ }^{26}$

We impose several sample restrictions in order to isolate the effect of the two natural experiments. For the 1994 sample, we require that: (1) charges were filed between September 1, 1993 and September 1,$1995 ;^{27}$ (2) defendants had no prior felony charges in Harris County regardless of conviction status; and, (3) defendants were charged with felony drug crimes involving a Penalty Group 1 controlled substance. ${ }^{28}$

For the 2007 sample, we require that: (1) charges were disposed between November 7, 2006 and November 7, 2008; ${ }^{29}$ (2) defendants had no prior felony charges in Harris County regardless of conviction status; (3) defendants were charged with a state jail felony drug offense; and, (4) defendants cases were sentenced in one of thirteen district courts that reacted to the election results the day following the election. ${ }^{30,31}$ The remaining courts did not change their sentencing practice discontinuously in response to the failed jail election. These courts fall into three categories: one court increased their use of deferred adjudication in anticipation prior to the election; ${ }^{32}$ some took a "wait and see" approach through only adjusting their sentencing practices

overall caseload, and criminal appeals were not included in the data.

${ }^{25}$ In 1994 (2007), we match $84.8 \%$ (88.3\%) to a valid incarceration spell.

${ }^{26}$ Only roughly two-thirds of our sample could be matched to a social security number. Individuals without a social security number on file were dropped from the labor market analysis.

${ }^{27}$ We exclude cases charged between August 31, 1994 and September 1, 1994 since the charging date could theoretically be sorted among those arrested in 48 hours prior to the new regime being implemented.

${ }^{28}$ Penalty Group 1 controlled substances are predominantly cocaine (both crack and non-crack), heroin, methamphetamine, ketamine, oxycodone and hydrocodone. A full listing can be found in the Texas Health and Safety Code $\$ 481.102$.

${ }^{29}$ We exclude cases disposed between November 6-8, 2007 since the exact day that each court changed its behavior varied slightly among the set.

${ }^{30}$ These are district courts 174, 177, 180, 184, 185, 208, 230, 232, 248, 263, 337, 338, and 351 .

${ }^{31}$ Defendants in Harris County are randomly assigned to district courts ensuring that the subset of defendants sentenced by these courts are representative of the defendant population as a whole.

${ }^{32}$ Court 209. 
until several weeks after the election; ${ }^{33}$ and a few others simply did not change their sentencing practices. ${ }^{34}$ We apply our regression discontinuity models to defendants from these excluded courts as a placebo exercise and do not observe any significant changes in their future outcomes (Table C2).

As depicted in Figures 2 and 3, the average defendant in each sample is approximately 30 years old with a slight upwards trend for the 2007 sample. Both samples are predominately male (over 75\%), around 30\% White, and exhibit similar rates of prior misdemeanor convictions. Half of the defendants are African-American in the 1994 sample which declines to around one-third in the 2007 sample with a corresponding increase in the fraction Hispanic.

We limit our analysis to defendants without prior felony charges for two distinct reasons. First, we are concerned that if the policy changes impact criminal recidivism then our study sample may be contaminated by endogenous entry that could differentially affect one side of the cutoff versus the other. Through imposing this restriction, we ensure that each defendant will only appear once in our estimation sample. Second, individuals without a felony record are particularly relevant in this setting since avoiding a criminal conviction (through a deferred adjudication of guilt or dismissed charge) will preserve their clean felony record. ${ }^{35}$

\section{Empirical Strategy}

We estimate the reduced form effect of the 1994 and 2007 changes in criminal sanctions for drug felony defendants using a sharp regression discontinuity (RD) design. We present both graphical evidence as well as statistical tests to confirm the reliability of our results. For our statistical tests, we follow the approach of Calonico et al. $(2014,2016 \mathrm{a})$ to obtain bias-corrected point estimates using local linear functions, optimal bandwidths and valid confidence intervals. Formally, we

\footnotetext{
${ }^{33}$ Courts 178,182 , and 183 .

${ }^{34}$ Courts 179, 228, 262, and 339 were already high users of deferred adjudication even prior to the election. Court 176 rarely ever used the alternative sentencing strategy either before or after the election.

${ }^{35} \mathrm{It}$ is possible, however, that defendants have been charged with and convicted of misdemeanor level charges.
} 
estimate the discontinuity $(\hat{\tau})$ based on the following setup:

$$
\tau=\mu_{+}-\mu_{-},
$$

where,

$$
\mu_{+}=\lim _{x \rightarrow 0^{+}} \mu(x), \quad \mu_{-}=\lim _{x \rightarrow 0^{-}} \mu(x), \quad \text { and } \quad \mu(x) \equiv E\left[Y_{i} \mid X_{i}=x\right] .
$$

In this notation, $X_{i}$ is the running variable that has a cutoff threshold at $X_{i}=0$ which generates a discontinuity in the outcome variable of interest $\left(Y_{i}\right) . \mu_{+}$and $\mu_{-}$represent the limit of the expectation of $Y_{i}$ given $X_{i}$ as it approaches the cutoff threshold from above and below respectively. As a result, $\tau$ should be thought to measure the magnitude of the jump in the outcome variable at the point of the discontinuity.

We parameterize $\mu(x)$ using a local linear polynomial function:

$$
\begin{gathered}
\hat{\tau}\left(h_{n}\right)=\hat{\mu}_{+, 1}\left(h_{n}\right)-\hat{\mu}_{-, 1}\left(h_{n}\right), \quad \text { where, } \\
\left(\hat{\mu}_{+, 1}\left(h_{n}\right), \hat{\mu}_{+, 1}^{(1)}\left(h_{n}\right)\right)^{\prime}=\underset{b_{0}, b_{1} \in \mathbb{R}}{\arg \min } \sum_{i=1}^{n} 1\left(X_{i} \geq 0\right)\left(Y_{i}-b_{0}-X_{i} b_{1}\right)^{2} K\left(X_{i} / h_{n}\right), \quad \text { and } \\
\left(\hat{\mu}_{-, 1}\left(h_{n}\right), \hat{\mu}_{-, 1}^{(1)}\left(h_{n}\right)\right)^{\prime}=\underset{b_{0}, b_{1} \in \mathbb{R}}{\arg \min } \sum_{i=1}^{n} 1\left(X_{i}<0\right)\left(Y_{i}-b_{0}-X_{i} b_{1}\right)^{2} K\left(X_{i} / h_{n}\right) .
\end{gathered}
$$

$K$ is the kernel function that determines the weighting scheme within a given bandwidth, while $h_{n}$ represents the size of the bandwidth itself. We opt for a data-driven bandwidth selector that selects the median bandwidth from three mean squared error-optimal methods for the RD treatment effect estimator, ${ }^{36}$ and utilize the Epanechnikov kernel function. Our primary specification also adjusts for baseline covariates of age, gender, race/ethnicity, and prior number of misdemeanor convictions. $^{37}$

We first measure the effect of the 1994 and 2007 changes on court disposition and type of

\footnotetext{
${ }^{36}$ We use the option msecomb2 within the STATA rdrobust command described by Calonico et al. (2016a) which uses the median bandwidth from the following methods: one common MSE-optimal bandwidth selector for the RD treatment effect estimator; two different bandwidth selectors (below and above); and one common MSE-optimal bandwidth selector for the sum of regression estimates. We present estimates using alternative bandwidth selectors in Tables $\mathrm{C} 3$ and $\mathrm{C} 4$.

${ }^{37}$ See Calonico et al. (2016b) for notation of this methodology including baseline covariates.
} 
sanction imposed to demonstrate our "first stage" - a discontinuous relationship between the running variable and these court outcomes and judgements. We then measure the reduced form effect of the transition between the low and high court deferral regimes on future offending behavior as captured through the data sources described in Section 2. Our running (or forcing) variable differs across the two quasi-experiments due to the nature of each change: the 1994 Penal Code Reform changes applied to offenders based on the date the charge was filed; the 2007 change in court behavior was based on the date the case was first disposed by the court (i.e., given a verdict).

To attribute a causal interpretation to our RD estimates, we must assume that defendants are effectively randomly allocated before and after the two thresholds. For the first estimation sample, individuals charged immediately after September 1, 1994 should be observationally equivalent to those charged before and we should not see a discontinuity in the total number of cases. For the second sample, defendants disposed immediately after November 6, 2007 should be observationally equivalent to those disposed before and we should not see a discontinuity in the total number of dispositions. ${ }^{38}$

Causal identification also requires that there is no discontinuous change in the likelihood of committing crimes in response to the change in sanction severity. If there exists a general deterrence effect, we should expect to see trends, and potentially a discontinuity, in the levels of criminal activity within our sample windows. Additional threats to our empirical strategy include changes in policing practices or sorting of offenders by prosecutors/judges across thresholds in order to guarantee they face one punishment regime versus the other. This is particularly concerning in the context of the 1994 reform when all relevant actors could fully anticipate the adoption of the new penal code. To the extent that there was endogenous sorting across the thresholds, we should expect to observe discontinuities in important predictors of future offending such as the prior misdemeanor records.

\footnotetext{
${ }^{38}$ Dispositions include case dismissals, guilty verdicts and deferred adjudications of guilt.
} 


\section{Empirical Results}

\subsection{Caseload Density and Baseline Characteristics}

In support of causal identification, we do not observe discontinuities in caseload densities or in the majority of defendant characteristics (Figures 1,2, and 3) and detect no statistical differences using our primary empirical methodology (Table 1). We do find marginally insignificant changes in the age of the defendent in 1994 as well as the defendent's gender in 2007. However, given our results demonstrate clear balance on the remaining demographic and prior criminal history characteristics and are robust to the inclusion or exclusion of controls, we do not feel that this potential difference reflects any discontinuity in any unobserved determinants of recidivism.

As a further test, we construct a recidivism risk score through separately estimating the following OLS equation in 1994 and 2007 ,

$$
\text { Total Charges }{ }_{i}^{5 \text { Years }}=\alpha+\beta \operatorname{Cov}_{i}+\varepsilon_{i},
$$

by OLS where $\operatorname{Cov}_{i}$ is the set of the observable covariates (i.e., age, sex, race/ethnicity, and prior misdemeanor convictions) as well as the corresponding two-way interactions. The risk score is defined as $\hat{\alpha}+\hat{\beta} \operatorname{Cov}_{i}$ and captures an offender's predicted rate of recidivism over five years based on their observable characteristics. ${ }^{39}$ Since no information from the running variable or discontinuity is used in constructing this index, the $\mathrm{RD}$ research design would predict that no sharp changes in the index should appear at either the September 1, 1994 or November 7, 2007 threshold dates. This is confirmed in Figure 4 as well as the final column of Table 1.

\subsection{Court Verdicts and Court-Imposed Sanctions}

While the defendants appear observationally equivalent across the two thresholds, the court outcomes differ quite dramatically (Figure 5 and Table 2). In 1994, the share of cases receiving

\footnotetext{
${ }^{39}$ If police or prosecutors act in a discriminatory manner and monitor certain sub-populations at higher than average rates (e.g., African-American men), then an alternative interpretation of this index would be having a higher or lower likelihood of involvement with the criminal justice system whether through differences in actual future behavior or differences in future monitoring.
} 
final convictions at disposition jumps from about 30 to 65 percent at the threshold date, a gain representing more than a 100 percent increase over the pre-cutoff mean. At the same time, the rate of court deferrals drops by about 35 percentage points indicating a nearly one-for-one tradeoff.

The 2007 experiment documents the opposite phenomena: court decisions switch from a low deferral to a high deferral regime. In fact, we observe an almost mirrored reflection of the shift in 1994. Convictions at disposition drop by 29 percentage points, and again the majority of these marginal cases appear to switch to a deferred adjudication status (22 percentage points) although we also measure an increase in the number of case dismissals (7 percentage points) as well.

The differences in conviction status carry over to sentenced sanctions (Figure 6 and Table 2). In 1994, we observe a small increase in defendants being sentenced to incarceration and a drop in sentences involving drug rehabilitation programs. ${ }^{40}$ In 2007, we observe a clear shift away from incarceration and towards probation in sentencing outcomes. At the discontinuity, we observe a drop of 28 percentage points in incarceration and a gain of 22 percentage points in probation. We also see a marginally insignificant increase in the reliance on drug treatment programs. The net decline in sanctions (i.e., incarceration or probation) reflects the higher dismissal rate observed during the post-period in 2007.

\subsection{Reoffending Outcomes}

To assess the impact of these policy shifts on future criminal justice outcomes, we present evidence for four separate measures of future offending over a five-year period following the focal charge: total bookings in the Harris County Jail, total charges in the Harris County Criminal Courts, total convictions in the Harris County Criminal Courts, and total days incarcerated in the Harris County Jail or a state prison. ${ }^{41}$ Overall, we find strong evidence that marginal defendants impacted by the discontinuities were less likely to reoffend during the follow-up period when

\footnotetext{
${ }^{40}$ This increase in sentenced incarceration though was subject to the mandated community supervised release requirement in the new penal code and so does not necessarily represent higher rates of actual experience in jail or prison.

${ }^{41}$ Days incarcerated will capture both the differential incarceration rates from the focal charge as well as new incarceration sentences resulting from future criminal activity. Later in this section, we examine the timing of the incarceration affects to assess the extent to which this total measure represents more of the former or latter mechanism.
} 
given court deferrals (Figure 7 and Table 3).

We estimate higher rates of reoffending for the post-1994 reform group who who had significantly lower deferral rates. We find that the new regime generated 0.78 additional charges per offender representing a 78 percent increase over the pre-reform average of one total charge in the five-year follow-up period. The magnitude of estimates on the other measures imply a 28 percent increase in jail bookings and an 86 percent increase in Harris County convictions. These effects are substantial in magnitude and are supported by the visual evidence presented in Figure 7.

We estimate lower rates of reoffending for the post-2007 election group who who had significantly higher deferral rates. Among the offenders disposed during the more lenient period, we find point estimates that are close to what is observed in 1994 and internally consistent across the different measures. We measure a decline of 0.73 jail bookings, 0.89 criminal charges filed, 0.67 convictions, and 80 days of incarceration. These estimates correspond to a 45 percent decrease in bookings, 65 percent decrease in county charges, 58 percent decrease in convictions, and a 41 percent decrease in total days incarcerated. These effects are precisely estimated and are supported by the graphical evidence in Figure 7.

The pattern of results in both 1994 and 2007 are suggestive of substantial changes in recidivism as a result of the shift in court verdicts and court-imposed sanctions. The stability of our estimates across these two natural experiments is particularly striking given the two changes are 13 years apart.

The timing of the realization of these effects is traced out in Figure $8 .{ }^{42}$ Both changes appear to have an increasing effect on reoffending over several years following the initial felony case. The largest impacts are generally observed in both samples during the third year post-charge, although the direction of the impact remains persistent throughout the five-year post-charge period. The timing of differences in incarceration in the bottom panel of Figure 8 suggest that our reoffending results are not heavily influenced by an incapacitation mechanism. ${ }^{43}$ While we

\footnotetext{
${ }^{42}$ These figures plot out estimates using our primary RD specification described in Section 3 for specific time windows. The first estimate reflects pre-charge effects covering five years prior to the focal charge and the following estimates reflect 12 month rolling intervals starting one year after the focal date up through five years after the focal date.

${ }^{43}$ We cannot tie a given incarceration spell observed to a specific conviction due to data limitations. The sentence for the focal offense could explain the 20 day difference in incarceration during the first year, but would not
} 
do not find significant differences in incarceration in 1994, we observe significantly lower rates of incarceration among the group experiencing a higher rate of court deferrals over the first two years following the focal charge in 2007. Given the growing magnitude of these estimates, the differences are surely both a function of the original court decision as well as a consequence of future criminal convictions.

To further explore these criminal outcomes, we estimate the impact on binary measures of recidivism during the five-year follow-up period (Table 4). These include any jail bookings, any county charges, any county convictions and ever being incarcerated. We find clear evidence that avoiding a felony conviction decreases the likelihood of ever receiving a future conviction $(0.15$ percentage points in both 1994 and 2007). The other coefficients in the table point in the same direction as the conviction results, but exhibit smaller magnitudes and generally lack statistical significance. The 2007 sample exhibits a particularly interesting pattern: the coefficients increase in magnitude when moving from booking to charges and from charges to convictions. A possible explanation of this pattern is that criminal convictions may have an impact on the likelihood of escalation from one stage to the next in the criminal justice system independent of any impacts to the underlying illegal activity itself. ${ }^{44}$

To assess heterogeneous impacts across different types of reoffending outcomes, we estimate effects for outcomes by crime type in Table 5. In both 1994 and 2007, we see evidence that future drug possession crimes account for a significant share of the overall effect on recidivism. We also observe significant coefficients with non-trivial magnitudes on property crimes. This suggests conviction status may be impacting self-sufficiency. The examination of discontinuities in labor market outcomes for defendants across these two discontinuities will allow for an important investigation of the impact of the changes on economic stability.

explain the observed differences in later years depicted in Figure 8 since the average sentence was only 34 days. ${ }^{44}$ An extreme reading of Table 4 could suggest that deferrals had no impact on underlying illegal behavior but instead only changed the way that police, prosecutors and judges treated and coded criminal episodes. This labeling effect hypothesis, however, could not account for the labor market outcomes to be discussed in the next section which, in our opinion, limits its explanatory power and relevance. 


\subsection{Labor Market Activity}

We begin our analysis of labor market outcomes by examining the five-year total impact on employment and earnings. ${ }^{45}$ The first four columns of Table 6 report estimates of the discontinuity in total formal earnings and quarters of employment over the five-year follow-up period. Figure 9 presents the corresponding graphical evidence for this analysis. Both types of evidence show higher earnings and quarters of employment for those with cases disposed after the November 2007 election. Earnings for the post-election group improved by $\$ 16,545$ over five years, a $75 \%$ increase relative to the average earnings of the low deferral rate group over the same follow-up period. This large effect on earnings is partially driven by an increase of 2.7 quarters of formal employment over the period. When evaluating effects for total quarters of employment at varying earnings thresholds per quarter, it appears that quarters with earnings in excess of the 2000 federal poverty level for a single adult ${ }^{46}$ drive the main employment effect.

We do not estimate significant differences in overall employment outcomes associated with the 1994 shift. We do, however, observe a significant decline in quarters with positive but low earnings (i.e., earnings below the federal poverty level for a single adult in 2000). Alone, this result would be suggestive at best, but later analysis focusing on heterogenous impacts (discussed in Section 4.5) as well as estimates based on an alternative research design (discussed in Appendix A) confirm lower labor market attachment among the low deferral rate group in 1994.

Figure 10 tracks the evolution of these outcomes over the follow-up period using a one-year rolling retrospective window. In 1994, the effects on below-poverty earnings peak roughly four years into the follow-up period. In 2007, we also observe effects later in the follow-up period when looking at the impacts on above-poverty earnings and total earnings. In contrast to the 1994 discontinuity, however, throughout the follow-up period we observe significant or marginally insignificant impacts to labor market outcomes associated with the 2007 increase in the use of court deferrals.

\footnotetext{
${ }^{45}$ All wage figures have been inflation adjusted to the year 2000 dollars using the Houston MSA consumer price index.

${ }^{46}$ The 2000 federal poverty level for a single adult is $\$ 8,350$, so we split quarters of employment as below or above $\$ 8,350 / 4=\$ 2,087.50$.
} 
We further examine the quality of labor market outcomes through evaluating the impacts to employment stability in the final two columns of Table 6 and employment by industry in Table 7 . For employment stability, we evaluate tenure specific to a firm (length in quarters of longest spell of continuous employment at the same firm) as well as continuous earnings spells (regardless of specific employer). Consistent with prior observations, we find deferrals in 2007 generated longer durations of continuous within-firm employment (2.2 quarters) and continuous earnings (2.5 quarters). This pattern of differential accumulation of continuous experience could explain the growing impact on total earnings observed in Figure 9.

In Table 7, we consider employment in the six most common North American Industry Classification System (NAICS) supersectors in our sample: (1) Construction; (2) Manufacturing; (3) Trade, Transportation and Utilities (primarily retail firms); (4) Professional and Business Services (primarily temporary employment agencies); (5) Education and Health Services (primarily home health services firms); and, (6) Leisure and Hospitality (primarily food service establishments). ${ }^{47,48}$ The results show less consistent evidence between the two experiments compared to our prior findings. In 1994, we observe a clear drop (1 quarter of employment) in the Trade, Transportation and Utilities supersector with insignificant declines in two additional supersectors: Construction; and, Leisure and Hospitality. In 2007, there is strong growth (1.1 quarters of employment) in the Education and Health services supersector and insignificant gains in three additional supersectors: Manufacturing; Trade, Transportation and Utilities; and, Professional and Business Services.

In Figure 11, we explore the timeline of effects in each of the industries yielding significant effects in Table 7 and plot patterns for an additional industry which help to illustrate the differing impacts. The 1994 discontinuity is associated with immediate and persistent declines in retail employment. Construction, in contrast, initially responds positively to the discontinuity perhaps

\footnotetext{
${ }^{47}$ The variables are constructed based on the NAICS code associated with the employer recorded in the quarterly earnings record. The two digit NAICS codes associated with each group are as follows: Construction (23); Manufacturing (31, 32, 33); Trade, Transportation and Utilities (22, 42, 44, 45, 48, 49); Professional and Business Services $(54,55,56)$; Education and Health Services $(61,62)$; and, Leisure and Hospitality $(71,72)$. For the categories reported in Appendix Table B2: Natural Resources and Mining (11, 21); Information (51); Finance Activities (52, 53); Other Services $(81,92)$.

${ }^{48}$ While it would be incredibly interesting to consider effects by occupation, such information is not reported in the earnings records.
} 
as a response to being displaced out of retail jobs. However, at the time the difference in reoffending rates is greatest in the 1994 comparison around three years following the focal charge, we begin to see employment declines in other industries such as Construction (Figure 11). ${ }^{49}$ The 2007 discontinuity is associated with a growing positive employment effect in the Education and Health Services industry sector. It appears that this effect grows as individuals transition out of lower-level employment in the Professional and Business Services industry sector. The vast majority of employment in this sector is with firms providing temporary employment services ("temp agencies"). ${ }^{50}$ These results suggest that those who benefit from court deferrals are able to pivot across employers and industries in response to changes in job opportunities.

Several factors could drive the differences between the labor market impacts in 1994 versus 2007 discussed in this section. First, differing labor market conditions across these two time periods, especially labor market opportunities for individuals with a criminal record, could alter the impact of deferrals. Relative to the mid-1990s, employment opportunities for our study population were more limited in the late-2000s due to a tightening of the labor market during The Great Recession and an increase in the visibility of felony convictions to potential employers (Finlay 2009). ${ }^{51}$ Given these differences in labor market conditions, we may expect a larger impact of a court deferral on labor market outcomes following the 2007 shift in sanctions for firsttime drug felony offenders, particularly in sectors with strong occupational licensing requirements (e.g., Education and Health Services). The impacts could also respond to a differential rate of incarceration, which has been shown to directly impact labor market outcomes in this context, given that 2007 showed a stronger effect on institutionalization (Mueller-Smith 2015).

\footnotetext{
${ }^{49}$ Declines in employment are also observed in the Leisure and Hospitality supersector around three years postcharge.

${ }^{50}$ Late growth in employment is also observed in Trade, Transportation and Utilities, while Manufacturing shows declines after initial positive effects like the Professional and Business Services supersector.

${ }^{51}$ During The Great Recession employment outcomes for young, low-educated, black males declined substantially more than other demographic groups (Hoynes et al. 2012). It is likely the case that within this group those with prior felony convictions were even worse off.
} 


\subsection{Further Results: Joint Estimation, Heterogeneity Analysis and Scaled Fuzzy RD Estimates}

In the two previous sections, we consider criminal and labor market outcomes independently. Theoretically the incidence of these impacts could fall on mutually exclusive subgroups, a common population or some combination thereof. Differentiating between these possibilities strengthens our understanding of the mechanisms at work as well as the potential joint determination of these plausibly interdependent outcome variables. ${ }^{52}$

To distinguish these possibilities, we create four mutually-exclusive outcomes for the fiveyear follow-up period to test these possibilities: stable individuals who work for at least one full year and have no recorded convictions during the five-year follow-up period; ${ }^{53}$ unstable offenders who working for less than one year and have at least one conviction in the follow-up period; a reoffending group who works for at least a year but also experience at least one future conviction; and a out of work group of offenders who neither work nor reoffend. These categories are illustrated in Figure 12.

The results presented in Table 8 suggest that the 1994 decrease in court deferrals led to a substantial increase in the fraction of unstable individuals who jointly experience lower levels of employment and a higher levels of future convictions. The fraction of this type increases from $23 \%$ of individuals to $36 \%$. A similar, yet insignificant, effect in the opposite direction is observed for the fraction of stable individuals who jointly experience improved employment and do not reoffend. These effects are especially interesting in comparison to the much smaller increase in reoffenders (Column 2). If the decrease in court deferrals exclusively led to changes in criminal offending with little effect on employment outcomes, we would expect similar-sized effects across these two categories.

In 2007 we estimate nearly a doubling of the fraction of individuals in the stable category and

\footnotetext{
${ }^{52}$ As an example, an offender who faces diminished labor market opportunities due to a felony conviction may be more likely to engage in property crime for economic stability. Similarly, an offender who receives a court deferral and then obtains a full-time job will have less time to devote towards criminal activity. These are clear departures from a world wherein one group suffers employment loss but no change in criminal behavior while another group exhibits the opposite pattern.

${ }^{53} \mathrm{We}$ selected one full year of employment as the cutoff since defendants are split roughly half and half between working four or more quarters or less than four quarters.
} 
close to a one-for-one decrease in the unstable category. Both estimates are statistically significant and large in magnitude. These estimated effects imply a striking difference in outcomes for these two observationally-equivalent groups of drug felony defendants in $2007-50 \%$ of individuals whose case is processed following the 2007 shift both work and desist from reoffending compared to $28 \%$ of those whose case is processed prior.

Given this finding, we are also interested in understanding if the impacts of the reforms are heterogeneous across different types of offenders. We focus on measuring whether effects differ across the spectrum of the predicted recidivism risk score. ${ }^{54}$ We prefer this approach to the typical sub-group analysis for several reasons. ${ }^{55}$ First, our sample sizes can be quite limited for some subgroups which undermines the precision of the estimates and could be misunderstood to indicate a lack of impact. Second, it is difficult to isolate effects specific to certain groups since there is a high degree of correlation between certain demographic traits. For example, female offenders are twice as likely to be white than male offenders, so heterogeneous effects across gender categories may also reflect differences across race.

This is accomplished by separately running our local polynomial RD estimates for each percentile in the risk score quantile function between percentiles one and ninety-nine. Because we are constrained by our sample size, we utilize a forty percentile uniform bandwidth centered at the focal percentile when estimating these coefficients. Since the quantile function is not defined below zero or above one hundred, asymmetric bandwidths occur above the 80th and below the 20 th percentiles. ${ }^{56,57}$

Figures 13 and 14 display the results of this exercise for court outcomes and future behavior. As seen in Figure 13, the impact on conviction status remains fairly constant throughout the

\footnotetext{
${ }^{54}$ See Section 4.1 for a description of the construction of this index. To account for the bias discussed in Abadie et al. (2016), the estimation of the risk score employs a leave-one-out or jackknife estimation procedure for the purpose of these exercises.

${ }^{55}$ Heterogeneity effects by various demographic groups are presented in Appendix Table B1.

${ }^{56}$ To better understand this exercise, extensive information on the shape of background characteristics, court outcomes and future criminal activity over the smoothed risk score quantile function is provided in Figures B1, B2, B3, and B4.

${ }^{57}$ This exercise requires the stronger assumption that defendants before and after the discontinuities exhibit similar risk score distributions. Figure B5 shows a series of local polynomial RD estimates using whether an offender was at or below a specific percentile in the risk score distribution as an outcome variable. This provides a consolidated way to demonstrate balance throughout the distribution (as opposed being balanced on average as was previously documented).
} 
distribution in 1994. In the first two thirds of risk score quantile function, conviction rates increase by roughly 40 percentage points and then continue to be elevated at about 30 percentage points in the remaining third of the distribution. This pattern is mirrored in the effects on court deferrals. The 2007 sample presents a slightly more complicated picture. First, convictions are most strongly affected in the top and bottom third of the risk score distribution. While impacts to deferred adjudication remain mostly constant, there is a positive impact on case dismissals in the top and bottom thirds of the distribution that parallels the strongest effects on convictions.

Figure 14 repeats the prior exercise but uses the total convictions and quarters with positive income as the outcome variables. In contrast to the previous figure, these graphs show a clear pattern that is consistent across both the 1994 and 2007. Those who are predicted to have the highest rate of recidivism exhibit the strongest response to the change in punishment across both reoffending (total convictions) and labor market outcomes (total quarters employed) over the five-year follow-up period. Figures B1 and B2 describe the background characteristics across the risk score distribution. Defendants in the top quartile of the risk distribution are most likely young, African-American men who have one or more prior misdemeanor convictions already on their record. ${ }^{58}$

As a final exercise, we return to the full sample and estimate treatment effects based on a fuzzy regression discontinuity design where the first stage outcome is an indicator for a court deferral. ${ }^{59}$ The estimated effects are presented in Table 9. While we prefer to focus on reduced form estimates, these results provide a sense of the very large magnitude of our estimated treatment effects on criminal justice and labor market outcomes. Conditional on strong assumptions, the estimates can be interpreted as the causal effect of a deferral ${ }^{60}$ compared to a felony conviction. One such assumption is that exogenous shifts do not occur between court deferrals and case dismissals. ${ }^{61}$ Violation of this assumption could lead to an underestimate of

\footnotetext{
${ }^{58}$ As evident in Figure B2, the bottom quartile of the recidivism risk distribution is more heavily hispanic. A potential explanation for this pattern could be a higher propensity for hispanic defendants to leave Harris County. Our estimated treatment effects may be attenuated at the lower quartile of the risk distribution to the extent these individuals are less likely to stay in Harris County during the five-year follow-up period.

${ }^{59}$ Because the 2007 experiment shows a small but significant impact on case dismissals we collapse court deferrals and case dismissals into a single outcome for this part of the analysis.

${ }^{60}$ To be explicit, a deferral and all of the corresponding implications for sanctions.

${ }^{61} \mathrm{As}$ an example, in 2007 rather than having 28.6 percent of the caseload being shifted from convictions into a combination of deferred adjudication and case dismissal, the full 28.6 percent could move from a conviction
} 
how many defendants have their case dispositions affected by the discontinuities which could lead to overestimates of the causal effects. Overall, the estimates imply quite substantial effects (ranging between 75 and 200 percent changes) of the reforms on future defendant behavior.

One potential explanation for the large magnitude of the scaled effects could be due to what we term an amplification effect. The idea behind this concept is that future criminal convictions exacerbate the observed exogenous differences in the court outcomes arising from the natural experiment. For example, if those who were convicted are more likely to reoffend and any further punishment arising from the new convictions also increases the risk of recidivism, then as our follow-up period progresses the gap between the two groups should grow. Since there is a strong negative age-crime profile documented throughout the literature this dynamic could only persist for so long, but it does present a plausible explanation as to how such large impacts could emerge from each of the natural experiments we examine.

\subsection{Robustness Checks}

Throughout our primary analysis our estimates have relied on outcomes from the Harris County court records. We also, however, test whether our results are robust to convictions recorded in the state-wide Computerized Criminal History $(\mathrm{CCH})$ Database in Table $\mathrm{C} 1$. While we expect smaller magnitudes since not all crimes are reported to the state-wide database, the pattern of results remains consistent with those based on the county records. We observe an increase of 0.33 convictions in 1994 and a decrease of 0.46 convictions in 2007, representing a 64 percent growth and a 49 percent contraction respectively. The changes observed at the state-level are almost entirely driven by difference in convictions reported to the state by Harris County arresting agencies, limiting our concerns about intra-state mobility. While we cannot directly test for inter-state mobility, the fact that we do not find effects in other Texas counties suggests that our

status to a deferred adjudication and an additional 7.3 percent that would have gotten deferred adjudication could received a case dismissal. Both scenarios would be consistent with our estimates in Table 2. But, in the former case, only 28.6 percent of the caseload is exogenously shifted in some way whereas in the latter 35.9 percent of the caseload is affected in what we think of as the potential first stage of this exercise (i.e., moving from harsh court outcomes to more lenient court outcomes). 
results are not likely biased by out-of-state movements. ${ }^{62}$

We conduct several additional robustness checks to confirm the reliability of our results. Table C2 presents estimated effects of a placebo experiment where we shift the cutoff dates to one year earlier (September 1, 1994 and November 6, 2006) or one year later (September 1, 1996 and November 6, 2008). We also estimate a placebo effect for non-responsive courts (as described in Section 2) from the 2007 experiment. The goal in these exercises is to investigate whether our findings could be picking up latent seasonal breaks. ${ }^{63}$ Overall, we do not find any meaningful discontinuities in court outcomes or in future criminal activity in these placebo exercises. We do find a statistically significant difference in the rate of deferred adjudications in the 2006 placebo experiment, but the magnitude is much smaller than our estimated magnitudes and effects are not reflected in other outcomes.

We also provide a number of other robustness checks including: alternative bandwidth selection methods (Table C3 and Table C4); alternative variance estimation strategies (Table C5; models without covariates included (Table C6); models without the bias correction or robust standard errors as suggested by Calonico et al. (2014) (Table C7); and models based on outcomes aggregated to the week level (Table C8). Among these tables, there is no evidence to suggest our findings are driven by arbitrary implementation decisions.

Because the running variable in both of our discontinuities rely on time variation, another strategy to quantify the magnitude of these effects is to estimate a structural break in a time series framework. We re-evaluate our key results using a standard time series framework in Appendix A. Overall, results are closely aligned with our preferred RD approach.

\footnotetext{
${ }^{62}$ While these state-wide results partially alleviate mobility concerns, there could be differences in defendants being forced to leave Texas. If hispanic immigrants are more or less likely to be deported, this could bias our estimated effects. However, we expect this bias to go in the opposite direction of our estimated effects as those receiving a felony conviction compared with a court deferral would be more likely to be deported.

${ }^{63}$ For example, the beginning of the school year or the timing of elections may impact criminal behavior or unobserved sample characteristics.
} 


\section{Conclusion}

We observe sharp discontinuities in future offending and labor market outcomes across two dramatic changes in the likelihood of court deferrals for first-time drug felony defendants in Harris County, TX. While these two changes occurred 13 years apart and have very different explanations, we find similar impacts on criminal sanctions a well as on recidivism outcomes. Through studying two natural experiments that together exhibit both increasing and decreasing deferral rates towards drug offenders in the same location, we can be more confident that our estimates represent a causal impact and are not simply capturing latent trends in recidivism or other unobserved shocks contemporaneous with the experiments.

Through a set of data-driven regression discontinuity plots and statistical tests, we demonstrate that first-time drug felony defendants—who are statistically indistinguishable on observable characteristics-differ in rates of convictions by approximately 30 percentage points in both scenarios. In the absence of a conviction, defendants were most likely to receive a court deferral in both 1994 and 2007, allowing them to avoid a permanent criminal record. Those who ended up on the more lenient side of the thresholds demonstrate consistently lower rates of reoffendingwith estimated magnitudes ranging from roughly 30 to $80 \%$ decreases across various measures of future reoffending. In 2007, those on the more lenient side of the threshold demonstrate large and persistent improvements in employment and earnings. Both natural experiments indicate a shift towards more stability (no future convictions and higher levels of employment) when court deferrals are more widely used.

A striking pattern emerges that those who have the highest rate of predicted recidivism based on their observed covariates stand the most to gain from a second chance in the form of a court deferral. These individuals are typically young, African-American men with one or more misdemeanor convictions already on their record. Our results suggest that intervening for this high risk population at this crucial period (i.e.g, when they are being charged with their first felony offense) could significantly alter their life course in a positive way. Given the sample restrictions (first-time felony drug offenders), we cannot comment on whether our observed relationship between recidivism risk and treatment effects extends to more serious, hardened 
offenders charged with other types of crimes.

Our conclusion that court deferrals decrease recidivism and improve labor market outcomes contrasts with recent work by Hansen (2015). Different geographic locations (Washington versus Texas) as well as different types of offenders (drunk drivers versus drug offenders) likely explain the discrepancy in our results. Together, we believe these studies demonstrate the challenge and complexity of studying a diverse criminal offender population.

Substantial changes to laws and sanctions associated with illegal drug use have been made at the state and federal level over the past several years. The overarching trend is towards more leniency, especially for first-time drug offenders. Our results suggest that these changes may lead to lower rates of reoffending and higher rates of rehabilitation over the coming years. Our results also suggest that improving defendant outcomes may be achievable through modifying sanctions in ways that do not require significant investments or changes to the existing criminal justice infrastructure. In summary, court deferral programs for low-risk drug offenders should be viewed as an attractive and feasible option for jurisdictions seeking to reduce the fiscal cost and community impact of their criminal justice system.

\section{References}

Abadie, A., Chingos, M. M. and West, M. R.: 2016, Endogenous stratification in randomized experiments. Working Paper, Retrieved from http://economics.mit.edu/files/11852 [Date Accessed: 11/29/2016].

Abrams, D. S.: 2012, stimating the deterrent effect of incarceration using sentencing enhancements, American Economic Journal: Applied Economics 4(4), 32-56.

Agan, A. Y. and Starr, S. B.: 2016, Ban the box, criminal records, and statistical discrimination: A field experiment. University of Michigan Law and Economics Research Paper No. 16-012, Retrieved from https://papers.ssrn.com/sol3/papers.cfm?abstract_id=2795795 [Date Accessed: 10/20/2016].

Aizer, A. and Doyle, J. J.: 2015, Juvenile incarceration, human capital, and future crime: Evidence from randomly assigned judges, The Quarterly Journal of Economics 130(2), 759-803.

Barbarino, A. and Mastrobuoni, G.: 2014, The incapacitation effect of incarceration: Evidence from several italian collective pardons, American Economic Journal: Economic Policy 6(1), 1-37. 
Bayer, P., Hjalmarsson, R. and Pozen, D.: 2009, Building criminal capital behind bars: Peer effects in juvenile corrections, Quarterly Journal of Economics 124(1), 105-147.

Buonanno, P. and Raphael, S.: 2013, Incarceration and Incapacitation: Evidence from the 2006 Italian collective pardon, American Economic Review 103(6), 2437-2465.

Calonico, S., Cattaneo, M. D., Farrell, M. H. and Titiunik, R.: 2016a, rdrobust: Software for Regression Discontinuity Designs. University of Michigan Working Paper, Retrieved from https://papers.ssrn.com/sol3/papers.cfm?abstract_id=2795795 [Date Accessed: 10/20/2016].

Calonico, S., Cattaneo, M. D., Farrell, M. H. and Titiunik, R.: 2016b, Regression discontinuity designs using covariates. University of Michigan Working Paper, Retrieved from http://www-personal.umich.edu/ cattaneo/papers/Calonico-Cattaneo-Farrell-Titiunik_ 2016_wp.pdf [Date Accessed: 11/29/2016].

Calonico, S., Cattaneo, M. D. and Titiunik, R.: 2014, Robust nonparametric confidence intervals for regression-discontinuity designs, Econometrica 82(6), 2295-2326.

Cattaneo, M., Jansson, M. and Ma, X.: 2016, Simple local regression distribution estimators with an application to manipulation testing. University of Michigan Working Paper, Retrieved from http://www-personal.umich.edu/ cattaneo/papers/Cattaneo-Jansson-Ma_2016_ LocPolDensity.pdf [Date Accessed: 11/29/2016].

Chiricos, T., Barrick, K., Bales, W. and Bontrager, S.: 2007, The labeling of convicted felons and its consequences for recidivism, Criminology 45(3), 547-581.

Di Tella, R. and Schargrodsky, E.: 2013, Criminal recidivism after prison and electronic monitoring, Journal of Political Economy 121(1), 28-73.

Doleac, J. L. and Hansen, B.: 2016, Does "ban the box" help or hurt low-skilled workers? Statistical discrimination and employment outcomes when criminal histories are hidden. National Bureau of Economic Research Working Paper No. w22469.

Drago, F., Galbiati, R. and Vertova, P.: 2009, The deterrent effects of prison: Evidence from a natural experiment, Journal of Political Economy 117(2), 257-280.

Fabelo, T.: 1997, Texas Criminal Justice Reforms: The Big Picture in Historical Perspective, Criminal Justice Policy Council.

Finlay, K.: 2009, Effect of employer access to criminal history data on the labor market outcomes of ex-offenders and non-offenders, Studies of labor market intermediation, University of Chicago Press, pp. 89-125.

Green, D. P. and Winik, D.: 2010, Using random judge assignments to estimate the effects of incarceration and probation on recidivism among drug offenders, Criminology 48(2), 357-388.

Grits for Breakfast: 2007a, Kuff: New jail building in Harris County "irresponsible to the point of negligence" [Blog Post]. Retrieved from http:

//gritsforbreakfast.blogspot.com.au/2007/11/kuff-new-jail-building-in-harris-county.html [Date Published: 11/4/2007, Date Accessed: 10/21/2016]. 
Grits for Breakfast: 2007b, Texans' Taxation Revulsion vs. their Incarceration Addiction: Which will prevail on county jail building? [Blog Post]. Retrieved from http://gritsforbreakfast.blogspot.com.au/2007/10/texans-taxation-revulsion-vs-their.html [Date Published: 10/14/2007, Date Accessed: 10/21/2016].

Hansen, B.: 2015, Punishment and deterrence: Evidence from drunk driving, American Economic Review 105(4), 1581-1617.

Helland, E. and Tabarrok, A.: 2007, Does three strikes deter? a nonparametric estimation, Journal of Human Resources 42(2), 309-330.

Holzer, H., Raphael, S. and Stoll, M.: 2007, The effect of an applicant's criminal history on employer hiring decisions and screening practices: Evidence from los angeles, Barriers to Rentry? The Labor Market for Released Prisoners in Post-Industrial America, Russell Sage Foundation, pp. 117-150.

Hoynes, H., Miller, D. L. and Schaller, J.: 2012, Who suffers during recessions?, The Journal of Economic Perspectives 26(3), 27-47.

Hughes, P. R.: 2005, Revised numbers show jail crowding is worse, The Houston Chronicle . Retrieved from http://www.chron.com/news/houston-texas/article/

Revised-numbers-show-jail-crowding-is-worse-1525007.php [Date Published: 8/5/2005, Date Accessed: 10/21/2016].

Johnson, R. and Raphael, S.: 2012, How much crime reduction does the maringal prison buy?, Journal of Law and Economics 55(2), 275-310.

Kuziemko, I. and Levitt, S. D.: 2004, An empirical analysis of imprisoning drug offenders, Journal of Public Economics 88(9), 2043-2066.

Lee, D. and McCrary, J.: 2016, The deterrence effect of prison: Dynamic theory and evidence. Forthcoming, Advances in Econometrics.

Levitt, S.: 1996, The effect of prison population size on crime rates: Evidence from prison overcrowding litigation, Quarterly Journal of Economics 111(2), 319-351.

Lovenheim, M. F. and Owens, E. G.: 2014, Does federal financial aid affect college enrollment? evidence from drug offenders and the higher education act of 1998, Journal of Urban Economics 81, 1-13.

Mastrobuoni, G. and Rivers, D. A.: 2016, Criminal discount factors and deterrence. Working Paper, Retrieved from https://papers.ssrn.com/sol3/papers.cfm?abstract_id=2730969 [Date Accessed: 10/20/2016].

Mueller-Smith, M.: 2015, The criminal and labor market impacts of incarceration. Working Paper, Retrieved from http://sites.lsa.umich.edu/mgms/wp-content/uploads/sites/283/2015/09/incar.pdf [Date Accessed: 10/20/2016].

Ouss, A.: 2011, Prison as a school of crime: Evidence from cell-level interaction. Working Paper, Retrieved from https://papers.ssrn.com/sol3/papers.cfm?abstract_id=1989803 [Date Accessed: 10/21/2016]. 
Owens, E.: 2009, More time, less crime? Estimating the incapacitative effect of sentence enhancements, Journal of Law and Economics 52(3), 551-579.

Pager, D.: 2003, The mark of a criminal record, American journal of sociology 108(5), 937-975.

Pager, D.: 2008, Marked: Race, crime, and finding work in an era of mass incarceration, University of Chicago Press.

Peterson, L. A.: 2008, Packed Harris jail may ship 1,130 inmates to Louisiana, The Houston Chronicle . Available at http://www.chron.com/news/houston-texas/article/ Packed-Harris-jail-may-ship-1-130-inmates-to-1672711.php [Date Published: 5/6/2008, Date Accessed: 10/21/2016].

Raphael, S.: 2014, The New Scarlet Letter?: Negotiating the US Labor Market with a Criminal Record, WE Upjohn Institute.

Shannon, S., Uggen, C., Schnittker, J., Massoglia, M., Thompson, M. and Wakefield, S.: 2016, The growth, scope, and spatial distribution of people with felony records in the united states, 1980-2010. Conditionally accepted for publication in Demography.

Shapiro, J. and Chen, K.: 2007, Do Harsher Prison Conditions Reduce Recidivism? A Discontinuity-Based Approach, American Law and Economics Review 9(1), 1-29.

Snyder, M.: 2007, Picknickers may share Buffalo Bayou with inmates, The Houston Chronicle . Retrieved from http://www.chron.com/news/houston-texas/article/ Picnickers-may-share-Buffalo-Bayou-with-inmates-1535996.php [Date Published: 10/10/2007, Date Accessed: 10/21/2016].

Stevenson, M.: 2015, Breaking bad: Mechanisms of social influence and the path to criminality in juvenile jails. SSRN Working Paper 2627394, Retrieved from https://ssrn.com/abstract=2627394 [Date Accessed: 11/29/2016].

Subramanian, R. and Moreno, R.: 2014, Drug war détente? A review of state-level drug law reform, 2009-2013, VERA Institute of Justice.

The Sentencing Project: 2014, Fact Sheet: Trends in U.S. Corrections. Retrieved from http://sentencingproject.org/wp-content/uploads/2016/01/Trends-in-US-Corrections.pdf [Date Accessed: 10/20/2016].

Uggen, C., Vuolo, M., Lageson, S., Ruhland, E. and Whitham, H. K.: 2014, The edge of stigma: An experimental audit of the effects of low-level criminal records on employment, Criminology 52(4), 627-654.

United States Department of Justice, Office of Justice Programs and Bureau of Justice Statistics: 2014, State Court Processing Statistics, 1990-2009: Felony Defendants in Large Urban Counties. [codebook]. Retrieved from http://doi.org/10.3886/ICPSR02038.v5 [Date Accessed: 10/20/2016]. 
1994 Penal Code Reform

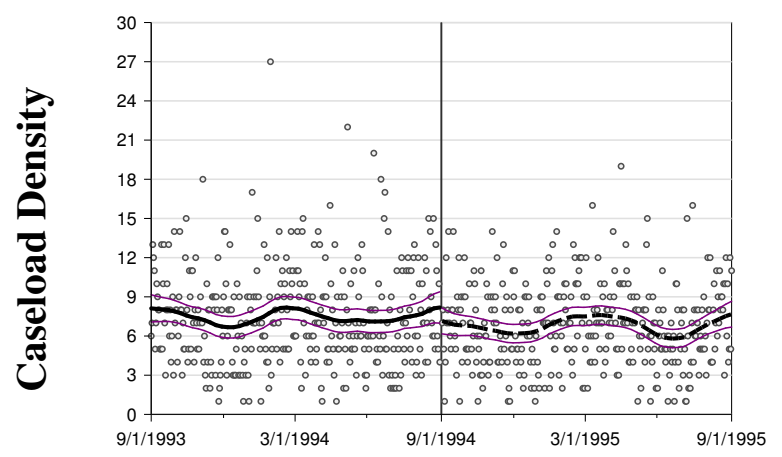

2007 Failed Jail Expansion

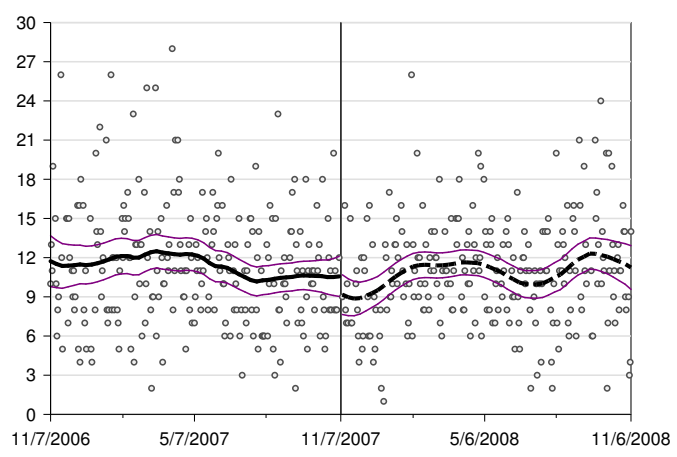

Figure 1: Discontinuities in caseload density

Figure Notes: This figure shows the relationship between the number of cases by date of filing (1994) or disposal (2007) and the focal date. The scatter plots depict the raw data relative to the running variable with kernel-weighted local-polynomial lines on either side of the cutoff. The scatter plots are pooled at the date level and the localpolynomial lines are based on the aggregated data at the exact date level. Formal manipulation testing procedures for local polynomial density estimators as proposed in Cattaneo et al. (2016) fail to reject the null of no manipulation with corresponding p-values of 0.19 (1994) and 0.31 (2007). 
1994 Penal Code Reform
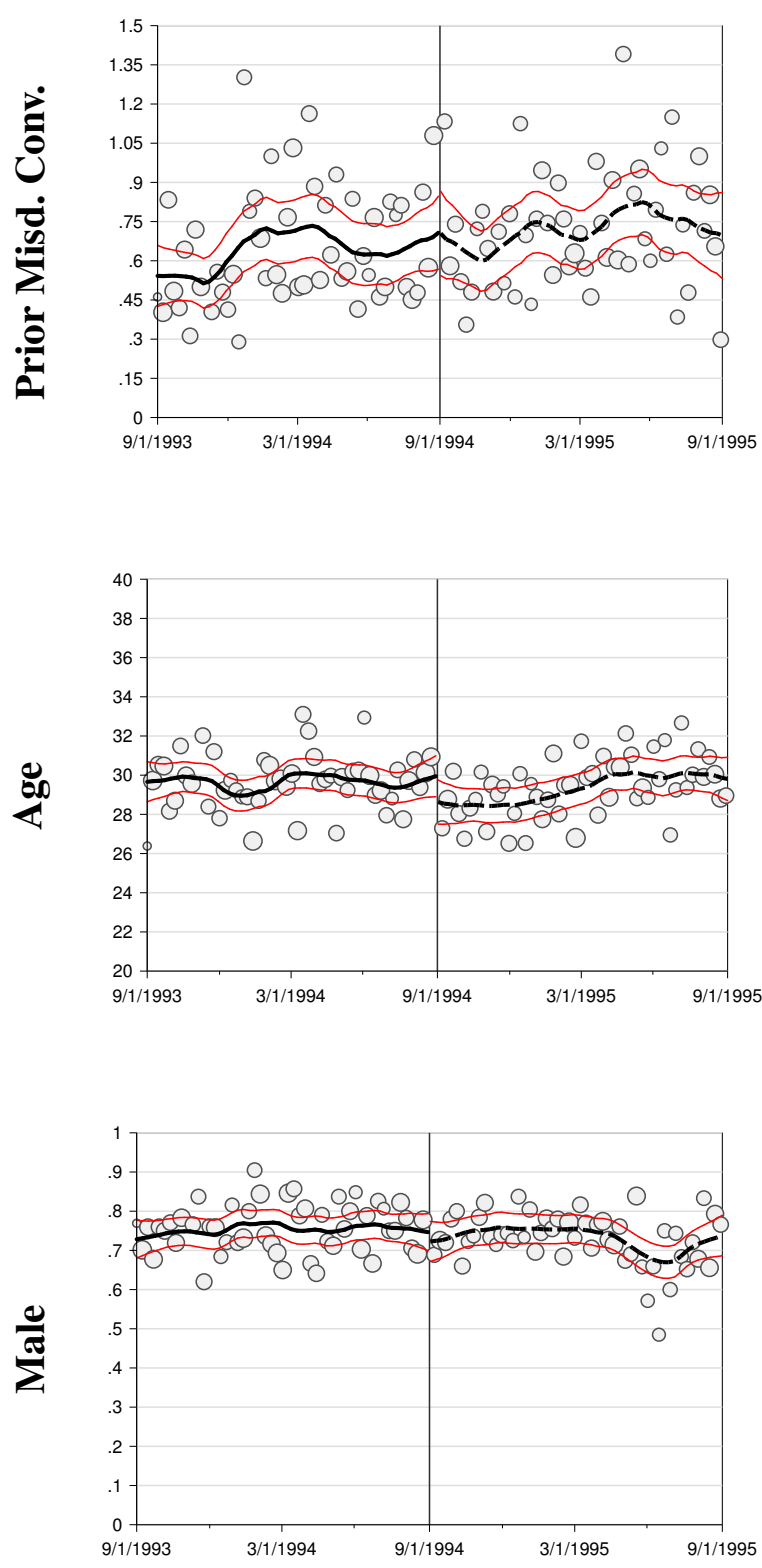

\section{Failed Jail Expansion}
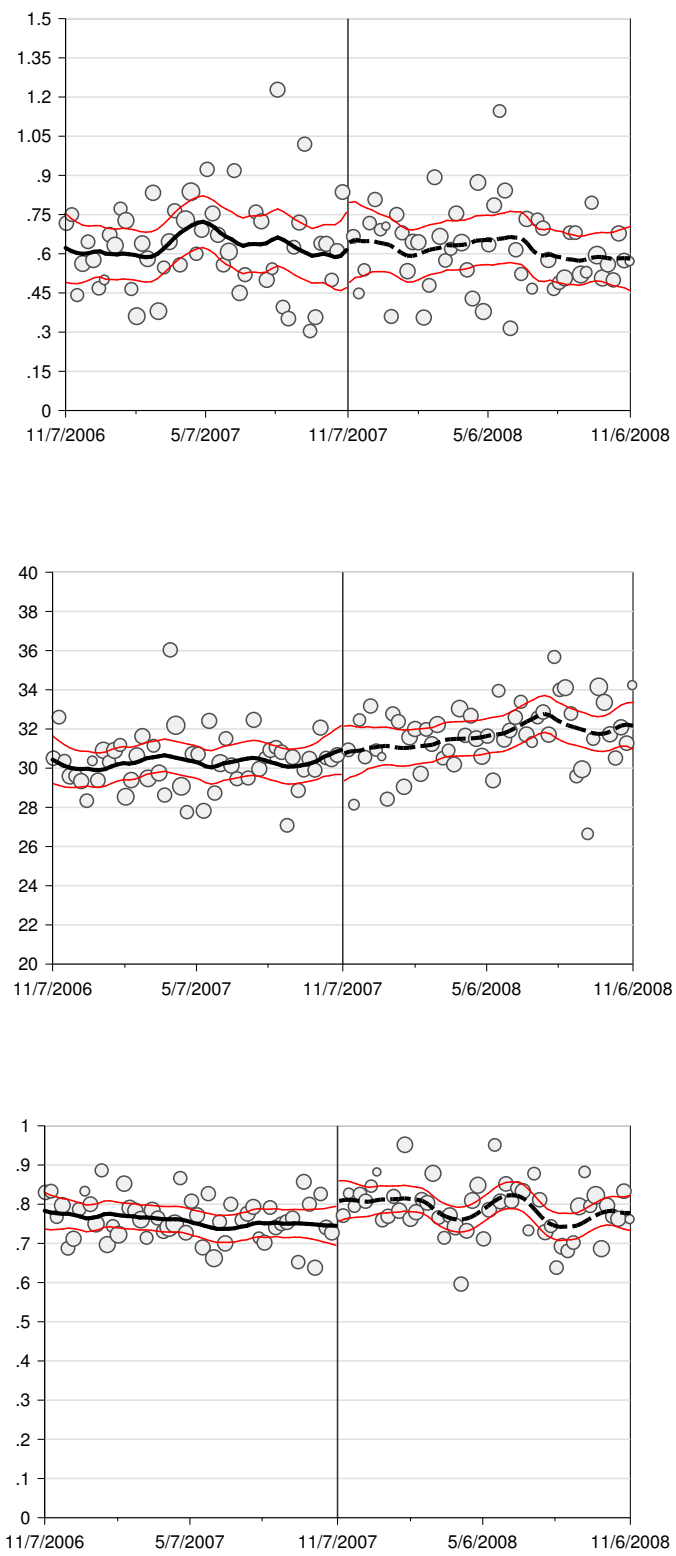

Figure 2: Discontinuities in baseline characteristics

Figure Notes: This figure shows the relationship between the focal date on baseline criminal history and demographic characteristics. The first row depicts the relationship between the total number of prior misdemeanor convictions and the running variable. The second row plots the average age for offenders charged (or disposed) by week. The third row displays the proportion of the case load each week which is male.

General Graphing Notes: All scatter plots depict the raw data relative to the running variable with kernel-weighted local-polynomial lines on either side of the cutoff. For readability, the scatter plots are pooled at the week level and weighted according to the total number of cases. However, the local-polynomial lines are based on the disaggregated data at the exact date level. Due to the nature of the changes, the date of filing is used as the running variable for the 1994 sample, while the date of disposition is used as the running variable for the 2007 sample. All plots and local-polynomial lines omit observations during the week of the cutoff. Sample restrictions are described in Section 1. 


\section{Penal Code Reform}
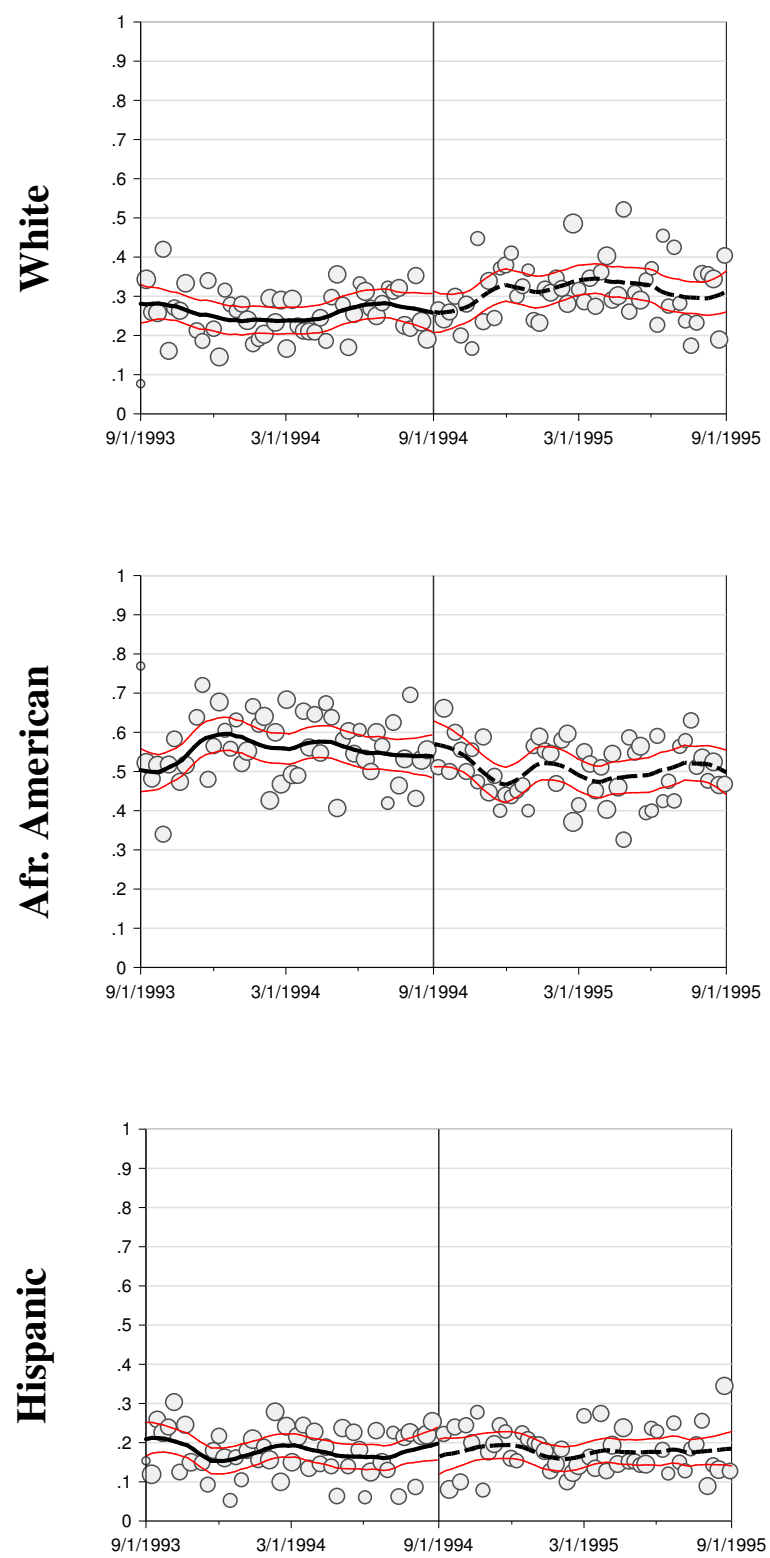

\section{Failed Jail Expansion}
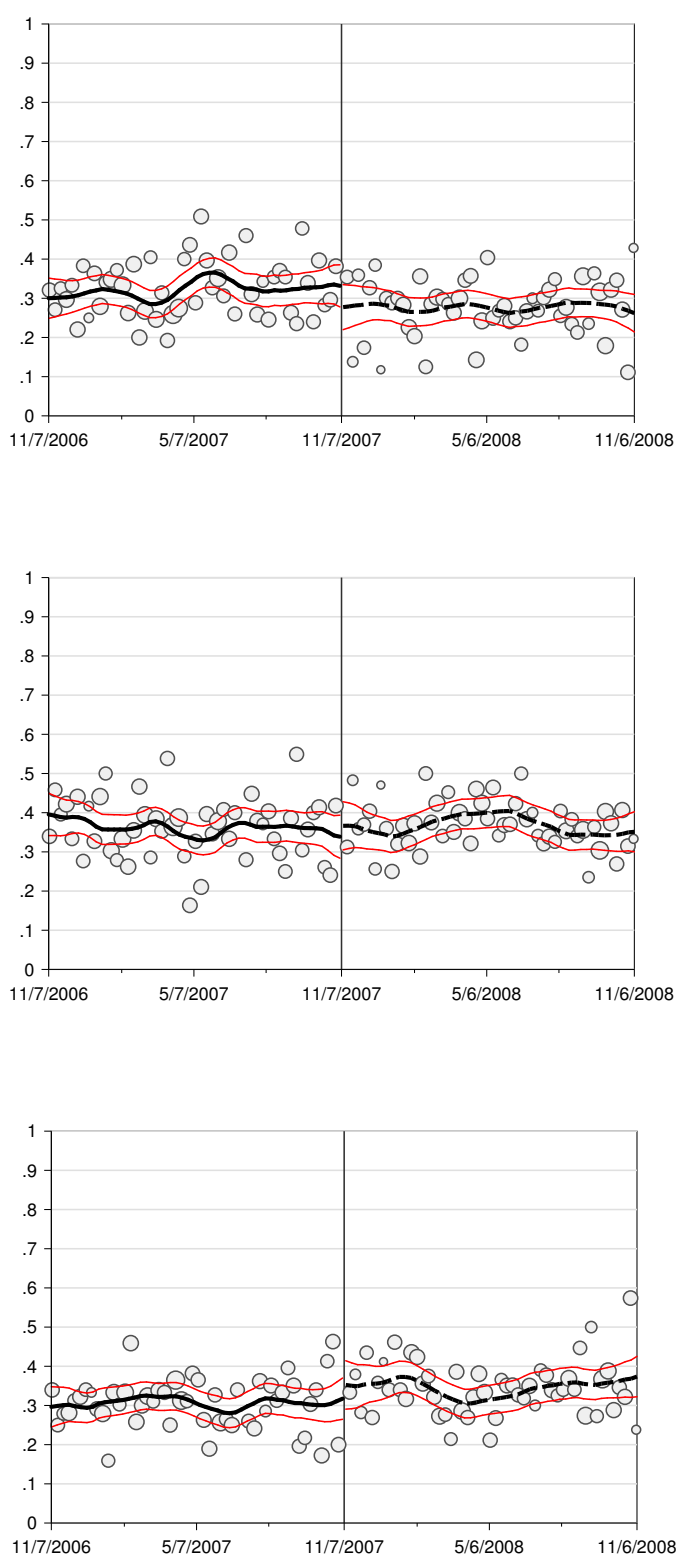

Figure 3: Discontinuities in baseline characteristics

Figure Notes: This figure shows the relationship between the focal date and the proportion of each week's cases by race and ethnicity categories. General graphing notes from Figure 2 apply. 


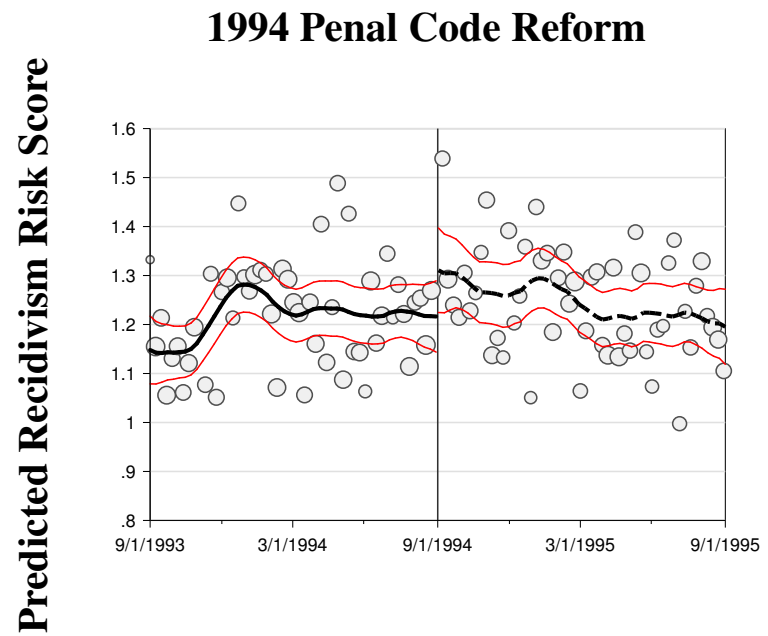

Figure 4: Discontinuities in composite recidivism risk score

Figure Notes: This figure shows the relationship between the focal date and the average predicted recidivism risk score for each week as described in the text in Section 4.1. General graphing notes from Figure 2 apply. 
1994 Penal Code Reform
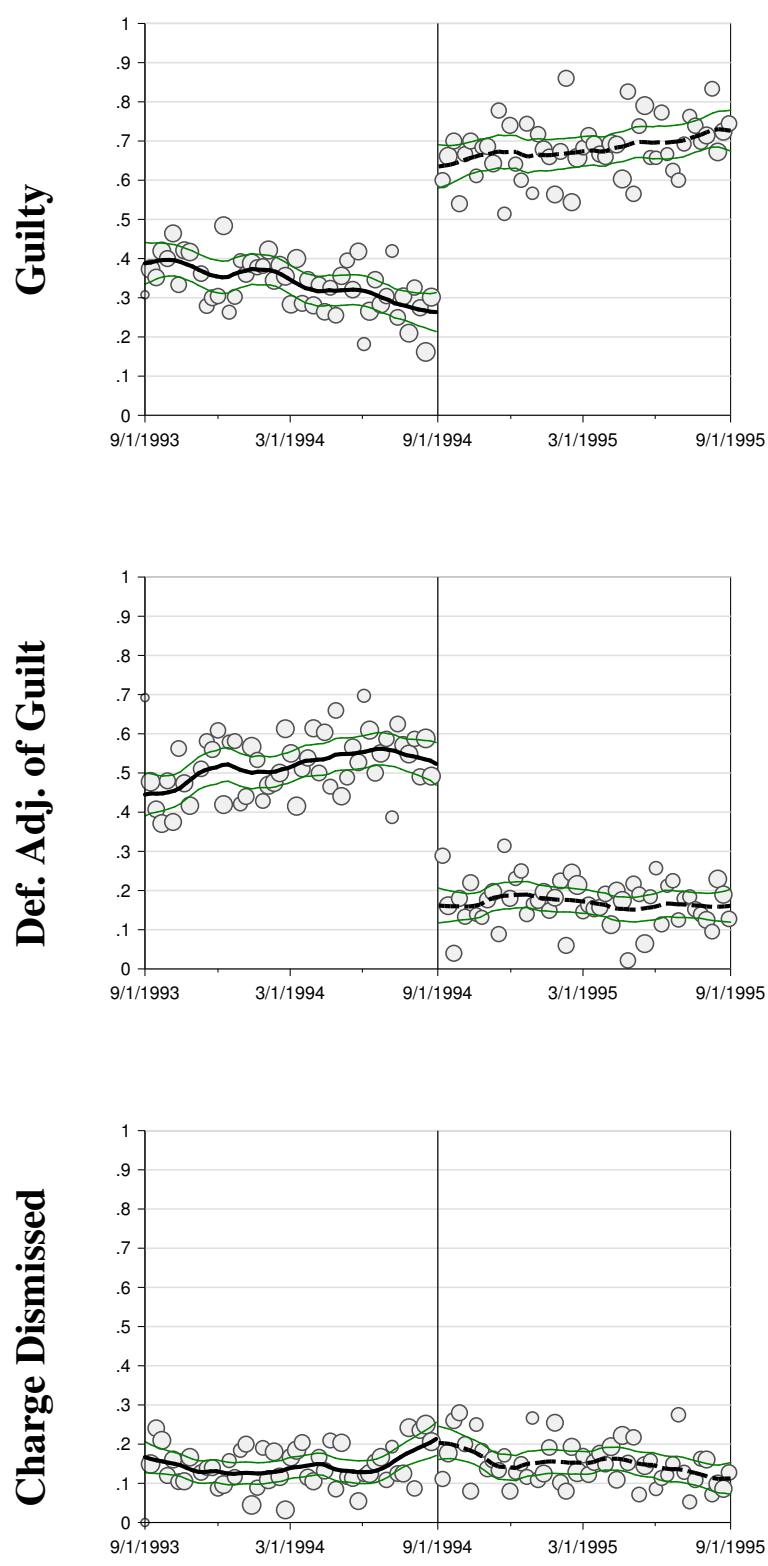

2007 Failed Jail Expansion
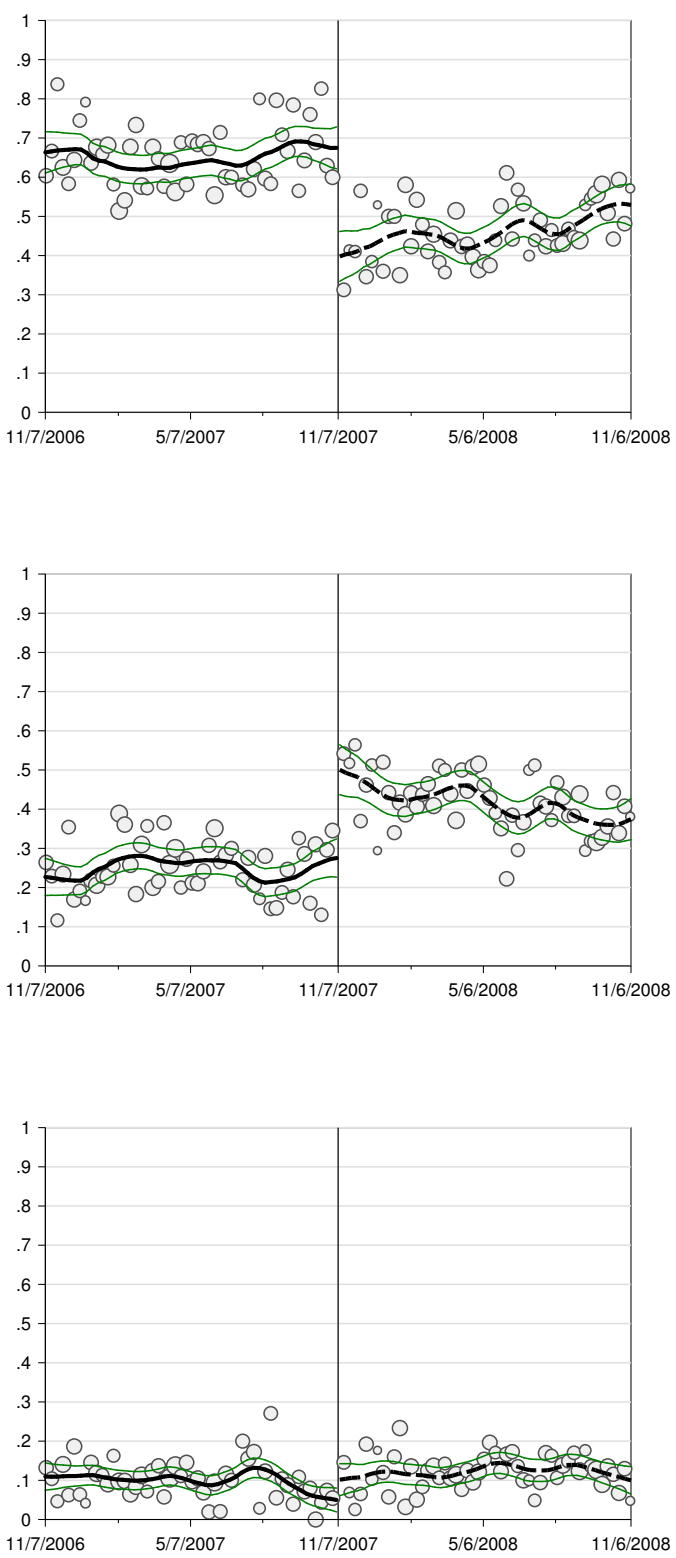

Figure 5: Discontinuities in court outcomes

Figure Notes: This figure shows the relationship between the focal date and court outcomes for our estimation sample. The first row shows the relationship between the focal date and a guilty verdict. In the case a criminal defendant does not receive a guilty verdict, he is either provided a deferred adjudication of guilt (second row) or the charge is dismissed (third row). General graphing notes from Figure 2 apply. 
1994 Penal Code Reform
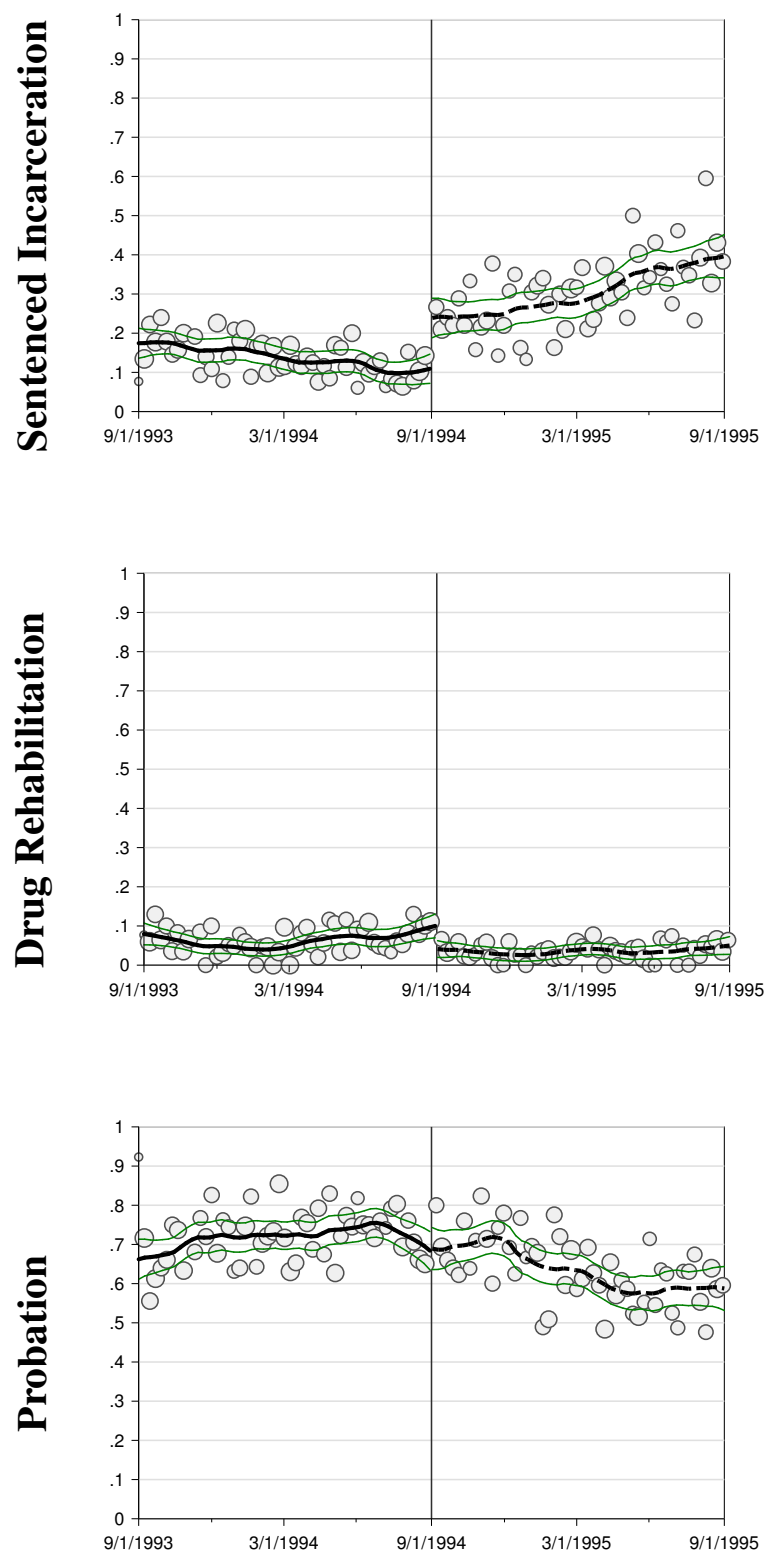

2007 Failed Jail Expansion
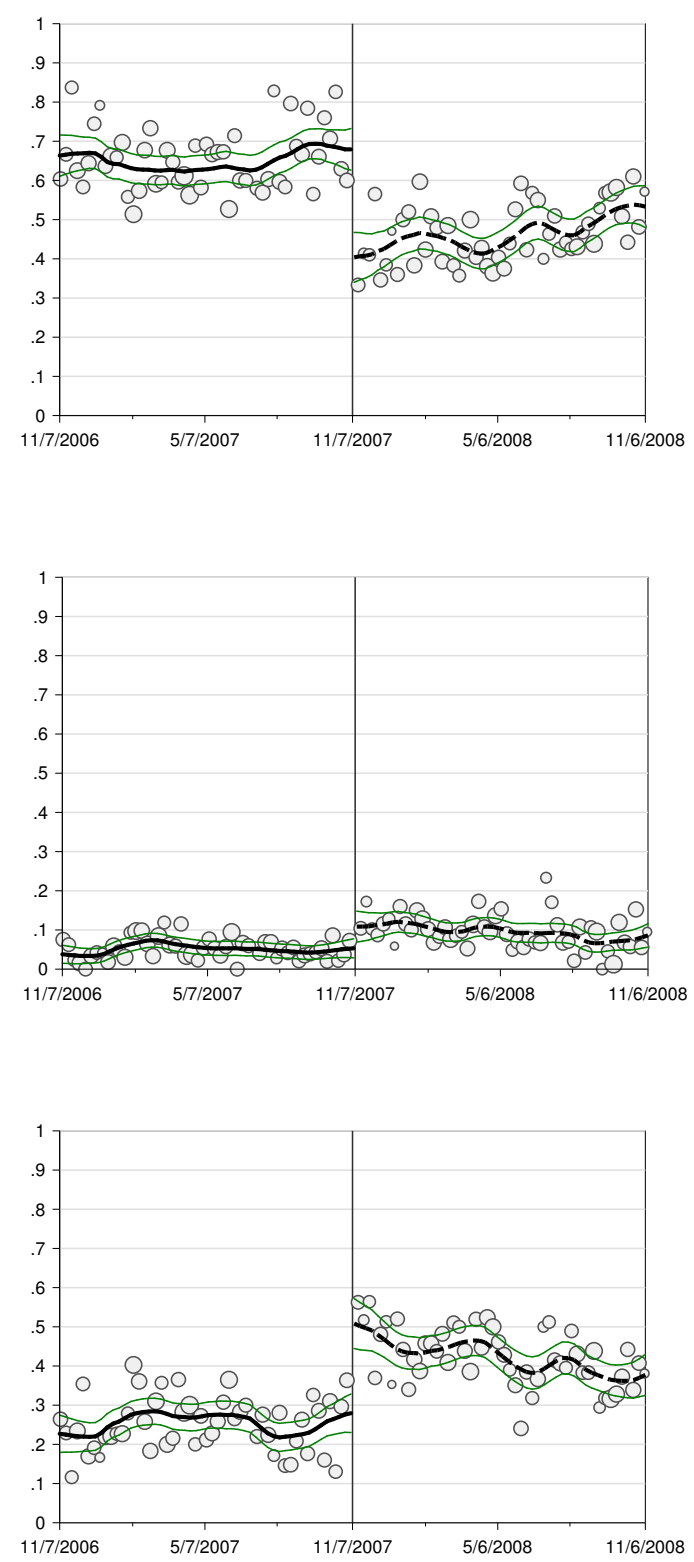

Figure 6: Discontinuities in status following court verdict

Figure Notes: This figure shows the relationship between the focal date and the immediate court imposed sanctions (or status following the court's decision) after considering the focal charge. The first row shows the relationship between the focal date and a direct (or immediate) incarceration sentence. The second row plots the proportion of cases assigned to a drug rehabilitation program. The third row depicts the relationship between the focal date and a required probation supervision. General graphing notes from Figure 2 apply. 
1994 Penal Code Reform
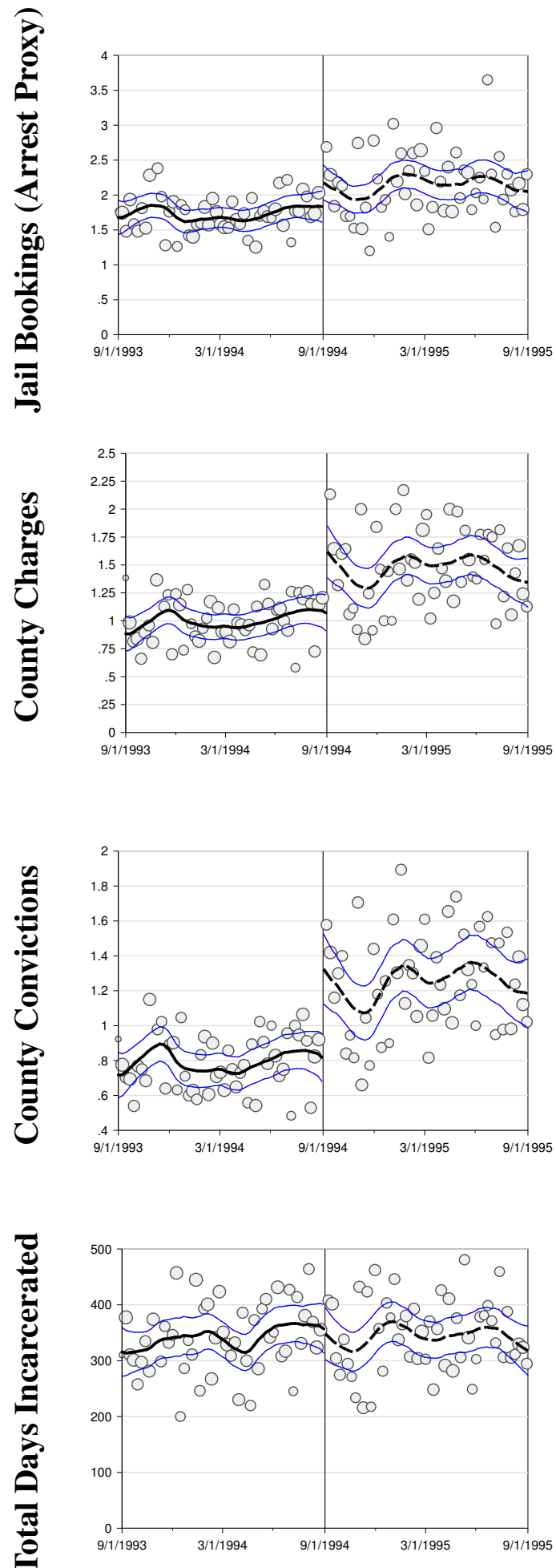

2007 Failed Jail Expansion
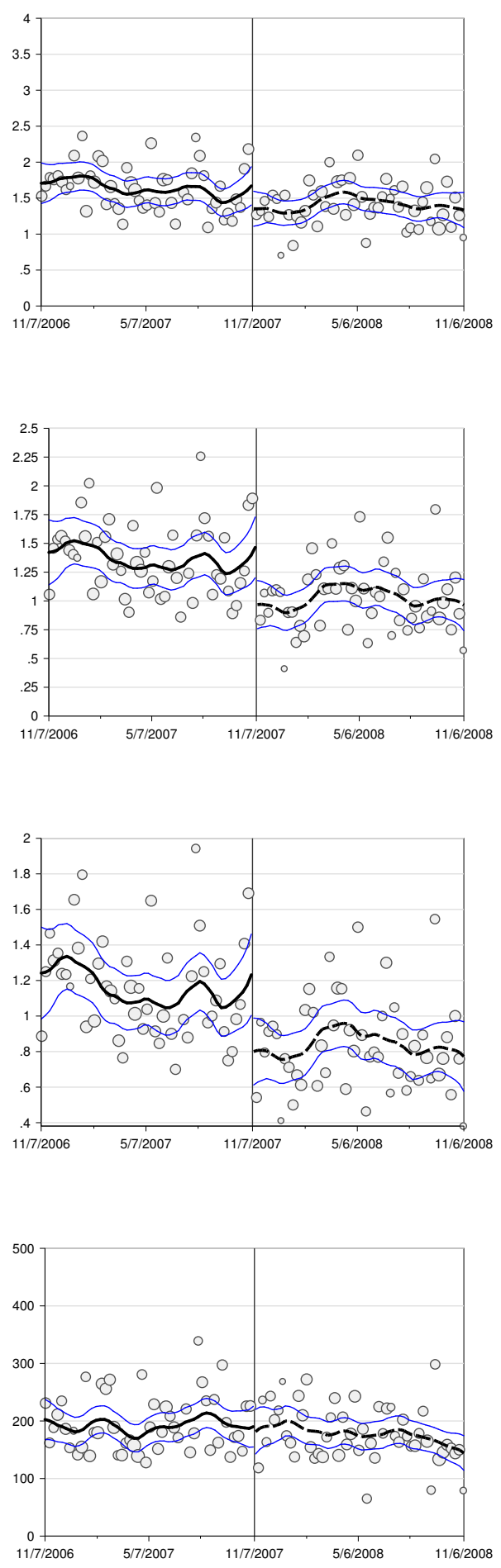

Figure 7: Five-year criminal justice outcomes

Figure Notes: This figure shows the relationship between the focal date and reoffending outcomes over a five-year follow-up period. The first row shows the relationship between the focal date and the total number of jail bookings in Harris County. The second row depicts the relationship between the focal date and the total number of charges filed with the Harris County criminal courts. The third row plots the relationship between the focal date and the total number of state-wide convictions. The fourth row depicts the relationship between the focal date and total time served in county or state confinement. General graphing notes from Figure 2 apply. 
1994 Penal Code Reform
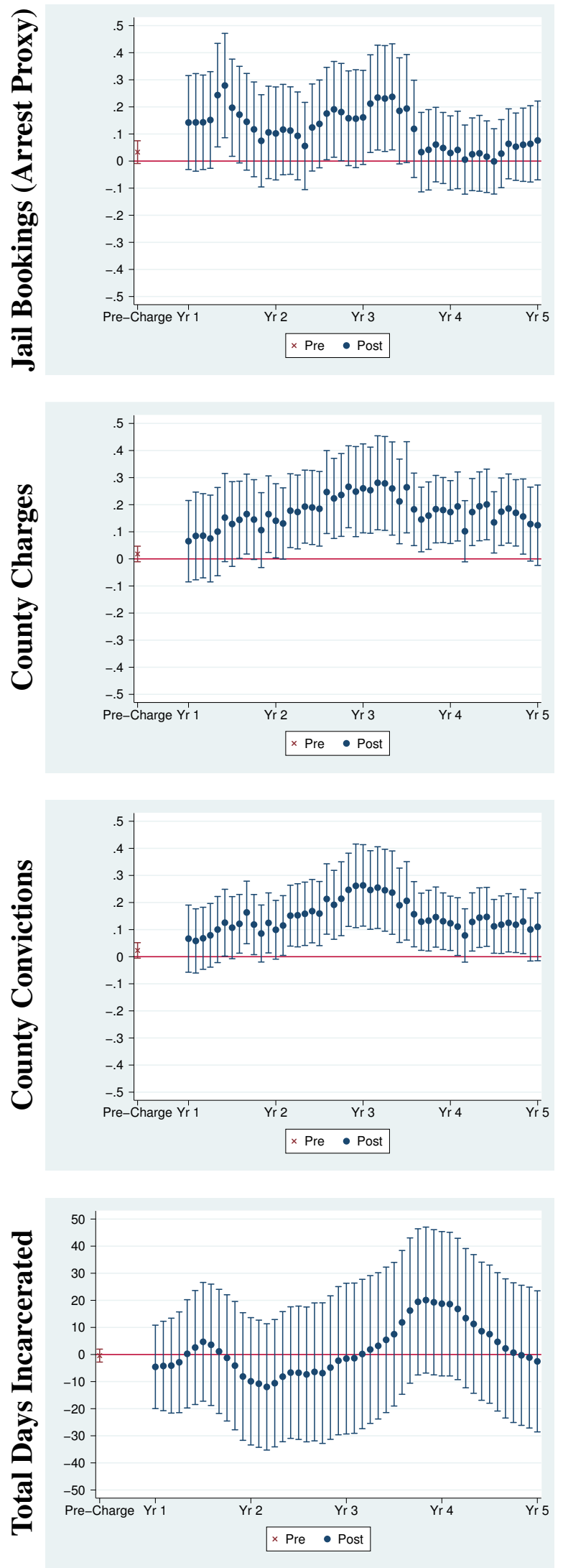

\section{Failed Jail Expansion}
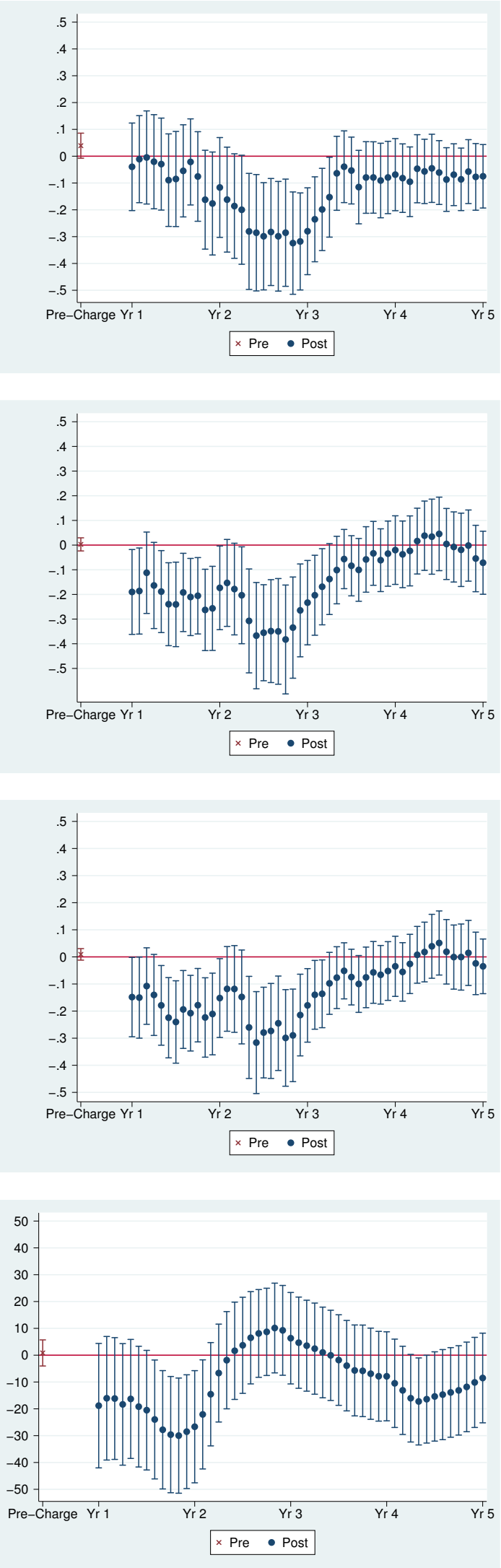

Figure 8: Estimated treatment effects over time, criminal justice outcomes

Figure Notes: This figure depicts estimated criminal reoffending effects from our primary regression discontinuity specifications for pre- and post-reform time windows. The estimate for the five-year pre-reform period is depicted in the first estimate presented. Following, point estimates and associated confidence intervals are plotted for rolling one-year windows during the post-reform period (looking back over the preceding 12 months or four quarters). General RD estimation notes from Table 1 apply. 
1994 Penal Code Reform
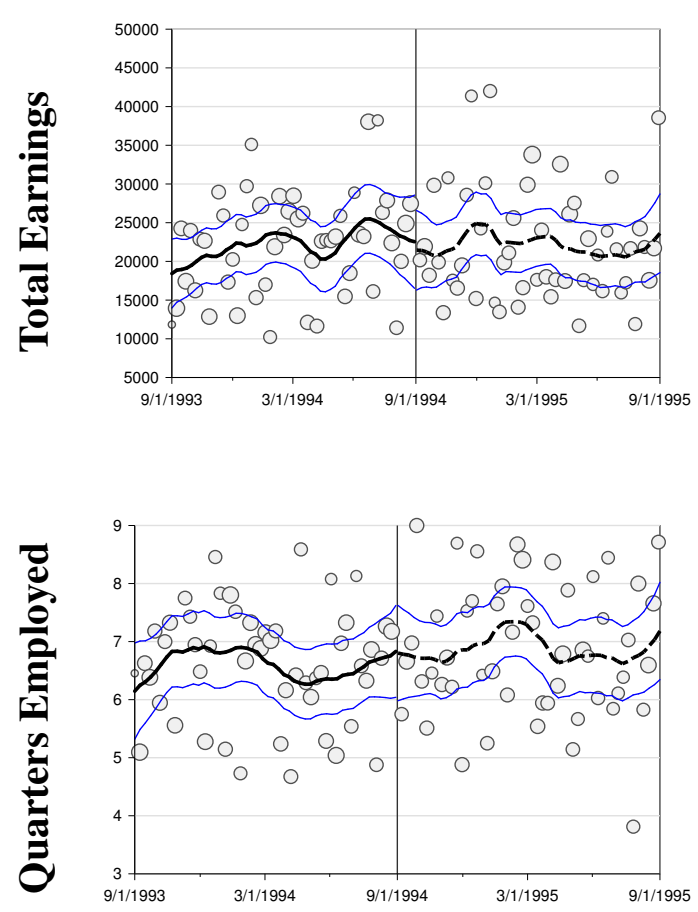

2007 Failed Jail Expansion
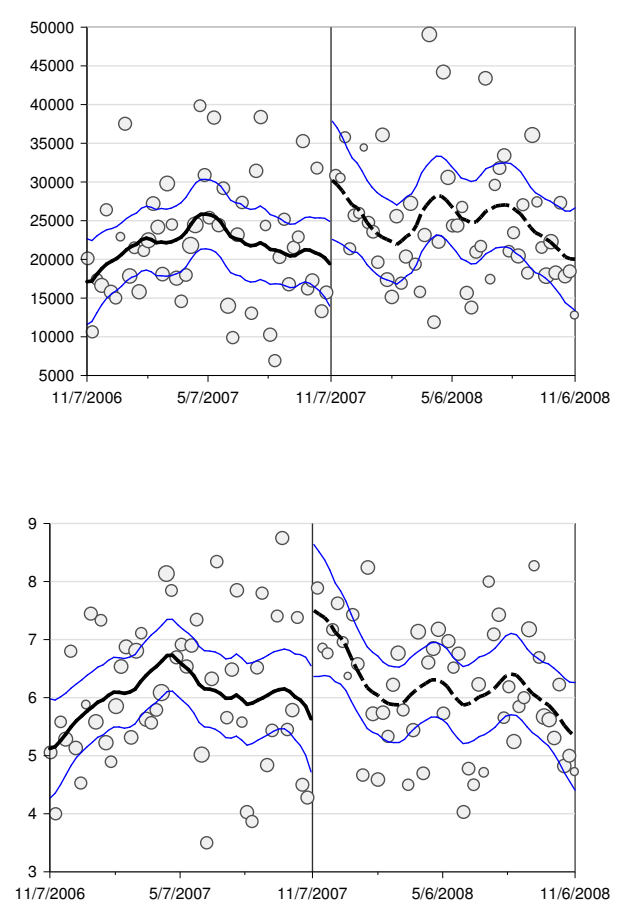

Figure 9: Five-year labor market outcomes

Figure Notes: This figure shows the relationship between the focal date and labor market outcomes. The first row shows the relationship between the focal date and the total formal earnings for a five-year follow-up period. The second row depicts the relationship between the focal date and the total number of quarters of formal employment for a five-year follow-up period. General graphing notes from Figure 2 apply. 
1994 Penal Code Reform
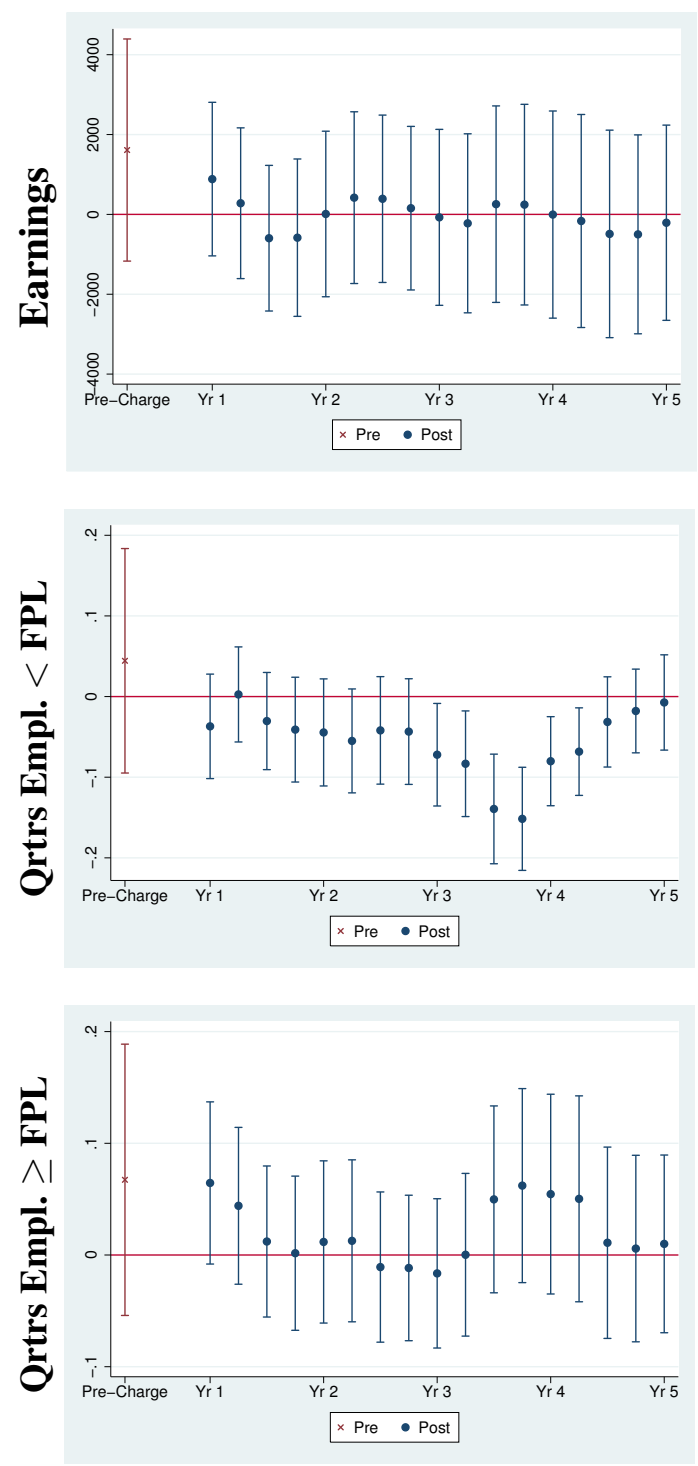

2007 Failed Jail Expansion
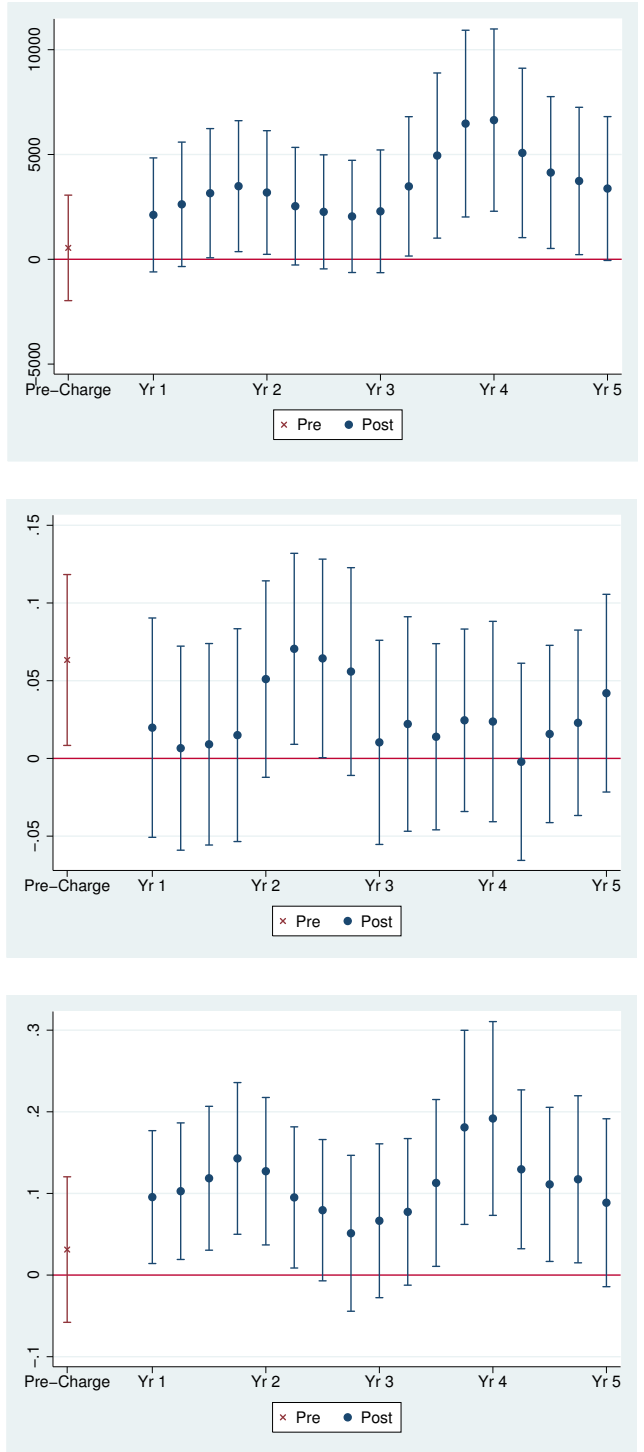

Figure 10: Labor market impacts over time

Figure Notes: This figure depicts estimated labor market effects from our primary regression discontinuity specifications for pre- and post-reform time windows. The estimate for the five-year pre-reform period is depicted in the first estimate presented for 2007, but is only based on a one year pre-reform period for the 1994 plots due to the availability of the quarterly unemployment insurance wage records. Following, point estimates and associated confidence intervals are plotted for rolling one-year windows during the post-reform period (looking back over the preceding 12 months or four quarters). General RD estimation notes from Table 1 apply. 
1994 Penal Code Reform

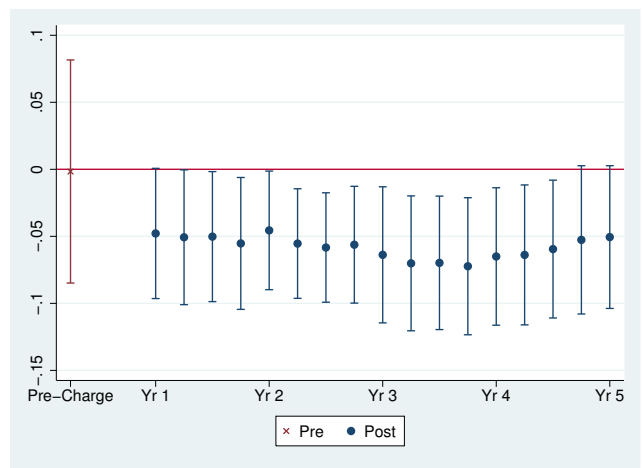

Trade, Trans., \& Utilities, 1994

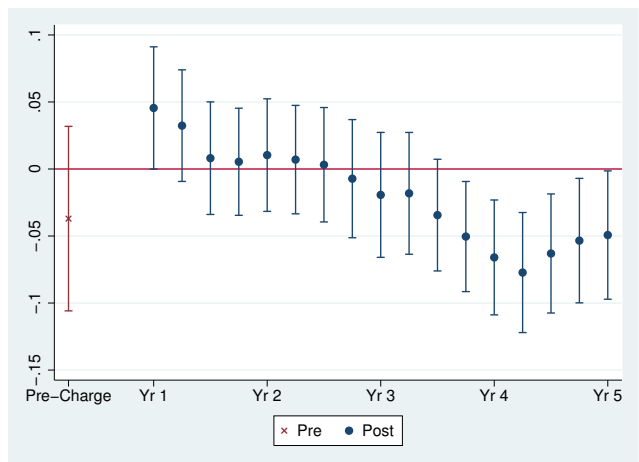

Construction, 1994
2007 Failed Jail Expansion

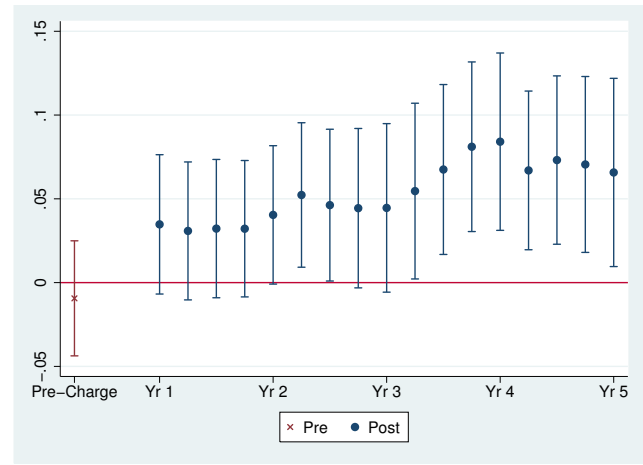

Educ. and Health, 2007

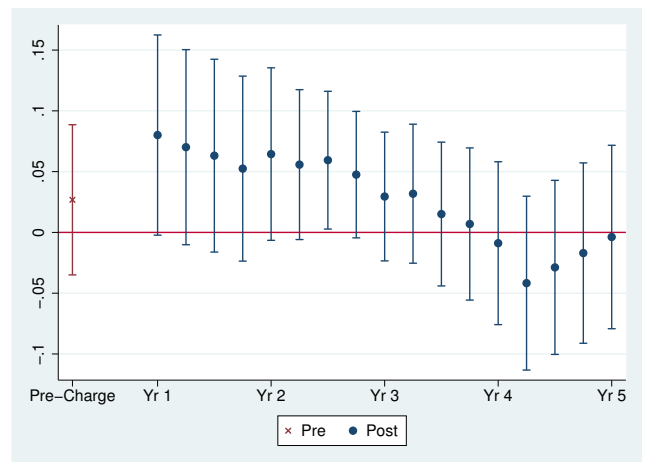

Prof. and Bus. Services, 2007

Figure 11: Industry dynamics in employment over time

Figure Notes: This figure depicts estimated effects for employment in certain industries from our primary regression discontinuity specifications for pre- and post-reform time windows. The estimate for the five-year pre-reform period is depicted in the first estimate presented for 2007, but is only based on a one year pre-reform period for the 1994 plots due to the availability of the quarterly unemployment insurance wage records. Following, point estimates and associated confidence intervals are plotted for rolling one-year windows during the post-reform period (looking back over the preceding 12 months or four quarters). General RD estimation notes from Table 1 apply.

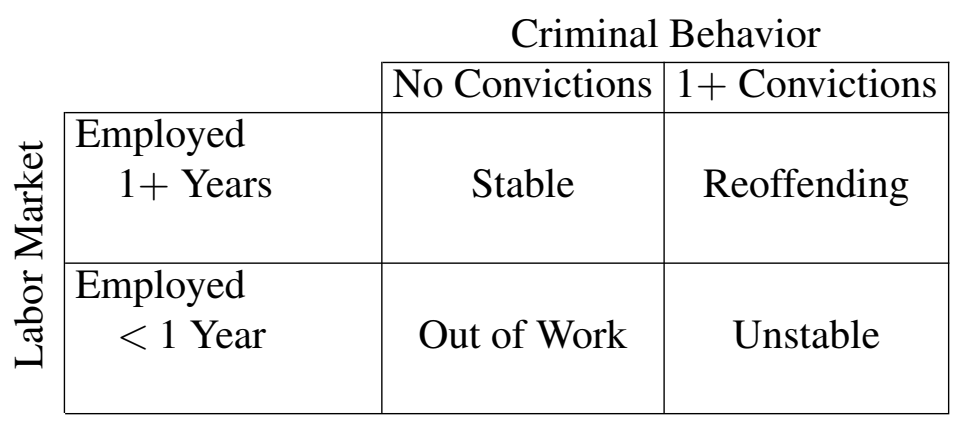

Figure 12: Definition of joint crime-labor outcomes

Figure Notes: This figure illustrates the mutually exclusive categories created to examine effects across combinations of crime and labor market outcomes. We create indicators for each category for our estimation sample and estimate the effects of each discontinuity on the proportion of offenders in each of these categories (presented in Table 8). 
1994 Penal Code Reform
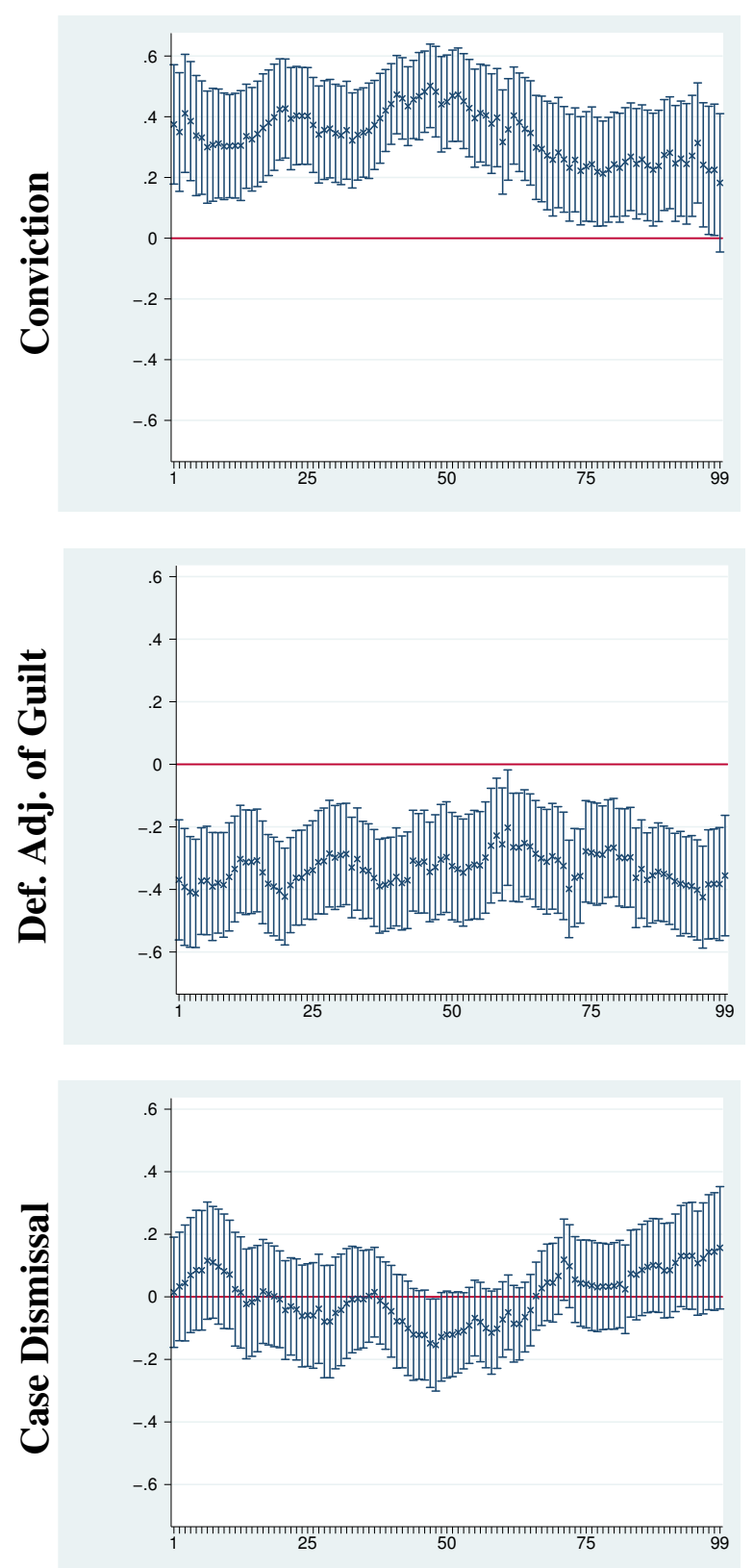

\section{Failed Jail Expansion}
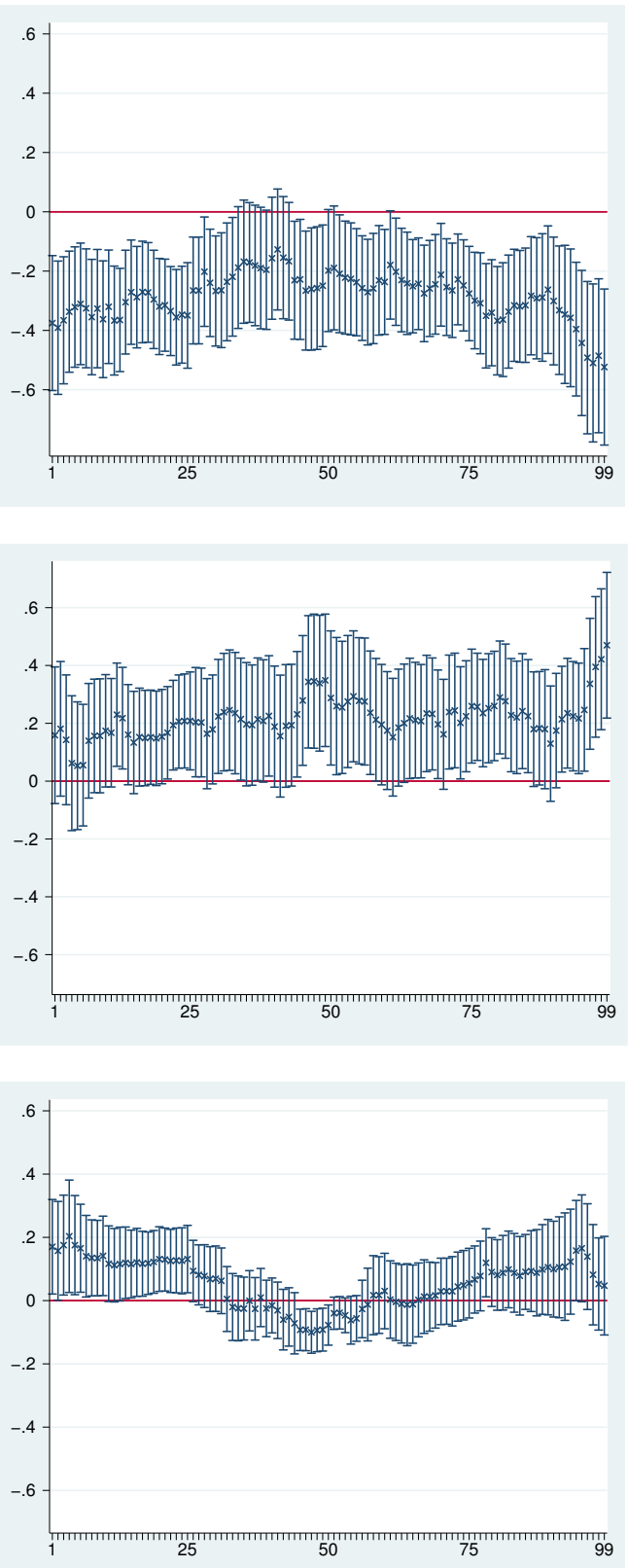

Figure 13: Discontinuities in court outcomes over risk score quantile function

Figure Notes: This figure displays the estimated impact of the discontinuities on court outcomes over the quantile function of the predicted recidivism risk score described in Section 3. Each coefficient reflects a distinct local polynomial RD estimate from regression centered at the focal percentile using a uniform kernel with a 40 percentile bandwidth. Estimates near the first and ninety-ninth percentiles will reflect narrower, asymmetric bandwidths. 
1994 Penal Code Reform
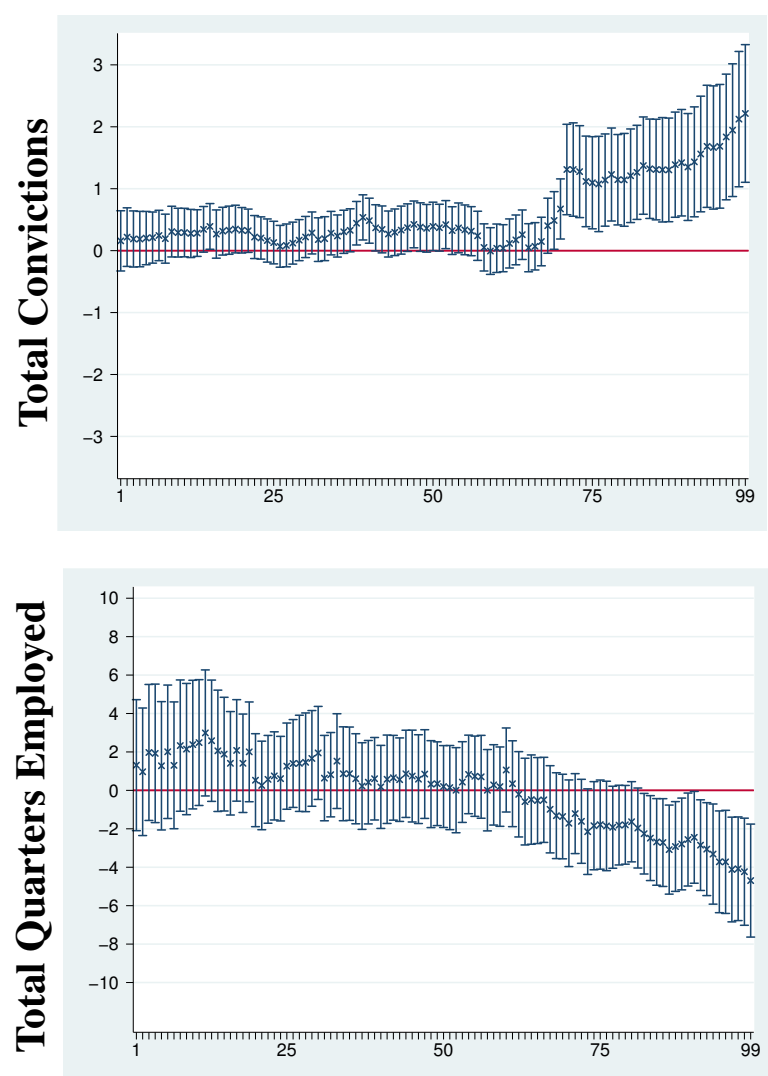

2007 Failed Jail Expansion
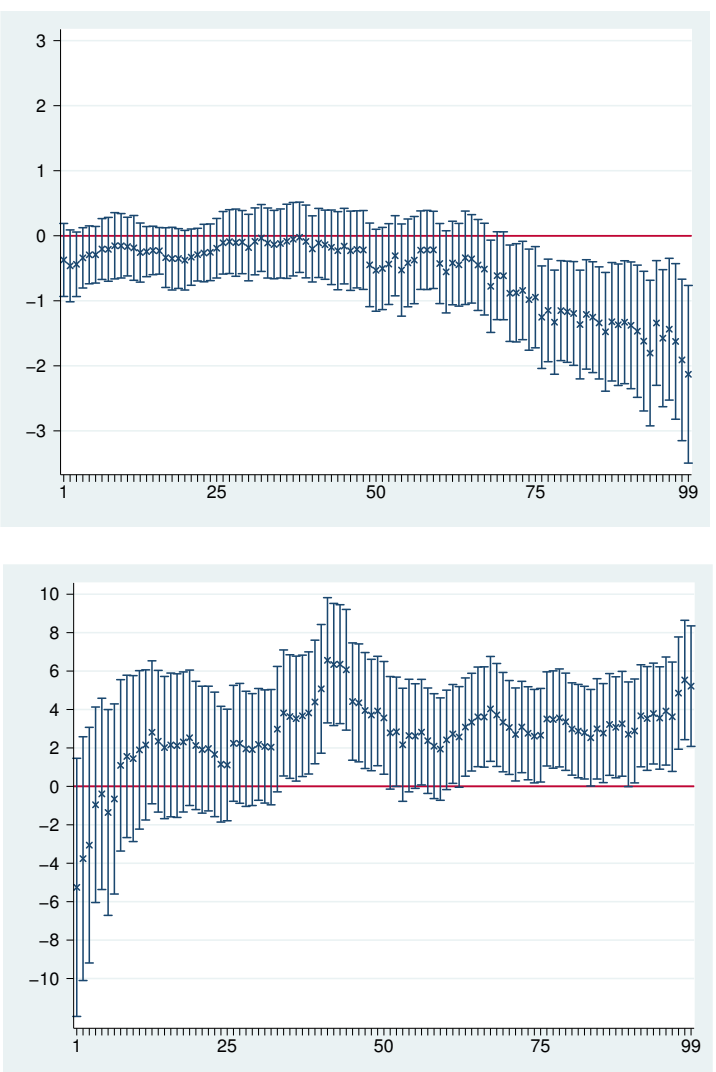

Figure 14: Discontinuities in criminal and labor market outcomes over risk score quantile function

Figure Notes: This figure shows the impact of the discontinuities on criminal and labor market behavior over the quantile function of the predicted recidivism risk score. Each coefficient reflects a distinct local polynomial RD estimate from regression centered at the focal percentile using a uniform kernel with a 40 percentile bandwidth. Estimates near the first and ninety-ninth percentiles will reflect narrower, asymmetric bandwidths. 
Table 1: Discontinuities in background characteristics

\begin{tabular}{lccccccc}
\hline & $\begin{array}{c}\text { Caseload } \\
\text { Density }\end{array}$ & $\begin{array}{c}\text { Prior } \\
\text { Misd. }\end{array}$ & Age & Male & Black & Hisp & $\begin{array}{c}\text { Recid. Risk } \\
\text { Score }\end{array}$ \\
\hline 1994: Post Reform & -1.721 & 0.034 & -1.709 & -0.035 & 0.071 & -0.079 & 0.149 \\
& $(1.444)$ & $(0.234)$ & $(1.342)$ & $(0.055)$ & $(0.068)$ & $(0.056)$ & $(0.117)$ \\
\hline Mean of Dep. Var. (Pre Reform) & 7.48 & 0.64 & 29.67 & 0.75 & 0.55 & 0.18 & 1.22 \\
Observations & 727 & 5,193 & 5,176 & 5,193 & 5,193 & 5,193 & 5,176 \\
Order Loc. Poly (p) & 1 & 1 & 1 & 1 & 1 & 1 & 1 \\
Order Bias (q) & 2 & 2 & 2 & 2 & 2 & 2 & 2 \\
BW Loc. Poly. (1/r) & $79 / 84$ & $92 / 99$ & $91 / 92$ & $121 / 113$ & $103 / 84$ & $81 / 84$ & $103 / 100$ \\
BW Bias (l/r) & $137 / 131$ & $148 / 168$ & $149 / 154$ & $198 / 186$ & $173 / 146$ & $136 / 143$ & $171 / 163$ \\
\hline \hline & & & & & & & \\
2007: Post Reform & -2.083 & 0.075 & -0.940 & 0.065 & 0.060 & 0.042 & 0.062 \\
& $(1.737)$ & $(0.170)$ & $(1.428)$ & $(0.056)$ & $(0.071)$ & $(0.069)$ & $(0.116)$ \\
\hline Mean of Dep. Var. (Pre Reform) & 11.34 & 0.63 & 30.33 & 0.76 & 0.36 & 0.31 & 1.24 \\
Observations & 497 & 5,524 & 5,523 & 5,524 & 5,524 & 5,524 & 5,523 \\
Order Loc. Poly (p) & 1 & 1 & 1 & 1 & 1 & 1 & 1 \\
Order Bias (q) & 2 & 2 & 2 & 2 & 2 & 2 & 2 \\
BW Loc. Poly. (1/r) & $98 / 97$ & $103 / 123$ & $111 / 100$ & $109 / 122$ & $100 / 92$ & $107 / 93$ & $105 / 92$ \\
BW Bias (l/r) & $161 / 159$ & $165 / 200$ & $187 / 162$ & $176 / 203$ & $168 / 150$ & $181 / 153$ & $172 / 151$ \\
\hline
\end{tabular}

$* \mathrm{p}<0.1, * * \mathrm{p}<0.05, * * * \mathrm{p}<0.01$.

Table Notes: This table presents estimates of discontinuities in pre-determined characteristics as recorded in the criminal court records from the Harris County District Court. The calculation of the recidivism risk score is described in Section 4.1.

General RD Estimation Notes: Local-polynomial regression-discontinuity point estimates are bias-corrected and rely on a Epanechnikov kernel. For bandwidth selection, we use a method which selects the median bandwidth from the set of MSE-optimal selection procedures. We use the $\mathrm{HC}_{2}$ heteroskedasticity-robust variance estimation. With the exception of tests for discontinuities in baseline characteristics, our preferred RD model also adjusts for baseline covariates (age, gender, race/ethnicity, and prior number of convictions). These procedures were implemented using the rdrobust package available in STATA (Calonico et al. 2016a). 
Table 2: Discontinuities in court outcomes

\begin{tabular}{lccccc}
\hline & Guilty & $\begin{array}{c}\text { Deferred } \\
\text { Adjudication } \\
\text { of Guilt }\end{array}$ & $\begin{array}{c}\text { Charge } \\
\text { Dismissed }\end{array}$ & $\begin{array}{c}\text { Sentenced to } \\
\text { Incarceration }\end{array}$ & $\begin{array}{c}\text { Drug } \\
\text { Treatment }\end{array}$ \\
\hline 1994: Post Reform & $0.358^{* * * *}$ & $-0.344^{* * *}$ & -0.022 & $0.137 * * *$ & $-0.078^{* *}$ \\
& $(0.061)$ & $(0.061)$ & $(0.057)$ & $(0.048)$ & $(0.036)$ \\
\hline Mean of Dep. Var. (Pre Reform) & 0.34 & 0.52 & 0.15 & 0.14 & 0.06 \\
Observations & 5,176 & 5,176 & 5,176 & 5,176 & 5,176 \\
Order Loc. Poly (p) & 1 & 1 & 1 & 1 & 1 \\
Order Bias (q) & 2 & 2 & 2 & 2 & 2 \\
BW Loc. Poly. (1/r) & $104 / 94$ & $90 / 104$ & $79 / 91$ & $118 / 105$ & $87 / 103$ \\
BW Bias (1/r) & $173 / 171$ & $150 / 175$ & $148 / 148$ & $194 / 169$ & $150 / 160$ \\
\hline \hline & & & & & \\
2007: Post Reform & $-0.286^{* * *}$ & $0.223 * * *$ & $0.073 *$ & $-0.276 * * *$ & 0.052 \\
& $(0.071)$ & $(0.075)$ & $(0.039)$ & $(0.074)$ & $(0.036)$ \\
\hline Mean of Dep. Var. (Pre Reform) & 0.65 & 0.25 & 0.10 & 0.65 & 0.05 \\
Observations & 5,523 & 5,523 & 5,523 & 5,523 & 5,523 \\
Order Loc. Poly (p) & 1 & 1 & 1 & 1 & 1 \\
Order Bias (q) & 2 & 2 & 2 & 2 & 2 \\
BW Loc. Poly. (1/r) & $93 / 93$ & $87 / 87$ & $92 / 116$ & $89 / 89$ & $121 / 119$ \\
BW Bias (1/r) & $157 / 153$ & $141 / 141$ & $153 / 188$ & $147 / 147$ & $204 / 190$ \\
\hline
\end{tabular}

$* \mathrm{p}<0.1, * * \mathrm{p}<0.05, * * * \mathrm{p}<0.01$.

Table Notes: This table presents estimates of discontinuities in court outcomes as recorded in the criminal court records from the Harris County District Court. General RD estimation notes from Table 1 apply. 
Table 3: Discontinuities in criminal outcomes

\begin{tabular}{|c|c|c|c|c|}
\hline & $\begin{array}{c}\text { Jail } \\
\text { Bookings } \\
5 \text { years } \\
\end{array}$ & $\begin{array}{l}\text { County } \\
\text { Charges } \\
5 \text { years }\end{array}$ & $\begin{array}{c}\text { County } \\
\text { Convictions } \\
5 \text { years }\end{array}$ & $\begin{array}{c}\text { Total Days } \\
\text { Incarcerated } \\
5 \text { years }\end{array}$ \\
\hline 1994: Post Reform & $\begin{array}{c}0.493 * \\
(0.283)\end{array}$ & $\begin{array}{l}0.777 * * * \\
(0.272)\end{array}$ & $\begin{array}{l}0.682 * * * \\
(0.217)\end{array}$ & $\begin{array}{c}24.332 \\
(52.344)\end{array}$ \\
\hline Mean of Dep. Var. (Pre Reform) & 1.73 & 1.00 & 0.79 & 341.48 \\
\hline Observations & 5,176 & 5,176 & 5,176 & 5,176 \\
\hline Order Loc. Poly (p) & 1 & 1 & 1 & 1 \\
\hline Order Bias (q) & 2 & 2 & 2 & 2 \\
\hline BW Loc. Poly. (1/r) & $84 / 83$ & $80 / 80$ & $86 / 86$ & $77 / 82$ \\
\hline BW Bias (1/r) & $164 / 139$ & $135 / 138$ & $139 / 148$ & $139 / 155$ \\
\hline 2007: Post Reform & $\begin{array}{c}-0.730 * * \\
(0.313)\end{array}$ & $\begin{array}{l}-0.887 * * * \\
(0.311)\end{array}$ & $\begin{array}{l}-0.665^{* * * *} \\
(0.251)\end{array}$ & $\begin{array}{l}-79.710^{* *} \\
(40.122)\end{array}$ \\
\hline Mean of Dep. Var. (Pre Reform) & 1.64 & 1.36 & 1.15 & 192.79 \\
\hline Observations & 5,523 & 5,523 & 5,523 & 5,523 \\
\hline Order Loc. Poly (p) & 1 & 1 & 1 & 1 \\
\hline Order Bias (q) & 2 & 2 & 2 & 2 \\
\hline BW Loc. Poly. (1/r) & 77 / 102 & $78 / 98$ & $94 / 114$ & $75 / 64$ \\
\hline BW Bias (1/r) & $142 / 166$ & $146 / 163$ & $163 / 181$ & $144 / 127$ \\
\hline
\end{tabular}

$* \mathrm{p}<0.1, * * \mathrm{p}<0.05, * * * \mathrm{p}<0.01$.

Table Notes: This table presents estimates of discontinuities in criminal offending over a five-year follow-up period. The first through fourth columns present estimates of the discontinuity (1994 in the top panel and 2007 in the bottom panel) for the following outcomes: the total number of jail bookings in Harris County, the total number of charges filed with the Harris County, and the total number of convictions in Harris County during the five-year follow-up period. The fourth column provides the estimated discontinuity in total days served in county or state confinement. General RD estimation notes from Table 1 apply. 
Table 4: Discontinuities in binary criminal outcomes

\begin{tabular}{|c|c|c|c|c|}
\hline & $\begin{array}{c}\text { Any Jail } \\
\text { Bookings } \\
5 \text { years }\end{array}$ & $\begin{array}{c}\text { Any County } \\
\text { Charges } \\
5 \text { years }\end{array}$ & $\begin{array}{c}\text { Any County } \\
\text { Convictions } \\
5 \text { years }\end{array}$ & $\begin{array}{c}\text { Ever } \\
\text { Incarcerated } \\
5 \text { years }\end{array}$ \\
\hline 1994: Post Reform & $\begin{array}{c}0.072 \\
(0.047)\end{array}$ & $\begin{array}{c}0.041 \\
(0.059)\end{array}$ & $\begin{array}{l}0.147 * * \\
(0.065)\end{array}$ & $\begin{array}{c}0.032 \\
(0.047)\end{array}$ \\
\hline Mean of Dep. Var. (Pre Reform) & 0.69 & 0.49 & 0.44 & 0.84 \\
\hline Observations & 5,176 & 5,176 & 5,176 & 5,176 \\
\hline Order Loc. Poly (p) & 1 & 1 & 1 & 1 \\
\hline Order Bias $(q)$ & 2 & 2 & 2 & 2 \\
\hline BW Loc. Poly. (1/r) & $132 / 132$ & $107 / 126$ & $79 / 104$ & $85 / 79$ \\
\hline BW Bias (1/r) & $229 / 223$ & $176 / 201$ & $145 / 172$ & $145 / 136$ \\
\hline 2007: Post Reform & $\begin{array}{c}-0.057 \\
(0.066)\end{array}$ & $\begin{array}{c}-0.102 \\
(0.068)\end{array}$ & $\begin{array}{c}-0.151^{* *} \\
(0.063)\end{array}$ & $\begin{array}{c}-0.091 * \\
(0.050)\end{array}$ \\
\hline Mean of Dep. Var. (Pre Reform) & 0.56 & 0.47 & 0.45 & 0.88 \\
\hline Observations & 5,523 & 5,523 & 5,523 & 5,523 \\
\hline Order Loc. Poly (p) & 1 & 1 & 1 & 1 \\
\hline Order Bias (q) & 2 & 2 & 2 & 2 \\
\hline BW Loc. Poly. (1/r) & $97 / 105$ & $103 / 103$ & $112 / 114$ & $108 / 84$ \\
\hline BW Bias (1/r) & $179 / 179$ & $184 / 167$ & $186 / 198$ & $174 / 149$ \\
\hline
\end{tabular}

$* \mathrm{p}<0.1, * * \mathrm{p}<0.05, * * * \mathrm{p}<0.01$.

Table Notes: This table presents estimates of discontinuities in binary criminal offending outcomes over a fiveyear follow-up period. reoffending outcomes over a five-year follow-up period. The first through fourth columns present estimates of the discontinuity (1994 in the top panel and 2007 in the bottom panel) for the following outcomes: any jail booking in Harris County, any charge filed with the Harris County, and any conviction in Harris County during the five-year follow-up period. The fourth column provides the estimated discontinuity any incarceration (county or state confinement). General RD estimation notes from Table 1 apply. 
Table 5: Discontinuities in criminal outcomes, by charge type

\begin{tabular}{|c|c|c|c|c|}
\hline & $\begin{array}{c}\text { County } \\
\text { Charges } \\
5 \text { years } \\
\text { DRUG POSS. }\end{array}$ & $\begin{array}{c}\text { County } \\
\text { Charges } \\
5 \text { years } \\
\text { DRUG DIST. }\end{array}$ & $\begin{array}{c}\text { County } \\
\text { Charges } \\
5 \text { years } \\
\text { PROPERTY }\end{array}$ & $\begin{array}{c}\text { County } \\
\text { Charges } \\
5 \text { years } \\
\text { VIOLENT }\end{array}$ \\
\hline 1994: Post Reform & $\begin{array}{c}0.184 \\
(0.121)\end{array}$ & $\begin{array}{c}0.026 \\
(0.059)\end{array}$ & $\begin{array}{l}0.136 * * \\
(0.059)\end{array}$ & $\begin{array}{c}0.014 \\
(0.043)\end{array}$ \\
\hline Mean of Dep. Var. (Pre Reform) & 0.30 & 0.11 & 0.14 & 0.10 \\
\hline Observations & 5,176 & 5,176 & 5,176 & 5,176 \\
\hline Order Loc. Poly (p) & 1 & 1 & 1 & 1 \\
\hline Order Bias (q) & 2 & 2 & 2 & 2 \\
\hline BW Loc. Poly. (1/r) & $84 / 82$ & $107 / 134$ & $75 / 95$ & $125 / 111$ \\
\hline BW Bias (l/r) & $139 / 143$ & $175 / 209$ & $148 / 163$ & 209 / 182 \\
\hline 2007: Post Reform & $\begin{array}{c}-0.223 * \\
(0.129)\end{array}$ & $\begin{array}{c}-0.031 \\
(0.033)\end{array}$ & $\begin{array}{c}-0.160 \\
(0.114)\end{array}$ & $\begin{array}{c}-0.049 \\
(0.058)\end{array}$ \\
\hline Mean of Dep. Var. (Pre Reform) & 0.46 & 0.05 & 0.31 & 0.13 \\
\hline Observations & 5,523 & 5,523 & 5,523 & 5,523 \\
\hline Order Loc. Poly (p) & 1 & 1 & 1 & 1 \\
\hline Order Bias (q) & 2 & 2 & 2 & 2 \\
\hline BW Loc. Poly. (1/r) & $105 / 109$ & $112 / 113$ & $114 / 100$ & $135 / 133$ \\
\hline BW Bias (1/r) & $173 / 181$ & $179 / 182$ & $187 / 160$ & $216 / 208$ \\
\hline
\end{tabular}

$* \mathrm{p}<0.1, * * \mathrm{p}<0.05, * * * \mathrm{p}<0.01$.

Table Notes: This table presents estimates of discontinuities in criminal offending outcomes over a five-year follow-up period by type of crime as indicated in each column title. General RD estimation notes from Table 1 apply. 
Table 6: Discontinuities in labor market outcomes

\begin{tabular}{|c|c|c|c|c|c|c|}
\hline & $\begin{array}{c}\text { Total } \\
\text { Earnings } \\
5 \text { years }\end{array}$ & $\begin{array}{c}\text { Total } \\
\text { Quarters } \\
\text { Employed } \\
5 \text { years }\end{array}$ & $\begin{array}{c}\text { Total } \\
\text { Quarters } \\
<100 \% \text { FPL } \\
5 \text { years }\end{array}$ & $\begin{aligned} & \text { Total } \\
& \text { Quarters } \\
& \geq 100 \% \text { FPL } \\
& \text { 5 years }\end{aligned}$ & $\begin{array}{c}\text { Length of } \\
\text { Longest } \\
\text { Employment } \\
\text { Spell } \\
5 \text { years }\end{array}$ & $\begin{array}{l}\text { Length of } \\
\text { Longest } \\
\text { Earnings } \\
\text { Spell } \\
5 \text { years }\end{array}$ \\
\hline 1994: Post Reform & $\begin{array}{c}7 \\
(5,938)\end{array}$ & $\begin{array}{c}-0.224 \\
(0.909)\end{array}$ & $\begin{array}{c}-1.257 * * \\
(0.548)\end{array}$ & $\begin{array}{c}0.388 \\
(0.719)\end{array}$ & $\begin{array}{c}0.283 \\
(0.561)\end{array}$ & $\begin{array}{c}0.170 \\
(0.754)\end{array}$ \\
\hline Mean of Dep. Var. (Pre Reform) & 22,238 & 6.60 & 2.98 & 3.62 & 3.54 & 5.00 \\
\hline Observations & 3,932 & 3,932 & 3,932 & 3,932 & 3,932 & 3,932 \\
\hline Order Loc. Poly (p) & 1 & 1 & 1 & 1 & 1 & 1 \\
\hline Order Bias (q) & 2 & 2 & 2 & 2 & 2 & 2 \\
\hline BW Loc. Poly. (1/r) & $101 / 112$ & $102 / 98$ & $66 / 78$ & $105 / 129$ & $105 / 112$ & $108 / 112$ \\
\hline BW Bias (1/r) & $177 / 185$ & $168 / 166$ & $133 / 134$ & $172 / 211$ & $178 / 183$ & $180 / 179$ \\
\hline 2007: Post Reform & $\begin{array}{l}16,545^{*} \\
(9,087)\end{array}$ & $\begin{array}{l}2.709 * * \\
(1.084)\end{array}$ & $\begin{array}{c}0.665 \\
(0.523)\end{array}$ & $\begin{array}{l}1.887 * * \\
(0.876)\end{array}$ & $\begin{array}{l}2.223 * * * \\
(0.811)\end{array}$ & $\begin{array}{l}2.515 * * * \\
(0.949)\end{array}$ \\
\hline Mean of Dep. Var. (Pre Reform) & 21,900 & 6.05 & 2.51 & 3.54 & 3.56 & 4.64 \\
\hline Observations & 3,502 & 3,502 & 3,502 & 3,502 & 3,502 & 3,502 \\
\hline Order Loc. Poly (p) & 1 & 1 & 1 & 1 & 1 & 1 \\
\hline Order Bias (q) & 2 & 2 & 2 & 2 & 2 & 2 \\
\hline BW Loc. Poly. (1/r) & $90 / 89$ & $114 / 114$ & $109 / 114$ & $142 / 138$ & $109 / 112$ & $113 / 115$ \\
\hline BW Bias $(1 / r)$ & $151 / 147$ & $185 / 209$ & $171 / 203$ & $228 / 223$ & $169 / 197$ & $182 / 207$ \\
\hline
\end{tabular}

$* \mathrm{p}<0.1, * * \mathrm{p}<0.05, * * * \mathrm{p}<0.01$.

Table Notes: This table presents estimates of discontinuities in labor market outcomes (from the quarterly unemployment insurance wage records) over a five-year follow-up period. The labor market outcomes vary across each column as indicated by the column title. The first two columns display the estimated discontinuities (1994 in top panel, 2007 in bottom) for formal earnings and employment over the follow-up period. All wage outcomes are adjusted to 2000 US dollars using the Houston MSA CPI index. In subsequent columns, we analyze effects for other labor market outcomes. First, the third and fourth column present estimates for the number of quarters over the follow-up period with employment at a level below or above the 2000 Federal Poverty Level for a single adult $(\$ 8,350)$. The fifth and sixth columns present estimated discontinuities in two measures of job churning and labor market stability. First, Column 5 estimates effects on the longest employment spell at a single employer. Column 6 estimates effects on the longest spell with consecutive earnings (offenders with no more than a quarter gap in between formal employment). General RD estimation notes from Table 1 apply. 
Table 7: Discontinuities in employment by industry

\begin{tabular}{|c|c|c|c|c|c|c|}
\hline & \multicolumn{6}{|c|}{ Total Quarters Employed over 5 Year Followup } \\
\hline & Constr. & Manufact. & $\begin{array}{c}\text { Trade, } \\
\text { Transp., } \\
\text { and Utilities }\end{array}$ & $\begin{array}{l}\text { Prof. and } \\
\text { Bus. } \\
\text { Services }\end{array}$ & $\begin{array}{l}\text { Educ. and } \\
\text { Health } \\
\text { Services }\end{array}$ & $\begin{array}{l}\text { Leisure and } \\
\text { Hospitality }\end{array}$ \\
\hline 1994: Post Reform & $\begin{array}{c}-0.486 \\
(0.407)\end{array}$ & $\begin{array}{c}0.052 \\
(0.395)\end{array}$ & $\begin{array}{c}-1.030 * * \\
(0.426)\end{array}$ & $\begin{array}{c}0.441 \\
(0.418)\end{array}$ & $\begin{array}{c}0.429 \\
(0.360)\end{array}$ & $\begin{array}{c}-0.267 \\
(0.378)\end{array}$ \\
\hline Mean of Dep. Var. (Pre Reform) & 0.80 & 0.64 & 1.44 & 1.37 & 0.49 & 1.14 \\
\hline Observations & 3,932 & 3,932 & 3,932 & 3,932 & 3,932 & 3,932 \\
\hline Order Loc. Poly (p) & 1 & 1 & 1 & 1 & 1 & 1 \\
\hline Order Bias $(q)$ & 2 & 2 & 2 & 2 & 2 & 2 \\
\hline BW Loc. Poly. (1/r) & $71 / 73$ & $124 / 102$ & $82 / 82$ & $120 / 112$ & $103 / 102$ & $103 / 90$ \\
\hline BW Bias $(1 / r)$ & $136 / 137$ & $192 / 176$ & $153 / 148$ & $185 / 177$ & $173 / 164$ & $165 / 148$ \\
\hline 2007: Post Reform & $\begin{array}{c}0.079 \\
(0.475)\end{array}$ & $\begin{array}{c}0.502 \\
(0.404)\end{array}$ & $\begin{array}{c}0.441 \\
(0.589)\end{array}$ & $\begin{array}{c}0.775 \\
(0.632)\end{array}$ & $\begin{array}{l}1.086^{* * *} \\
(0.478)\end{array}$ & $\begin{array}{c}-0.091 \\
(0.493)\end{array}$ \\
\hline Mean of Dep. Var. (Pre Reform) & 0.68 & 0.55 & 1.14 & 1.64 & 0.52 & 1.53 \\
\hline Observations & 3,502 & 3,502 & 3,502 & 3,502 & 3,502 & 3,502 \\
\hline Order Loc. Poly (p) & 1 & 1 & 1 & 1 & 1 & 1 \\
\hline Order Bias (q) & 2 & 2 & 2 & 2 & 2 & 2 \\
\hline BW Loc. Poly. (1/r) & $108 / 121$ & $86 / 86$ & $98 / 117$ & $108 / 128$ & $122 / 122$ & $132 / 122$ \\
\hline BW Bias (1/r) & $167 / 193$ & $142 / 152$ & $159 / 186$ & $175 / 195$ & $187 / 197$ & $215 / 193$ \\
\hline
\end{tabular}

$* \mathrm{p}<0.1, * * \mathrm{p}<0.05, * * * \mathrm{p}<0.01$.

Table Notes: This table presents estimates of discontinuities in labor market outcomes (from the quarterly unemployment insurance wage records) over a five-year follow-up period for formal employment in specific industry supersectors (determined using 2-digit NAICS codes). We present results for the industries with the highest employment rates for our estimation sample. Effects for the other less-relevant industries are presented in Appendix Table B2. General RD estimation notes from Table 1 apply. 
Table 8: Discontinuities in joint labor market and reoffending outcomes

\begin{tabular}{|c|c|c|c|c|}
\hline & Stable & Reoffending & Out of Work & Unstable \\
\hline 1994: Post Reform & $\begin{array}{c}-0.079 \\
(0.063)\end{array}$ & $\begin{array}{c}0.005 \\
(0.064)\end{array}$ & $\begin{array}{c}-0.010 \\
(0.045)\end{array}$ & $\begin{array}{c}0.133 * * \\
(0.067)\end{array}$ \\
\hline Mean of Dep. Var. (Pre Reform) & 0.33 & 0.24 & 0.20 & 0.23 \\
\hline Observations & 3,932 & 3,932 & 3,932 & 3,932 \\
\hline Order Loc. Poly (p) & 1 & 1 & 1 & 1 \\
\hline Order Bias (q) & 2 & 2 & 2 & 2 \\
\hline BW Loc. Poly. (1/r) & $117 / 128$ & $90 / 108$ & $141 / 146$ & $74 / 90$ \\
\hline BW Bias (1/r) & $194 / 206$ & $149 / 175$ & $230 / 233$ & $148 / 155$ \\
\hline 2007: Post Reform & $\begin{array}{l}0.219 * * * \\
(0.069)\end{array}$ & $\begin{array}{c}-0.049 \\
(0.073)\end{array}$ & $\begin{array}{c}-0.015 \\
(0.066)\end{array}$ & $\begin{array}{c}-0.162^{* *} \\
(0.072)\end{array}$ \\
\hline Mean of Dep. Var. (Pre Reform) & 0.28 & 0.23 & 0.23 & 0.26 \\
\hline Observations & 3,502 & 3,502 & 3,502 & 3,502 \\
\hline Order Loc. Poly (p) & 1 & 1 & 1 & 1 \\
\hline Order Bias $(q)$ & 2 & 2 & 2 & 2 \\
\hline BW Loc. Poly. (1/r) & $144 / 149$ & $117 / 118$ & $122 / 135$ & $103 / 118$ \\
\hline BW Bias $(1 / r)$ & $227 / 236$ & $182 / 189$ & $206 / 220$ & $167 / 193$ \\
\hline
\end{tabular}

$* \mathrm{p}<0.1, * * \mathrm{p}<0.05, * * * \mathrm{p}<0.01$.

Table Notes: This table presents estimates of discontinuities for four mutually-exclusive categories considering labor market outcomes and criminal offending outcomes jointly over the five-year follow-up period. These categories are illustrated in Figure 12. General RD estimation notes from Table 1 apply. 
Table 9: Estimated fuzzy RD treatment effects

\begin{tabular}{|c|c|c|c|c|}
\hline & $\begin{array}{c}\text { Any County } \\
\text { Convictions } \\
5 \text { years }\end{array}$ & $\begin{array}{c}\text { Total County } \\
\text { Convictions } \\
5 \text { years }\end{array}$ & $\begin{array}{c}\text { Total Quarters } \\
\text { Employed } \\
5 \text { Years }\end{array}$ & $\begin{array}{c}\text { Total } \\
\text { Earnings } \\
5 \text { years }\end{array}$ \\
\hline 1994: Court Deferral & $\begin{array}{c}-0.376^{* *} \\
(0.173)\end{array}$ & $\begin{array}{c}-1.984 * * * \\
(0.680)\end{array}$ & $\begin{array}{c}0.708 \\
(2.584)\end{array}$ & $\begin{array}{c}-5.137 \\
(17.3838)\end{array}$ \\
\hline High Conviction Period Mean & 0.53 & 1.25 & 6.89 & 22,203 \\
\hline Observations & 5,176 & 5,176 & 3,932 & 3,932 \\
\hline Order Loc. Poly (p) & 1 & 1 & 1 & 1 \\
\hline Order Bias (q) & 2 & 2 & 2 & 2 \\
\hline BW Loc. Poly. (1/r) & $91 / 113$ & $82 / 95$ & $87 / 81$ & $85 / 85$ \\
\hline BW Bias $(1 / r)$ & $161 / 185$ & $144 / 151$ & $141 / 137$ & $141 / 141$ \\
\hline 2007: Felony Conviction & $\begin{array}{c}-0.489 * \\
(0.260)\end{array}$ & $\begin{array}{c}-2.172 * * \\
(0.988)\end{array}$ & $\begin{array}{l}7.813^{* *} \\
(3.403)\end{array}$ & $\begin{array}{c}40.635 * \\
(23.025)\end{array}$ \\
\hline High Conviction Period Mean & 0.45 & 1.15 & 6.05 & 21,900 \\
\hline Observations & 5,523 & 5,523 & 3,502 & 3,502 \\
\hline Order Loc. Poly (p) & 1 & 1 & 1 & 1 \\
\hline Order Bias (q) & 2 & 2 & 2 & 2 \\
\hline BW Loc. Poly. (1/r) & $97 / 92$ & $96 / 89$ & $103 / 121$ & $116 / 93$ \\
\hline BW Bias (1/r) & $160 / 147$ & $156 / 145$ & $176 / 190$ & $206 / 172$ \\
\hline
\end{tabular}

$* \mathrm{p}<0.1, * * \mathrm{p}<0.05, * * * \mathrm{p}<0.01$.

Table Notes: This table presents estimates from a fuzzy RD design where we instrument for a court deferral with the discontinuities for our overall criminal offending outcomes and our primary labor market outcomes. Because the 2007 experiment shows a small but significant impact on case dismissals, for this part of the analysis we redefine court deferrals to also include case dismissals as a combined outcome. As a result, in this exercise if CourtDeferral $=0$ then by construction Conviction $=1$. General RD estimation notes from Table 1 apply. 


\section{A. A Time Series Approach to Estimating the Causal Effect of Court Deferrals}

The previously discussed results in this paper are identified off of a regression discontinuity (RD) framework wherein we have conceptualized the date of charge or the date of disposition for a given defendant as an individual characteristic. We examine the discrete change in court outcomes at two distinct discontinuities in these "characteristics" to identify the causal effect of the changes in punishment. This approach should alleviate any concerns about a selection bias or an omitted variable bias influencing our results.

Our application of the sharp RD methodology in this setting may be considered different than the standard application since our forcing variables are time-based. This appendix applies a time series econometric approach to measuring the effects of the two sharp changes in 1994 and 2007. While we prefer a local RD approach since we believe it requires less restrictive assumptions, a time series approach can better capture the potential interdependence of observations over the forcing variables which could be important for both identification and inference.

In this section, we re-evaluate our key results using a time series framework. We collapse the data to a weekly time series and use two years of pre-reform data to model the time series process for our key outcomes of interest. These models are applied to the full data to evaluate whether there are structural breaks at the two discontinuity dates. Once we establish structural breaks, we perform two complementary exercises to estimate the causal effect of the discontinuities. First, we use an interrupted time series analysis and, second, we use a pre-reform calibrated model to measure the post-reform (out-of-sample) forecast error. Both exercises yield results that closely mirror our RD results.

\section{A.1. Modelling the Time Series}

In this exercise, we first determine the degree of serial correlation in our weekly observations. For each of the key dependent variables we estimate a series of $A R(p)$ models with successively more autoregressive lags of the dependent variable. We fit each model to two years of pre-reform data 
collapsed to the weekly level, and include indicators for each calendar month, a monthly linear time trend and average defendant characteristics (age, race, sex, and misdemeanor record). ${ }^{64}$ We rely on the Akaike Information Criteria (AIC) to evaluate which specification best fits the observed patterns, a method which penalizes models with more parameters. The AIC for each estimated $A R(p)$ specification is presented in Table A1.

Our estimates imply mixed degrees of serial correlation in our dependent variables (after including our set of controls). In both samples, we select models with no lagged dependent variables for the total future county convictions and caseload density demonstrating limited interdependence in these variables over time. Conviction rates and total employment in 1994 are best fit with four lagged dependent variables and the remaining series suggest one or two lagged values using the AIC selection criteria.

The estimated models using the selected $A R(p)$ lag length are presented in Tables A2 and A3. We estimate a strong correlation over time in 1994, specifically in the deferral, conviction rates and employment outcomes. Elsewhere, the degree of autocorrelation is not as strong.

\section{A.2. Testing for Structural Breaks}

To evaluate whether the discontinuities we study can be explained as a function of serial dependence, trends and/or seasonality, we test for whether there is a structural break at the two threshold dates using the full sample of data (i.e., two years of pre-reform data and one year post). We perform a Wald test to evaluate the null hypothesis of no structural breaks. These test statistics and associated p-values are provided at the bottom of Tables A2 and A3.

We find strong evidence of structural breaks occurring in both the 1994 and 2007 series for our measures of court outcomes (court deferrals and conviction rates) as well as defendant outcomes (total future convictions over five years and total quarters employed over five years). ${ }^{65}$ Consistent with previous analysis of caseload densities around the thresholds, we fail to reject the null of no structural break in caseload size. This is consistent with evidence discussed in the RD framework

\footnotetext{
${ }^{64}$ The model for total observations omits defendant characteristics given potential concerns about simultaneity.

${ }^{65}$ Additionally, Sup Wald tests (not shown) over the same sample correctly identify the structural breaks as occurring during the weeks of our discontinuities.
} 
and supports our identification assumption that the density and background characteristics are smooth across the discontinuity dates.

\section{A.3. Estimating the Impact of the Discontinuities}

To evaluate the impact of the discontinuities on defendant outcomes, we employ two complementary strategies. First, we analyze the data using a simple interrupted time series model and present results in Table A4. This basic design uses the time series models selected with the AIC criteria and introduces two additional parameters: a variable indicating when the reform is active (Post) and an interaction between this indicator variable and the running variable to allow a change in trend at the threshold date (Week $x$ Post). In practice we observe this as similar to estimating a linear regression discontinuity design while allowing for some pre-specified degrees of autocorrelation across the running variables. Consistent with our evaluation of the structural breaks, we estimate clear impact of the reform as captured by the estimated coefficient on the Post indicator variable. In both 1994 and 2007, there is clear evidence of a shift in court outcomes at the threshold dates as well as a corresponding shift in outcome variables. Using these time series methods, we see a clear negative impact of the low-deferral regime in 1994 on labor market outcomes, an effect we did not observe in the RD framework. While the direction of the effects in 2007 are consistent with our RD estimates, the estimates become marginally insignificant and imply more modest magnitudes. These differences in our labor market effect estimates suggest that the local polynomial RD approach is affected by changes in trends around each discontinuity. Figure A1 presents the raw time series data and the fitted interrupted time series models.

Second, we present results using an alternative strategy in which we calibrate a time series model using pre-reform data and evaluate how well it predicts the series immediately after the discontinuity. In contrast to the interrupted time series model, this approach does not assume the data before and after the discontinuity follow a common data generating process. The effect of the discontinuity can then be measured as the average forecast error in the post-threshold period. Since it is difficult to extrapolate trends far out into the future with an out-of-sample prediction, 
we use two years of pre-reform data to forecast one quarter following each reform.

To calculate standard errors, we employ a multi-step forecast simulation procedure. This approach first generates a set of realized in-sample forecast errors and then builds out a series of simulated iterative out-of-sample forecast predictions that randomly draw (with replacement) from the set of in-sample forecast errors. The empirical quantiles for each successive out-ofsample period are used to obtain the confidence intervals over the period. We also take the average quarterly out-of-sample forecast error for each of the 5,000 simulations per series to generate statistical significance thresholds.

The results of this forecast error exercise are presented in Figure A2 and Table A5. The plots illustrate a pattern in which the realized observations in both 1994 and 2007 are systematically above or below the predicted path. The only exception is the caseload size outcome, which has a lower degree of one-way deviations. The magnitude of the deviations for the court and future outcomes often puts the realized observations at or beyond the simulated confidence interval bands.

The average forecast error over the first out-of-sample quarter, which we interpret as the impact of the discontinuity, yield results that are closely aligned with the estimates from the interrupted time series analysis. 
1994 Penal Code Reform
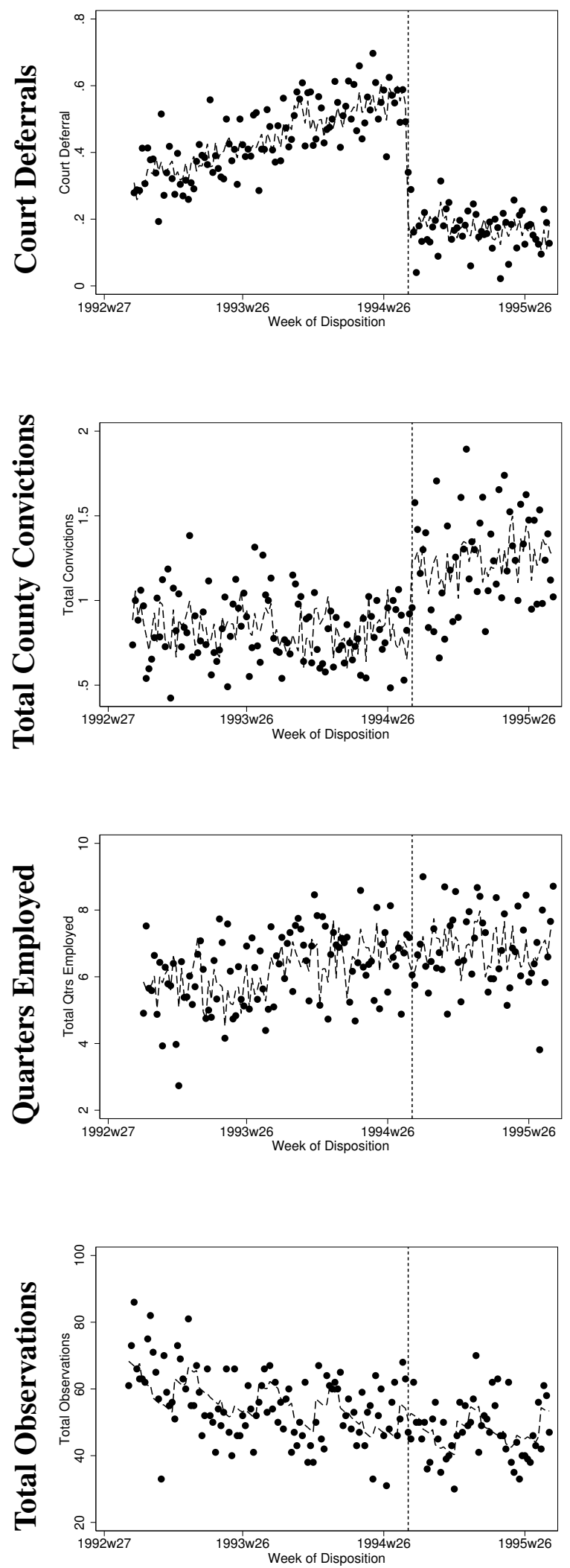

2007 Failed Jail Expansion
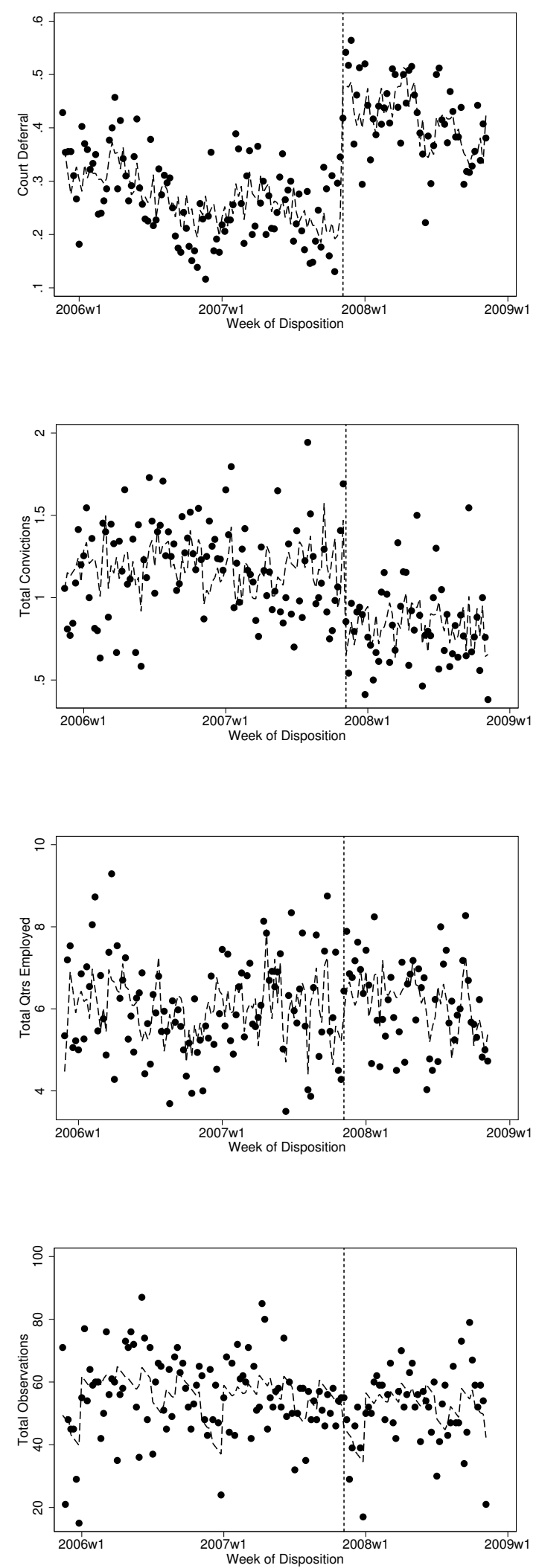

Figure A1: Interrupted time series plots

Figure Notes: This figure presents the raw time series data and the fitted interrupted time series model. The interrupted times series model selects a lags according to the AIC criteria and introduces a variable indicating the post discontinuity period and an interaction between the post threshold period and the week. The lags selected for each outcome and sample are indicated in Table A1 and estimates in Table A4. 
1994 Penal Code Reform
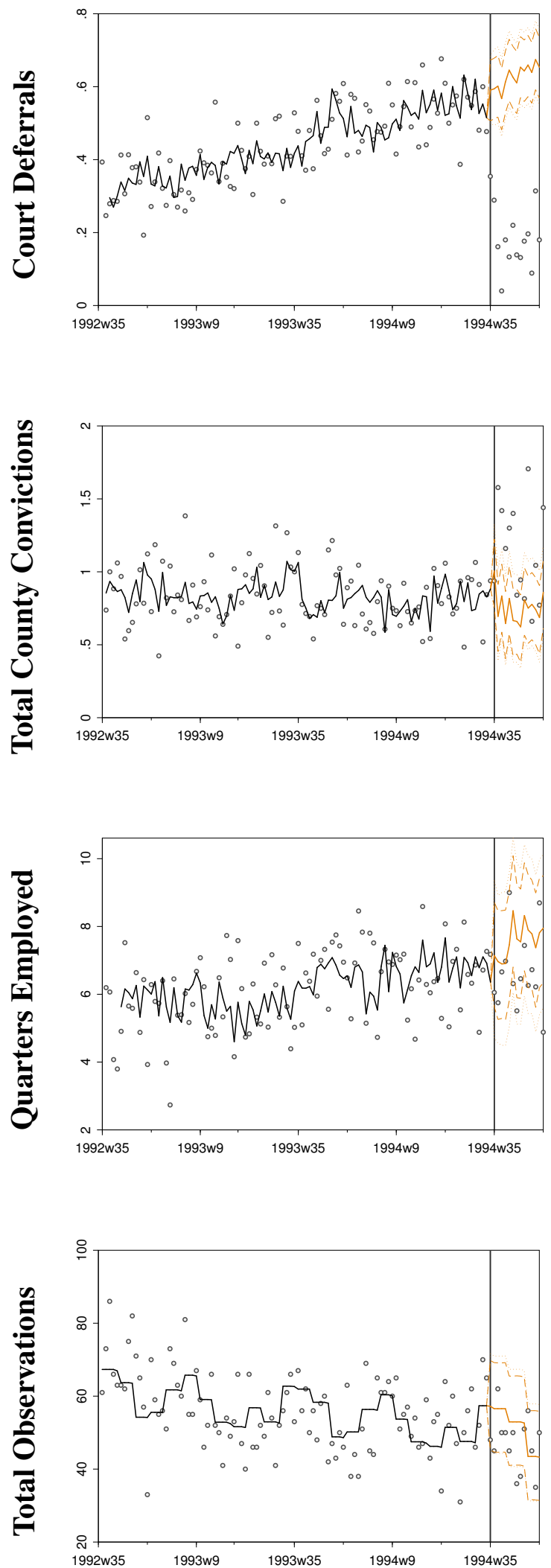

\section{Failed Jail Expansion}
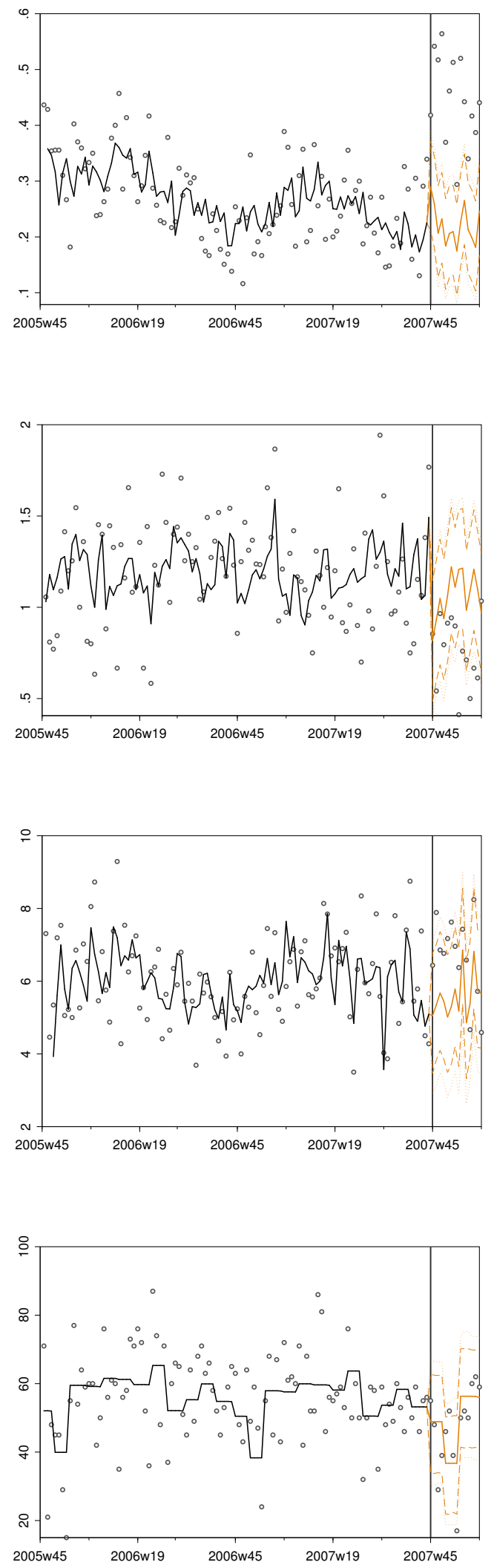

Figure A2: Comparing observed trends and forecasted out-of-sample predictions

Figure Notes: This figure presents the raw time series data and a model which is calibrated with pre-reform data and then we compare actual post-reform outcomes to predicted outcomes extending the model through the discontinuity. Since it is difficult to extrapolate trends far into the future, we use two years of pre-reform data to forecast one quarter post-reform. Results from this analysis are presented in Table A5. 
Table A1: Time series model selection

\begin{tabular}{lccccc}
\hline & $\begin{array}{c}\text { Court } \\
\text { Deferral }\end{array}$ & Conviction & $\begin{array}{c}\text { Total County } \\
\text { Convictions }\end{array}$ & $\begin{array}{c}\text { Total Quarters } \\
\text { Employed }\end{array}$ & $\begin{array}{c}\text { Caseload } \\
\text { Density }\end{array}$ \\
\hline AR(p) Lag Length, 1994 & & & & & \\
0 & -220.1 & -229.5 & -24.8 & 313.8 & 732.4 \\
1 & -224.1 & -229.4 & -24.5 & 312.6 & 734.4 \\
2 & -225.3 & -231.3 & -23.1 & 309.7 & 736 \\
3 & -224.3 & -230.8 & -22.2 & 311.4 & 737.5 \\
4 & -223.5 & -233.9 & -20.9 & 308.9 & 739.5 \\
Selected Lag Length & 2 & 4 & 0 & 4 & 0 \\
AR(p) Lag Length, 2007 & & & & 308.1 & 781.6 \\
0 & -231.5 & -209.3 & 41.5 & 309.9 & 783.6 \\
1 & -233.5 & -207.4 & 43.5 & 304.3 & 783 \\
2 & -232 & -209.9 & 45.4 & 306.3 & 784.2 \\
3 & -230.7 & -208.0 & 47.3 & 308.2 & 784.4 \\
4 & -228.7 & -207.0 & 49.2 & 2 & 0 \\
\hline
\end{tabular}

$* \mathrm{p}<0.1, * * \mathrm{p}<0.05, * * * \mathrm{p}<0.01$.

Table Notes: This table presents the Akaike Information Criteria (AIC) for time series models which successively more autoregressive lags of the dependent variable. We fit each model to two years of pre-reform data, and include indicators for each calendar month, a monthly linear time trend and average defendant characteristics (age, race, sex, and misdemeanor record). The models which minimizes the AIC for each outcome are presented in Tables A2 and A3 and in Figure A1. 
Table A2: Time series estimated model, 1994

\begin{tabular}{|c|c|c|c|c|c|}
\hline & $\begin{array}{c}\text { Court } \\
\text { Deferral }\end{array}$ & Conviction & $\begin{array}{c}\text { Total } \\
\text { County } \\
\text { Convictions }\end{array}$ & $\begin{array}{c}\text { Total } \\
\text { Quarters } \\
\text { Employed }\end{array}$ & $\begin{array}{c}\text { Total } \\
\text { Caseload }\end{array}$ \\
\hline Lag Dep. Var. & $\begin{array}{c}-0.271 * * \\
(0.111)\end{array}$ & $\begin{array}{l}-0.270^{* *} \\
(0.118)\end{array}$ & & $\begin{array}{c}-0.202^{*} \\
(0.114)\end{array}$ & \\
\hline Lag2 Dep. Var. & $\begin{array}{c}-0.197^{*} \\
(0.108)\end{array}$ & $\begin{array}{c}-0.297 * * \\
(0.118)\end{array}$ & & $\begin{array}{l}-0.257 * * \\
(0.114)\end{array}$ & \\
\hline Lag3 Dep. Var. & & $\begin{array}{c}-0.185 \\
(0.111)\end{array}$ & & $\begin{array}{c}-0.012 \\
(0.118)\end{array}$ & \\
\hline Lag4 Dep. Var. & & $\begin{array}{c}-0.222 * \\
(0.118)\end{array}$ & & $\begin{array}{c}-0.218^{*} \\
(0.117)\end{array}$ & \\
\hline January & $\begin{array}{c}0.002 \\
(0.042)\end{array}$ & $\begin{array}{c}0.023 \\
(0.040)\end{array}$ & $\begin{array}{c}0.041 \\
(0.114)\end{array}$ & $\begin{array}{c}0.272 \\
(0.561)\end{array}$ & $\begin{array}{c}-0.647 \\
(4.990)\end{array}$ \\
\hline February & $\begin{array}{c}-0.011 \\
(0.041)\end{array}$ & $\begin{array}{c}0.066 \\
(0.042)\end{array}$ & $\begin{array}{c}-0.012 \\
(0.110)\end{array}$ & $\begin{array}{l}1.260 * * \\
(0.626)\end{array}$ & $\begin{array}{c}4.050 \\
(5.198)\end{array}$ \\
\hline March & $\begin{array}{c}0.037 \\
(0.042)\end{array}$ & $\begin{array}{c}-0.009 \\
(0.040)\end{array}$ & $\begin{array}{c}0.009 \\
(0.115)\end{array}$ & $\begin{array}{c}0.376 \\
(0.670)\end{array}$ & $\begin{array}{c}-2.407 \\
(5.205)\end{array}$ \\
\hline April & $\begin{array}{c}0.023 \\
(0.040)\end{array}$ & $\begin{array}{c}-0.035 \\
(0.038)\end{array}$ & $\begin{array}{c}-0.012 \\
(0.109)\end{array}$ & $\begin{array}{c}0.490 \\
(0.546)\end{array}$ & $\begin{array}{c}-8.045 \\
(5.017)\end{array}$ \\
\hline May & $\begin{array}{c}0.020 \\
(0.041)\end{array}$ & $\begin{array}{c}0.061 \\
(0.042)\end{array}$ & $\begin{array}{c}0.138 \\
(0.113)\end{array}$ & $\begin{array}{c}0.322 \\
(0.596)\end{array}$ & $\begin{array}{c}-8.454 \\
(5.237)\end{array}$ \\
\hline June & $\begin{array}{c}0.029 \\
(0.042)\end{array}$ & $\begin{array}{c}0.027 \\
(0.041)\end{array}$ & $\begin{array}{c}0.089 \\
(0.114)\end{array}$ & $\begin{array}{c}0.084 \\
(0.570)\end{array}$ & $\begin{array}{c}-2.793 \\
(5.256)\end{array}$ \\
\hline July & $\begin{array}{c}0.012 \\
(0.040)\end{array}$ & $\begin{array}{c}0.016 \\
(0.040)\end{array}$ & $\begin{array}{c}0.076 \\
(0.110)\end{array}$ & $\begin{array}{c}0.185 \\
(0.553)\end{array}$ & $\begin{array}{c}-6.276 \\
(5.086)\end{array}$ \\
\hline August & $\begin{array}{c}-0.024 \\
(0.045)\end{array}$ & $\begin{array}{l}-0.050 \\
(0.042)\end{array}$ & $\begin{array}{c}0.199 \\
(0.122)\end{array}$ & $\begin{array}{l}0.000 \\
(.)\end{array}$ & $\begin{array}{c}3.449 \\
(5.425)\end{array}$ \\
\hline September & $\begin{array}{l}0.000 \\
(.)\end{array}$ & $\begin{array}{l}0.000 \\
(.)\end{array}$ & $\begin{array}{l}0.000 \\
(.)\end{array}$ & $\begin{array}{c}0.407 \\
(0.679)\end{array}$ & $\begin{array}{l}0.000 \\
(.)\end{array}$ \\
\hline October & $\begin{array}{c}0.051 \\
(0.041)\end{array}$ & $\begin{array}{c}0.014 \\
(0.039)\end{array}$ & $\begin{array}{c}0.011 \\
(0.112)\end{array}$ & $\begin{array}{l}1.529 * * \\
(0.635)\end{array}$ & $\begin{array}{c}0.326 \\
(5.091)\end{array}$ \\
\hline November & $\begin{array}{l}0.088^{* *} \\
(0.042)\end{array}$ & $\begin{array}{c}-0.070^{*} \\
(0.039)\end{array}$ & $\begin{array}{c}0.099 \\
(0.113)\end{array}$ & $\begin{array}{c}1.313^{*} \\
(0.683)\end{array}$ & $\begin{array}{c}-8.476 \\
(5.200)\end{array}$ \\
\hline December & $\begin{array}{c}0.049 \\
(0.042)\end{array}$ & $\begin{array}{c}-0.059 \\
(0.040)\end{array}$ & $\begin{array}{c}0.021 \\
(0.112)\end{array}$ & $\begin{array}{l}1.087^{*} \\
(0.628)\end{array}$ & $\begin{array}{l}-6.928 \\
(5.195)\end{array}$ \\
\hline Month Trend & $\begin{array}{l}0.018^{* * *} \\
(0.003)\end{array}$ & $\begin{array}{l}-0.024 * * * \\
(0.004)\end{array}$ & $\begin{array}{c}-0.006^{*} \\
(0.003)\end{array}$ & $\begin{array}{l}0.137 * * * \\
(0.030)\end{array}$ & $\begin{array}{l}-0.458^{* * *} \\
(0.154)\end{array}$ \\
\hline Observations & 99 & 99 & 99 & 99 & 99 \\
\hline Wald Test for Structural Break & 117.3 & 104.1 & 83.8 & 27.7 & 16.3 \\
\hline P-Value & 0.00 & 0.00 & 0.00 & 0.23 & 0.24 \\
\hline
\end{tabular}

$* \mathrm{p}<0.1, * * \mathrm{p}<0.05, * * * \mathrm{p}<0.01$

Table Notes: This table presents the results from the time series models with lags selected through the AIC criteria to evaluate the September 1, 1994 shift for each of the dependent variables indicated in the column titles. We fit each model to two years of pre-reform data, and include indicators for each calendar month, a monthly linear time trend and average defendant characteristics (age, race, sex, and misdemeanor record). The predictions from the model are presented in Figure A1. 
Table A3: Time series estimated model, 2007

\begin{tabular}{|c|c|c|c|c|c|}
\hline & $\begin{array}{c}\text { Court } \\
\text { Deferral }\end{array}$ & Conviction & $\begin{array}{c}\text { Total } \\
\text { County } \\
\text { Convictions }\end{array}$ & $\begin{array}{c}\text { Total } \\
\text { Quarters } \\
\text { Employed }\end{array}$ & $\begin{array}{c}\text { Total } \\
\text { Caseload }\end{array}$ \\
\hline Lag Dep. Var. & $\begin{array}{c}0.196^{*} \\
(0.113)\end{array}$ & $\begin{array}{c}0.022 \\
(0.111)\end{array}$ & & $\begin{array}{c}0.058 \\
(0.098)\end{array}$ & \\
\hline Lag2 Dep. Var. & & $\begin{array}{c}-0.226^{*} \\
(0.114)\end{array}$ & & $\begin{array}{c}-0.248^{* *} \\
(0.100)\end{array}$ & \\
\hline January & $\begin{array}{c}0.041 \\
(0.042)\end{array}$ & $\begin{array}{l}-0.061 \\
(0.047)\end{array}$ & $\begin{array}{c}0.045 \\
(0.164)\end{array}$ & $\begin{array}{l}1.265^{* *} \\
(0.634)\end{array}$ & $\begin{array}{c}3.322 \\
(6.911)\end{array}$ \\
\hline February & $\begin{array}{c}0.052 \\
(0.045)\end{array}$ & $\begin{array}{c}-0.091^{*} \\
(0.051)\end{array}$ & $\begin{array}{l}-0.070 \\
(0.168)\end{array}$ & $\begin{array}{l}2.084 * * * \\
(0.669)\end{array}$ & $\begin{array}{c}3.441 \\
(7.131)\end{array}$ \\
\hline March & $\begin{array}{c}0.056 \\
(0.044)\end{array}$ & $\begin{array}{l}-0.105^{* *} \\
(0.050)\end{array}$ & $\begin{array}{c}-0.185 \\
(0.169)\end{array}$ & $\begin{array}{l}1.633^{* *} \\
(0.659)\end{array}$ & $\begin{array}{c}5.521 \\
(7.119)\end{array}$ \\
\hline April & $\begin{array}{c}0.080 * \\
(0.045)\end{array}$ & $\begin{array}{l}-0.143 * * * \\
(0.052)\end{array}$ & $\begin{array}{c}0.044 \\
(0.166)\end{array}$ & $\begin{array}{l}2.100 * * * \\
(0.667)\end{array}$ & $\begin{array}{c}5.570 \\
(6.974)\end{array}$ \\
\hline May & $\begin{array}{c}0.052 \\
(0.043)\end{array}$ & $\begin{array}{c}-0.098^{*} \\
(0.050)\end{array}$ & $\begin{array}{c}-0.147 \\
(0.165)\end{array}$ & $\begin{array}{l}1.713^{* *} \\
(0.651)\end{array}$ & $\begin{array}{c}4.044 \\
(6.975)\end{array}$ \\
\hline June & $\begin{array}{c}0.029 \\
(0.046)\end{array}$ & $\begin{array}{c}-0.071 \\
(0.051)\end{array}$ & $\begin{array}{l}-0.050 \\
(0.171)\end{array}$ & $\begin{array}{l}1.128 * \\
(0.657)\end{array}$ & $\begin{array}{l}10.098 \\
(7.110)\end{array}$ \\
\hline July & $\begin{array}{c}0.014 \\
(0.043)\end{array}$ & $\begin{array}{c}-0.073 \\
(0.050)\end{array}$ & $\begin{array}{c}0.105 \\
(0.166)\end{array}$ & $\begin{array}{l}1.515^{* *} \\
(0.644)\end{array}$ & $\begin{array}{l}-2.563 \\
(6.879)\end{array}$ \\
\hline August & $\begin{array}{c}0.002 \\
(0.045)\end{array}$ & $\begin{array}{l}-0.071 \\
(0.052)\end{array}$ & $\begin{array}{c}0.046 \\
(0.173)\end{array}$ & $\begin{array}{c}0.962 \\
(0.659)\end{array}$ & $\begin{array}{c}0.572 \\
(7.132)\end{array}$ \\
\hline September & $\begin{array}{c}0.003 \\
(0.043)\end{array}$ & $\begin{array}{c}0.005 \\
(0.048)\end{array}$ & $\begin{array}{c}-0.029 \\
(0.169)\end{array}$ & $\begin{array}{c}1.158 * \\
(0.653)\end{array}$ & $\begin{array}{c}5.175 \\
(7.151)\end{array}$ \\
\hline October & $\begin{array}{c}-0.010 \\
(0.043)\end{array}$ & $\begin{array}{c}0.001 \\
(0.048)\end{array}$ & $\begin{array}{c}0.092 \\
(0.166)\end{array}$ & $\begin{array}{c}0.588 \\
(0.638)\end{array}$ & $\begin{array}{c}0.628 \\
(6.939)\end{array}$ \\
\hline November & $\begin{array}{l}0.000 \\
(.)\end{array}$ & $\begin{array}{l}0.000 \\
(.)\end{array}$ & $\begin{array}{l}0.000 \\
(.)\end{array}$ & $\begin{array}{l}0.000 \\
(.)\end{array}$ & $\begin{array}{l}0.000 \\
(.)\end{array}$ \\
\hline December & $\begin{array}{c}0.008 \\
(0.045)\end{array}$ & $\begin{array}{c}-0.022 \\
(0.052)\end{array}$ & $\begin{array}{c}0.051 \\
(0.176)\end{array}$ & $\begin{array}{c}0.815 \\
(0.683)\end{array}$ & $\begin{array}{c}-17.087 * * \\
(7.322)\end{array}$ \\
\hline Month Trend & $\begin{array}{c}-0.002 \\
(0.001)\end{array}$ & $\begin{array}{l}0.004 * * * \\
(0.002)\end{array}$ & $\begin{array}{l}-0.003 \\
(0.005)\end{array}$ & $\begin{array}{c}0.020 \\
(0.019)\end{array}$ & $\begin{array}{c}-0.234 \\
(0.199)\end{array}$ \\
\hline Observations & 99 & 99 & 99 & 99 & 99 \\
\hline Wald Test for Structural Break & 49.2 & 66 & 21.6 & 42.1 & 7.4 \\
\hline P-Value & 0.00 & 0.00 & 0.30 & 0.00 & 0.88 \\
\hline
\end{tabular}

$* \mathrm{p}<0.1, * * \mathrm{p}<0.05, * * * \mathrm{p}<0.01$.

Table Notes: This table presents the results from the time series models with lags selected through the AIC criteria to evaluate the November 7, 2007 shift for each of the dependent variables indicated in the column titles. We fit each model to two years of pre-reform data, and include indicators for each calendar month, a monthly linear time trend and average defendant characteristics (age, race, sex, and misdemeanor record). The predictions from the model are presented in Figure A1. 
Table A4: Interrupted time series estimates

\begin{tabular}{cccccc}
\hline & Guilty & $\begin{array}{c}\text { Court } \\
\text { Deferral }\end{array}$ & $\begin{array}{c}\text { Total } \\
\text { Convictions }\end{array}$ & $\begin{array}{c}\text { Total Qtrs } \\
\text { Employed }\end{array}$ & $\begin{array}{c}\text { Total } \\
\text { Observations }\end{array}$ \\
\hline Sample = 1994 & $0.361^{* * *}$ & $-0.419 * * *$ & $0.371^{* * *}$ & $-1.061^{* * *}$ & -3.758 \\
Post & $(0.073)$ & $(0.081)$ & $(0.103)$ & $(0.396)$ & $(3.143)$ \\
Week of Charge & $-0.018^{* * *}$ & 0.009 & 0.008 & 0.158 & -0.707 \\
Week x Post & $(0.006)$ & $(0.006)$ & $(0.019)$ & $(0.097)$ & $(0.752)$ \\
Observations & $0.006^{* * *}$ & $-0.004 * * *$ & $0.005^{*}$ & -0.009 & $0.176^{* *}$ \\
Sample = 2007 & $(0.001)$ & $(0.001)$ & $(0.003)$ & $(0.011)$ & $(0.086)$ \\
Post & 152 & 154 & 156 & 152 & 156 \\
Week of Disposition & & & & & 0.423 \\
Week x Post & $(0.049)$ & $(0.035)$ & $(0.105)$ & $(0.423)$ & $(5.087)$ \\
& 0.007 & -0.003 & -0.005 & 0.103 & -1.152 \\
Observations & $(0.006)$ & $(0.005)$ & $(0.020)$ & $(0.085)$ & $(0.909)$ \\
& 0.000 & -0.001 & -0.001 & -0.012 & -0.005 \\
& $(0.001)$ & $(0.001)$ & $(0.002)$ & $(0.010)$ & $(0.132)$ \\
\end{tabular}

$* \mathrm{p}<0.1, * * \mathrm{p}<0.05, * * * \mathrm{p}<0.01$.

Table Notes: This table adds an indicator for post-reform and an interaction between the post indicator and the weekly running variable to the $A R(p)$ models presented in Tables A2 and A3 to test whether there is a significant break. These models are similar to our RD specifications but include lagged dependent variables.

Table A5: Average forecast error and bootstrapped significance thresholds

\begin{tabular}{|c|c|c|c|c|c|c|c|}
\hline & \multirow{2}{*}{$\begin{array}{c}\text { Out of Sample } \\
\text { Average Forecast } \\
\text { Error }\end{array}$} & \multicolumn{6}{|c|}{$\begin{array}{c}\text { Bootstrapped Empirical } \\
\text { Simulated Forecast Quantiles }\end{array}$} \\
\hline & & 0.01 & 0.05 & 0.10 & 0.90 & 0.95 & 0.99 \\
\hline \multicolumn{8}{|l|}{ Sample $=1994$} \\
\hline Court Deferral & $-0.46 * * *$ & -0.04 & -0.02 & -0.02 & 0.02 & 0.02 & 0.04 \\
\hline Conviction & $0.42 * * *$ & -0.03 & -0.02 & -0.01 & 0.01 & 0.02 & 0.03 \\
\hline Total County Convictions & $0.42 * * *$ & -0.11 & -0.08 & -0.06 & 0.06 & 0.08 & 0.11 \\
\hline Total Quarters Employed & $-0.96 * * *$ & -0.54 & -0.32 & -0.24 & 0.22 & 0.29 & 0.47 \\
\hline Caseload Density & -3.95 & -5.53 & -4.05 & -3.2 & 2.99 & 3.85 & 5.53 \\
\hline \multicolumn{8}{|l|}{ Sample $=2007$} \\
\hline Court Deferral & $0.23 * * *$ & -0.06 & -0.04 & -0.03 & 0.03 & 0.04 & 0.06 \\
\hline Conviction & $-0.27 * * *$ & -0.05 & -0.03 & -0.02 & 0.02 & 0.03 & 0.05 \\
\hline Total County Convictions & $-0.33 * * *$ & -0.17 & -0.12 & -0.09 & 0.09 & 0.11 & 0.16 \\
\hline Total Quarters Employed & $0.78 * * *$ & -0.61 & -0.38 & -0.29 & 0.32 & 0.41 & 0.64 \\
\hline Caseload Density & -2.16 & -7.35 & -5.26 & -4.1 & 4.14 & 5.25 & 7.26 \\
\hline
\end{tabular}

$* \mathrm{p}<0.1, * * \mathrm{p}<0.05, * * * \mathrm{p}<0.01$

Table Notes: This table presents results using an empirical methodology in which we calibrate a time series model using two years of pre-reform data and evaluate how well it predicts the series immediately after the discontinuity (in the first quarter following the shift). The effect of the discontinuity is measured as the average forecast error in the post-threshold period. To calculate standard errors, we employ a multi-step forecast simulation procedure. This approach first generates a set of realized in-sample forecast errors and then builds out a series of simulated iterative out-of-sample forecast predictions that randomly draw (with replacement) from the set of in-sample forecast errors. The empirical quantiles for each successive out-of-sample period are used to obtain the confidence intervals over the period. We take the average quarterly out-of-sample forecast error for each of the 5,000 simulations per series to generate statistical significance thresholds. 


\section{B. Supplemental Heterogeneity Analysis Results}
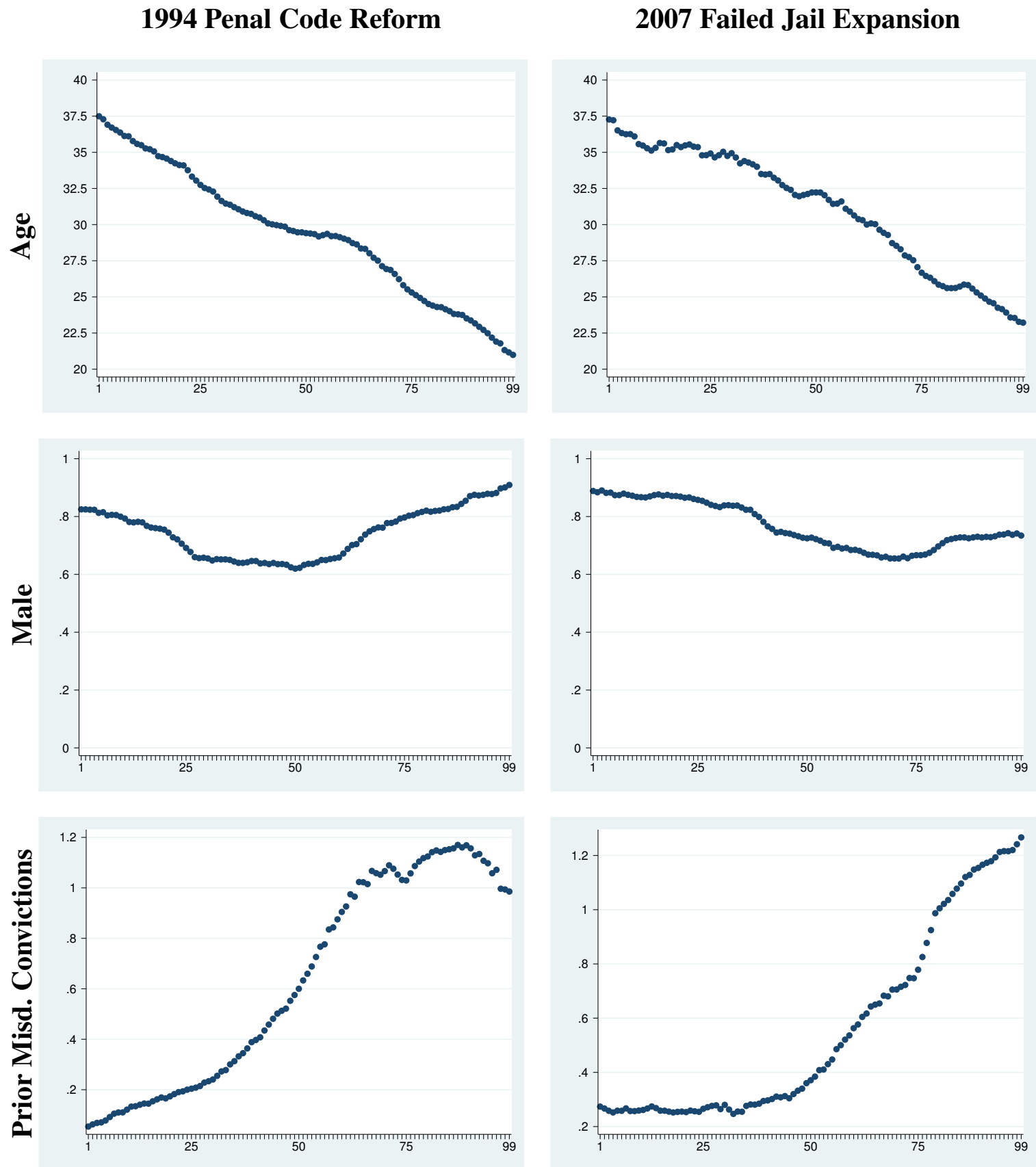

Figure B1: Background characteristics over risk score quantile function

Figure Notes: This figure shows the relationship between the demographic characteristics and prior criminal record and the quantile function of the predicted recidivism risk score. Each point estimate documents the average trait in a 40 percentile bandwidth centered at the focal percentile using a uniform kernel. Estimates near the first and ninety-ninth percentiles will reflect narrower, asymmetric bandwidths. 
1994 Penal Code Reform
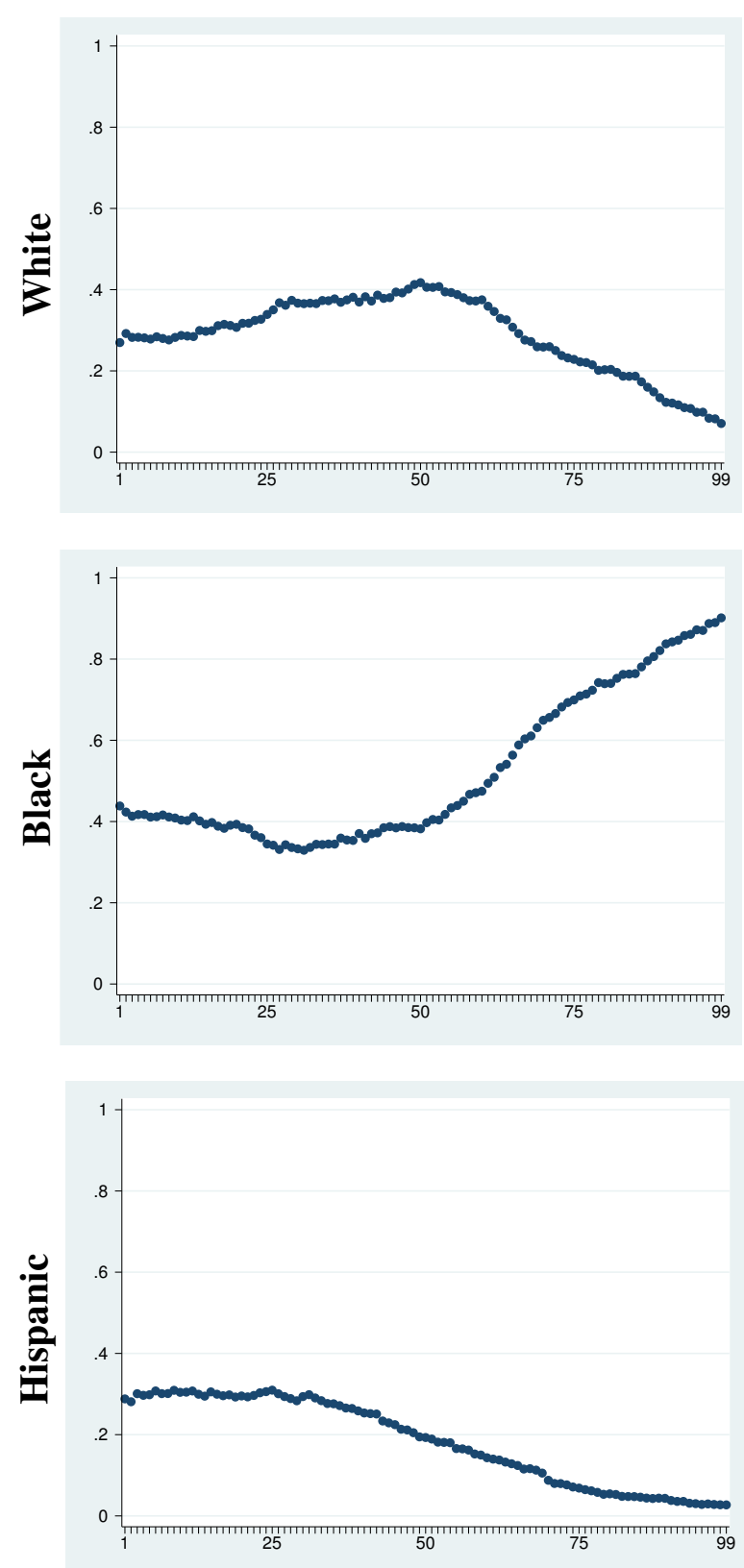

2007 Failed Jail Expansion
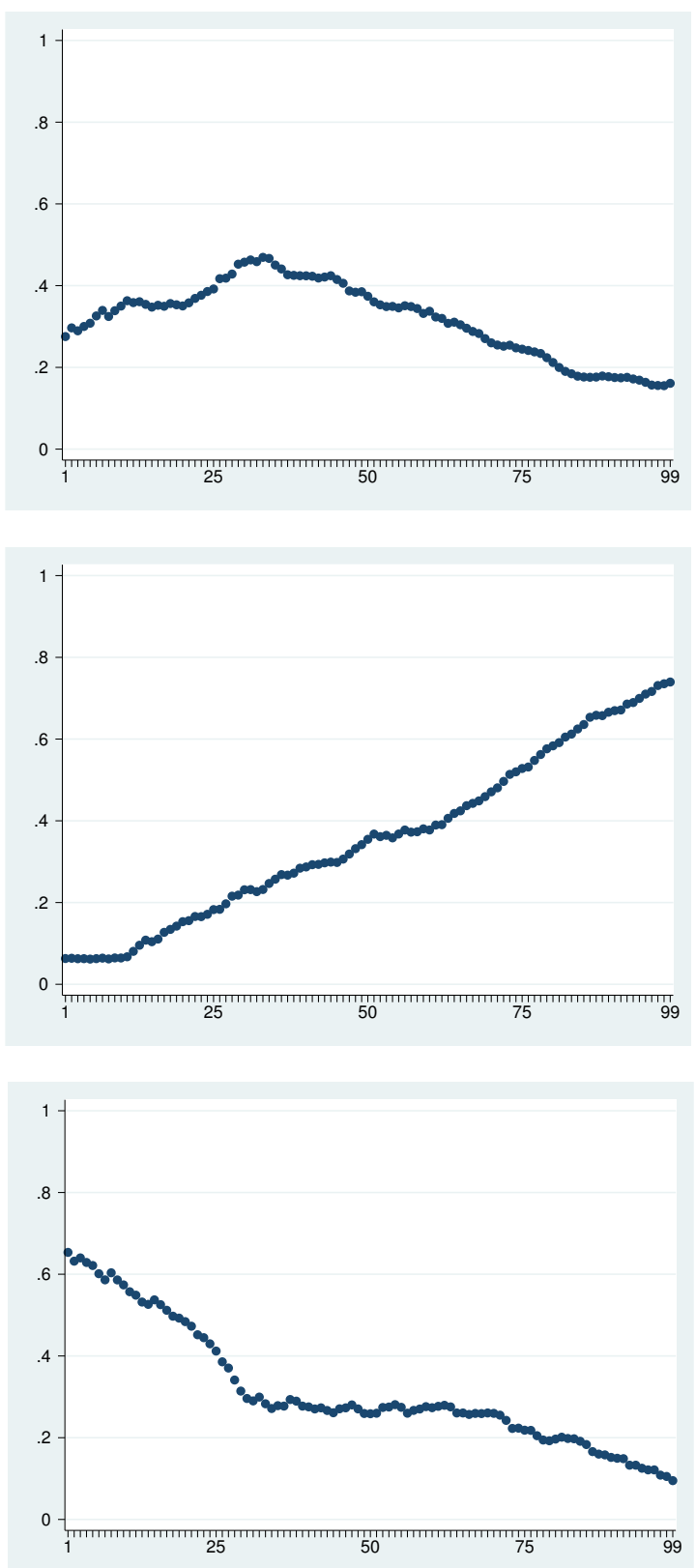

Figure B2: Race/ethnicity over risk score quantile function

Figure Notes: This figure shows the relationship between the demographic characteristics and the quantile function of the predicted recidivism risk score. Each point estimate documents the average racial share in a 40 percentile bandwidth centered at the focal percentile using a uniform kernel. Estimates near the first and ninety-ninth percentiles will reflect narrower, asymmetric bandwidths. 
1994 Penal Code Reform
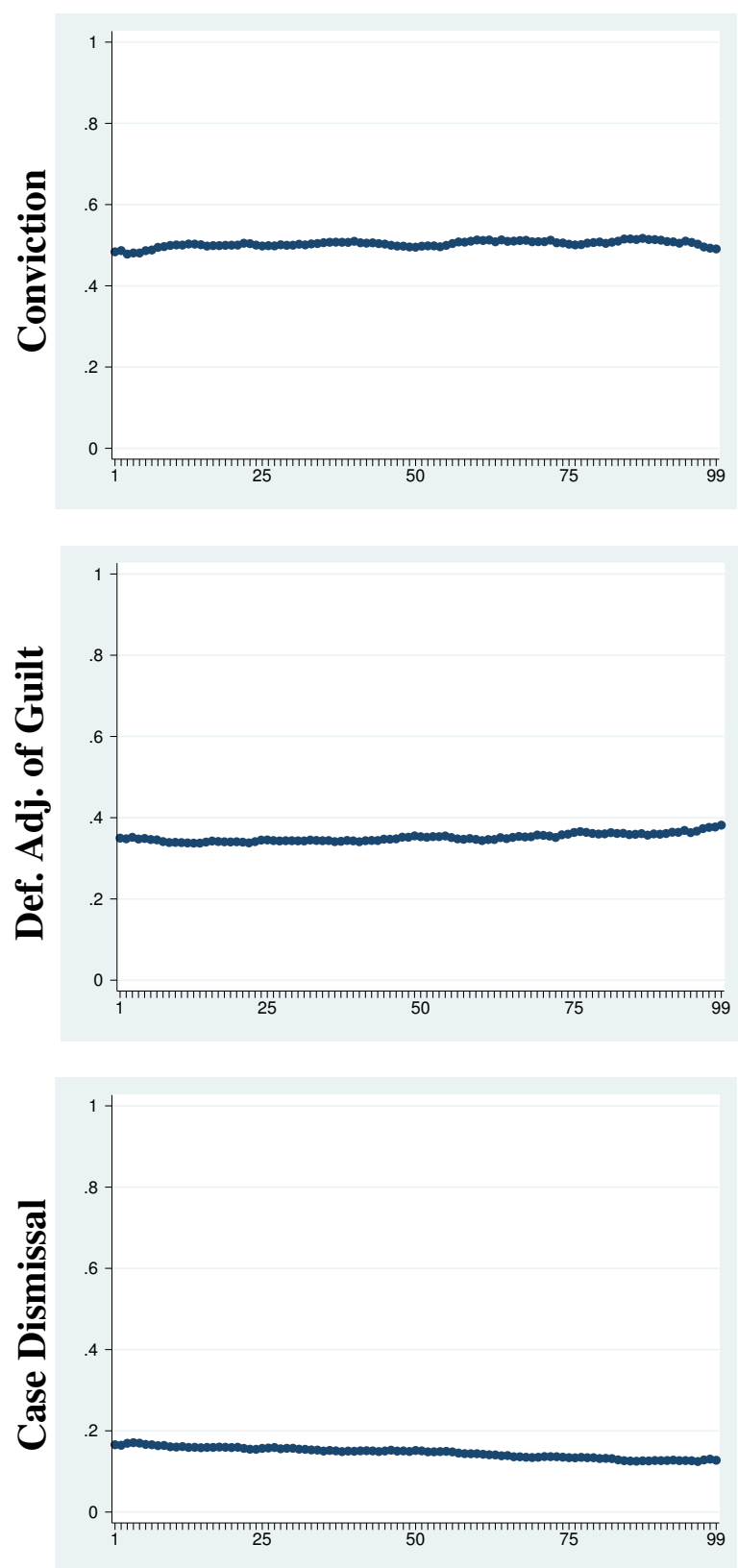

2007 Failed Jail Expansion
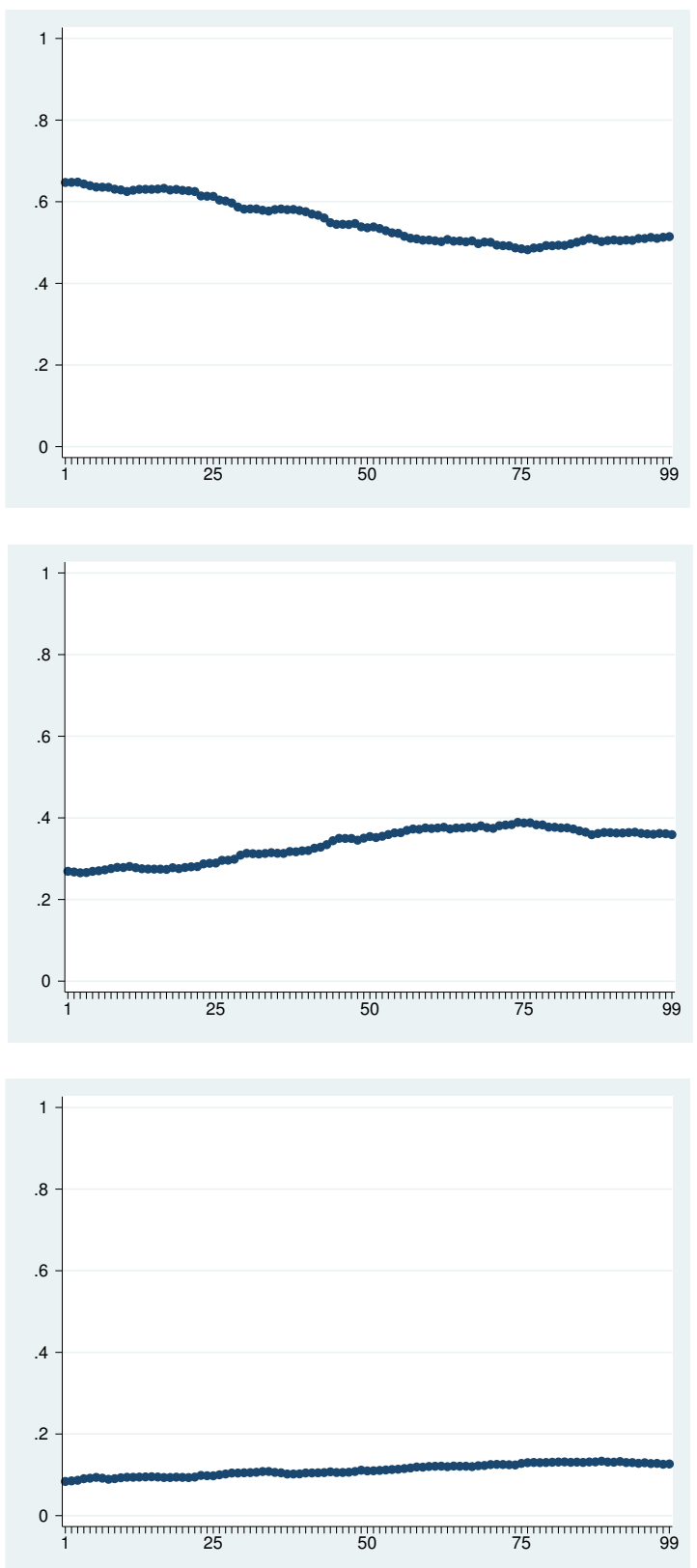

Figure B3: Court outcomes over risk score quantile function

Figure Notes: This figure shows the relationship between the focal outcome variables and the quantile function of the predicted recidivism risk score. Each point estimate documents the average outcome in a 40 percentile bandwidth centered at the focal percentile using a uniform kernel. Estimates near the first and ninety-ninth percentiles will reflect narrower, asymmetric bandwidths. 
1994 Penal Code Reform
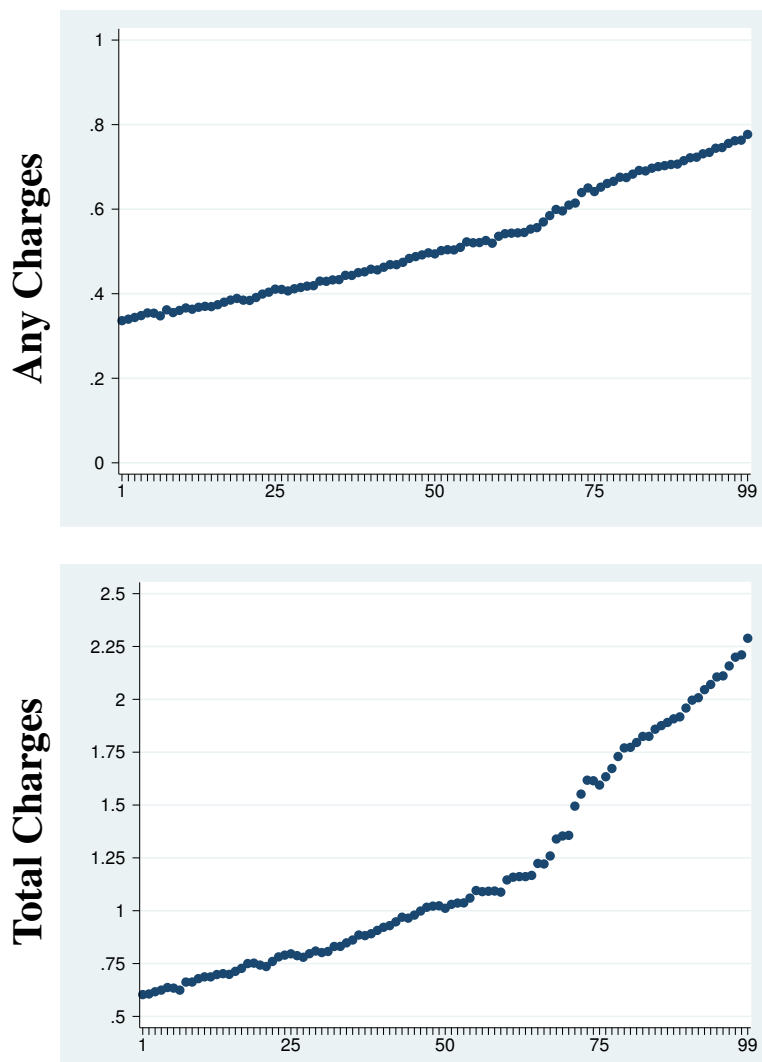

2007 Failed Jail Expansion
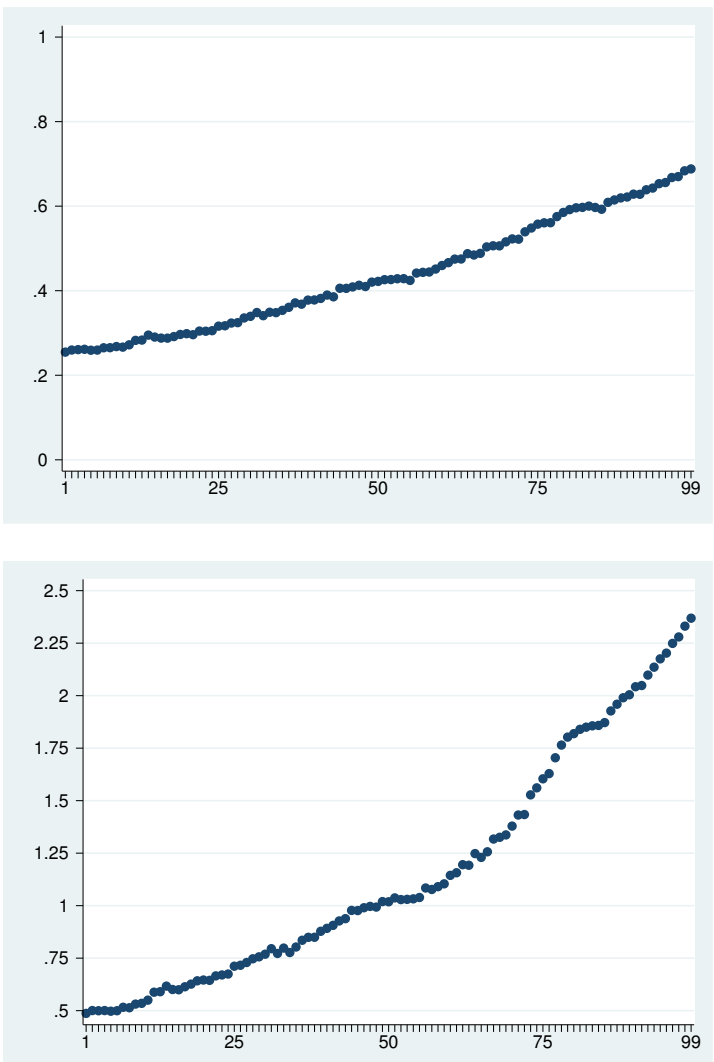

Figure B4: Five-year criminal behavior over risk score quantile function

Figure Notes: This figure shows the relationship between the focal outcome variables and the quantile function of the predicted recidivism risk score. Each point estimate documents the average outcome in a 40 percentile bandwidth centered at the focal percentile using a uniform kernel. Estimates near the first and ninety-ninth percentiles will reflect narrower, asymmetric bandwidths.

1994 Penal Code Reform

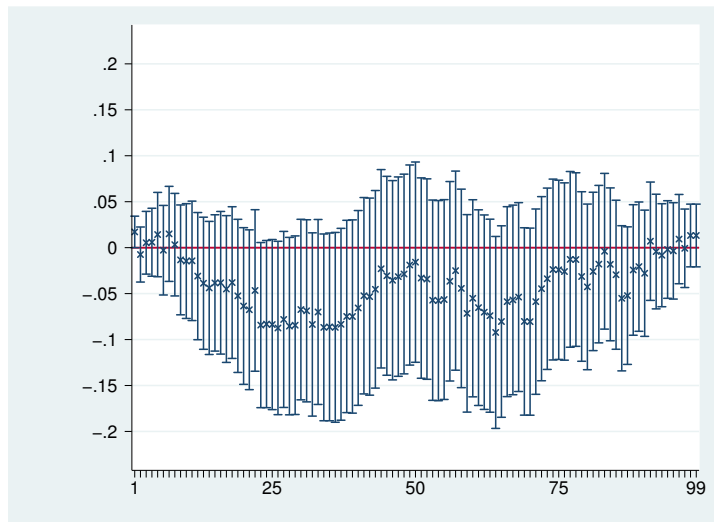

2007 Failed Jail Expansion

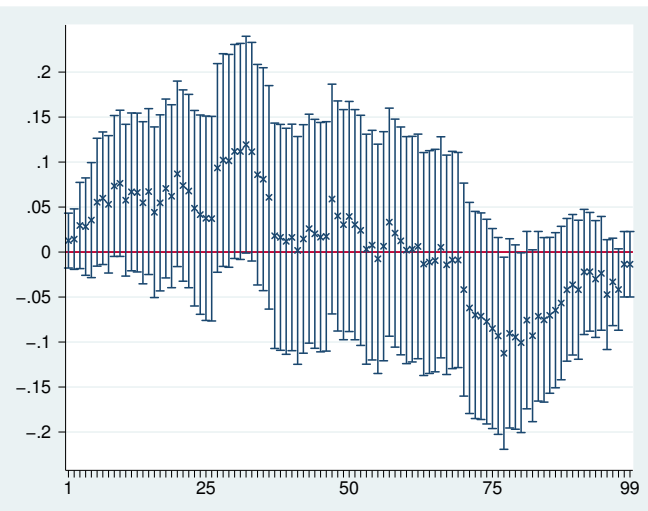

Figure B5: RD balance across risk score quantile function

Figure Notes: This figure shows a series of separate regressions over the quantile function of the predicted recidivism risk score. The percentile-specific estimates document the relationship between the focal date and the CDF of the risk score at that percentile. For uniformity, relevant bandwidths were estimated at the median using specification choices from Figure 2 and applied to the other regressions. Covariates, however, were excluded from the estimation. $90 \%$ confidence intervals are included. 
Table B1: Discontinuities in criminal outcomes, heterogeneous effects

\begin{tabular}{|c|c|c|c|c|c|c|c|}
\hline & $\begin{array}{c}\text { County } \\
\text { Convict. } \\
5 \text { years }\end{array}$ & $\begin{array}{c}\text { County } \\
\text { Convict. } \\
5 \text { years }\end{array}$ & $\begin{array}{c}\text { County } \\
\text { Convict. } \\
5 \text { years }\end{array}$ & $\begin{array}{c}\text { County } \\
\text { Convict. } \\
5 \text { years }\end{array}$ & $\begin{array}{c}\text { County } \\
\text { Convict. } \\
5 \text { years }\end{array}$ & $\begin{array}{l}\text { County } \\
\text { Convict. } \\
5 \text { years }\end{array}$ & $\begin{array}{c}\text { County } \\
\text { Convict. } \\
5 \text { years }\end{array}$ \\
\hline & FULL & MALE & FEMALE & BLACK & HISP & $\mathrm{AGE}<30$ & $\mathrm{AGE} \geq 30$ \\
\hline 1994: Post Reform & $\begin{array}{l}0.682 * * * \\
(0.217)\end{array}$ & $\begin{array}{l}0.606^{* *} \\
(0.257)\end{array}$ & $\begin{array}{l}0.755^{* *} \\
(0.326)\end{array}$ & $\begin{array}{l}0.650 * * \\
(0.314)\end{array}$ & $\begin{array}{c}0.211 \\
(0.335)\end{array}$ & $\begin{array}{l}1.010^{* * * *} \\
(0.354)\end{array}$ & $\begin{array}{c}0.349 \\
(0.227)\end{array}$ \\
\hline Mean of Dep. Var. (Pre Reform) & 1.00 & 1.08 & 0.77 & 1.21 & 0.72 & 1.25 & 0.73 \\
\hline Observations & 5,176 & 3,850 & 1,326 & 2,756 & 919 & 2,765 & 2,411 \\
\hline Order Loc. Poly (p) & 1 & 1 & 1 & 1 & 1 & 1 & 1 \\
\hline Order Bias (q) & 2 & 2 & 2 & 2 & 2 & 2 & 2 \\
\hline BW Loc. Poly. (1/r) & $86 / 86$ & $92 / 92$ & $87 / 91$ & $99 / 100$ & $111 / 92$ & $70 / 68$ & $79 / 101$ \\
\hline BW Bias $(1 / r)$ & $139 / 148$ & $155 / 156$ & $144 / 163$ & $153 / 167$ & $186 / 161$ & $128 / 122$ & $135 / 160$ \\
\hline 2007: Post Reform & $\begin{array}{c}-0.665^{* * * *} \\
(0.251)\end{array}$ & $\begin{array}{c}-0.916^{* * *} \\
(0.281)\end{array}$ & $\begin{array}{c}0.326 \\
(0.596)\end{array}$ & $\begin{array}{c}-0.598 \\
(0.431)\end{array}$ & $\begin{array}{c}-0.659 * \\
(0.344)\end{array}$ & $\begin{array}{c}-0.448 \\
(0.297)\end{array}$ & $\begin{array}{c}-1.016^{* *} \\
(0.418)\end{array}$ \\
\hline Mean of Dep. Var. (Pre Reform) & 1.36 & 1.34 & 1.43 & 1.86 & 0.98 & 1.60 & 1.06 \\
\hline Observations & 5,523 & 4,265 & 1,258 & 2,014 & 1,798 & 3,006 & 2,517 \\
\hline Order Loc. Poly (p) & 1 & 1 & 1 & 1 & 1 & 1 & 1 \\
\hline Order Bias (q) & 2 & 2 & 2 & 2 & 2 & 2 & 2 \\
\hline BW Loc. Poly. (1/r) & $94 / 114$ & $91 / 91$ & $116 / 121$ & $138 / 130$ & $77 / 74$ & $127 / 109$ & $71 / 72$ \\
\hline BW Bias (1/r) & $163 / 181$ & $168 / 158$ & 185 / 186 & $221 / 219$ & $145 / 134$ & $210 / 175$ & $132 / 145$ \\
\hline
\end{tabular}

$* \mathrm{p}<0.1, * * \mathrm{p}<0.05, * * * \mathrm{p}<0.01$.

Table Notes: This table presents estimates of discontinuities in the number of convictions in Harris County over the five-year follow-up period for different gender-, race-, or age-specific subsamples. General RD estimation notes from Table 1 apply. 
Table B2: Discontinuities in employment by other industries

\begin{tabular}{|c|c|c|c|c|}
\hline & \multicolumn{4}{|c|}{ Total Quarters Employed Over 5 Year Follow-up } \\
\hline & $\begin{array}{l}\text { Nat. Resources } \\
\text { and Mining }\end{array}$ & Information & $\begin{array}{l}\text { Finance } \\
\text { Activities }\end{array}$ & $\begin{array}{c}\text { Other } \\
\text { Services }\end{array}$ \\
\hline 1994: Post Reform & $\begin{array}{l}-0.060 \\
(0.163)\end{array}$ & $\begin{array}{c}0.037 \\
(0.098)\end{array}$ & $\begin{array}{c}0.118 \\
(0.256)\end{array}$ & $\begin{array}{l}-0.188 \\
(0.201)\end{array}$ \\
\hline Mean of Dep. Var. (Pre Reform) & 0.08 & 0.10 & 0.17 & 0.39 \\
\hline Observations & 3,932 & 3,932 & 3,932 & 3,932 \\
\hline Order Loc. Poly (p) & 1 & 1 & 1 & 1 \\
\hline Order Bias (q) & 2 & 2 & 2 & 2 \\
\hline BW Loc. Poly. (1/r) & $84 / 75$ & $144 / 137$ & $110 / 113$ & $73 / 76$ \\
\hline BW Bias (1/r) & $130 / 123$ & $238 / 234$ & $162 / 165$ & $138 / 150$ \\
\hline 2007: Post Reform & $\begin{array}{c}-0.067 \\
(0.137)\end{array}$ & $\begin{array}{c}0.048 \\
(0.085)\end{array}$ & $\begin{array}{c}0.244 \\
(0.230)\end{array}$ & $\begin{array}{c}0.322 \\
(0.399)\end{array}$ \\
\hline Mean of Dep. Var. (Pre Reform) & 0.09 & 0.04 & 0.14 & 0.30 \\
\hline Observations & 3,502 & 3,502 & 3,502 & 3,502 \\
\hline Order Loc. Poly (p) & 1 & 1 & 1 & 1 \\
\hline Order Bias (q) & 2 & 2 & 2 & 2 \\
\hline BW Loc. Poly. (1/r) & $122 / 120$ & $47 / 45$ & $77 / 71$ & $141 / 121$ \\
\hline BW Bias (1/r) & $195 / 191$ & $133 / 122$ & $141 / 116$ & $216 / 182$ \\
\hline
\end{tabular}

$* \mathrm{p}<0.1, * * \mathrm{p}<0.05, * * * \mathrm{p}<0.01$.

Table Notes: This table presents estimates of discontinuities in labor market outcomes (from the quarterly unemployment insurance wage records) over a five-year follow-up period for formal employment in specific industries (determined using 2-digit NAICS codes). We present results for the industry supersectors with the highest employment rates for our estimation sample in Table 7. General RD estimation notes from Table 1 apply. 


\section{Robustness Exercises}

Table C1: Discontinuities in criminal activity in state-wide computerized criminal history $(\mathrm{CCH})$ file

\begin{tabular}{lccc}
\hline & $\begin{array}{c}\text { TX CCH } \\
\text { Conviction } \\
5 \text { years }\end{array}$ & $\begin{array}{c}\text { TX CCH } \\
\text { Conviction } \\
\text { Harris } \\
5 \text { years }\end{array}$ & $\begin{array}{c}\text { TX CCH } \\
\text { Conviction } \\
\text { Not Harris } \\
5 \text { years }\end{array}$ \\
\hline 1994: Post Reform & $0.325^{*}$ & $0.316^{*}$ & 0.006 \\
& $(0.179)$ & $(0.168)$ & $(0.056)$ \\
\hline Mean of Dep. Var. (Pre Reform) & 0.51 & 0.44 & 0.07 \\
Observations & 5,176 & 5,176 & 5,176 \\
Order Loc. Poly (p) & 1 & 1 & 1 \\
Order Bias (q) & 2 & 2 & 2 \\
BW Loc. Poly. (1/r) & $87 / 93$ & $86 / 87$ & $144 / 159$ \\
BW Bias (1/r) & $151 / 165$ & $143 / 166$ & $233 / 249$ \\
\hline \hline & & & -0.079 \\
2007: Post Reform & $-0.455^{* *}$ & $-0.388^{* *}$ & $(0.062)$ \\
\hline Mean of Dep. Var. (Pre Reform) & $(0.184)$ & $(0.167)$ & 0.18 \\
Observations & 0.92 & 0.74 & 5,523 \\
Order Loc. Poly (p) & 5,523 & 5,523 & 2 \\
Order Bias (q) & 1 & 1 & $82 / 69$ \\
BW Loc. Poly. (1/r) & 2 & 2 & $149 / 143$ \\
BW Bias (1/r) & $125 / 122$ & $139 / 132$ & \\
\hline
\end{tabular}

$* \mathrm{p}<0.1, * * \mathrm{p}<0.05, * * * \mathrm{p}<0.01$.

Table Notes: This table presents estimates of discontinuities in future criminal convictions using the Texas statewide conviction database. General RD estimation notes from Table 1 apply. 
Table C2: RD results using placebo samples

\begin{tabular}{|c|c|c|c|c|}
\hline & Guilty & $\begin{array}{c}\text { Deferred } \\
\text { Adjudication } \\
\text { of Guilt }\end{array}$ & $\begin{array}{c}\text { Total County } \\
\text { Convictions } \\
5 \text { years }\end{array}$ & $\begin{array}{c}\text { Total Quarters } \\
\text { Employed } \\
5 \text { Years }\end{array}$ \\
\hline 1993: Placebo & $\begin{array}{c}0.021 \\
(0.053)\end{array}$ & $\begin{array}{c}0.006 \\
(0.057)\end{array}$ & $\begin{array}{l}-0.356 * * \\
(0.181)\end{array}$ & $\begin{array}{c}0.023 \\
(0.755)\end{array}$ \\
\hline $\begin{array}{l}\text { Mean of Dep. Var. (Pre Reform) } \\
\text { Observations }\end{array}$ & $\begin{array}{c}0.49 \\
5,733\end{array}$ & $\begin{array}{c}0.36 \\
5,733\end{array}$ & $\begin{array}{c}0.86 \\
5,733\end{array}$ & $\begin{array}{c}5.69 \\
4,270\end{array}$ \\
\hline 1995: Placebo & $\begin{array}{l}-0.010 \\
(0.055)\end{array}$ & $\begin{array}{l}-0.023 \\
(0.046)\end{array}$ & $\begin{array}{l}-0.057 \\
(0.188)\end{array}$ & $\begin{array}{l}-0.104 \\
(0.947)\end{array}$ \\
\hline $\begin{array}{l}\text { Mean of Dep. Var. (Pre Reform) } \\
\text { Observations }\end{array}$ & $\begin{array}{c}0.68 \\
5,060\end{array}$ & $\begin{array}{c}0.17 \\
5,060\end{array}$ & $\begin{array}{c}1.26 \\
5,060\end{array}$ & $\begin{array}{c}6.86 \\
3,913\end{array}$ \\
\hline 2006: Placebo & $\begin{array}{l}-0.050 \\
(0.044)\end{array}$ & $\begin{array}{l}0.079 * * \\
(0.039)\end{array}$ & $\begin{array}{l}-0.239 \\
(0.201)\end{array}$ & $\begin{array}{c}0.020 \\
(0.731)\end{array}$ \\
\hline $\begin{array}{l}\text { Mean of Dep. Var. (Pre Reform) } \\
\text { Observations }\end{array}$ & $\begin{array}{c}0.59 \\
9,866\end{array}$ & $\begin{array}{c}0.29 \\
9,866\end{array}$ & $\begin{array}{c}1.20 \\
9,866\end{array}$ & $\begin{array}{c}6.11 \\
6,454\end{array}$ \\
\hline 2007: Placebo & $\begin{array}{l}-0.012 \\
(0.093)\end{array}$ & $\begin{array}{l}-0.043 \\
(0.084)\end{array}$ & $\begin{array}{c}0.013 \\
(0.270)\end{array}$ & $\begin{array}{c}0.672 \\
(1.454)\end{array}$ \\
\hline $\begin{array}{l}\text { Mean of Dep. Var. (Pre Reform) } \\
\text { Observations }\end{array}$ & $\begin{array}{c}0.63 \\
3,886\end{array}$ & $\begin{array}{c}0.26 \\
3,886\end{array}$ & $\begin{array}{c}1.06 \\
3,886\end{array}$ & $\begin{array}{c}6.57 \\
2,412\end{array}$ \\
\hline 2008: Placebo & $\begin{array}{c}0.045 \\
(0.050)\end{array}$ & $\begin{array}{l}-0.035 \\
(0.052)\end{array}$ & $\begin{array}{c}0.137 \\
(0.139)\end{array}$ & $\begin{array}{l}-0.048 \\
(0.817)\end{array}$ \\
\hline $\begin{array}{l}\text { Mean of Dep. Var. (Pre Reform) } \\
\text { Observations }\end{array}$ & $\begin{array}{c}0.47 \\
9,081\end{array}$ & $\begin{array}{c}0.39 \\
9,081\end{array}$ & $\begin{array}{c}0.86 \\
9,081\end{array}$ & $\begin{array}{c}6.13 \\
5,429\end{array}$ \\
\hline
\end{tabular}

$* \mathrm{p}<0.1, * * \mathrm{p}<0.05, * * * \mathrm{p}<0.01$.

Table Notes: This table presents estimated discontinuities for samples one year prior and one year post our discontinuities as placebo tests. We also include results for a 2007 placebo sample which is composed on the non-responsive courts, specifically District Courts: 176, 177, 178, 180, 182, 183, 185, 226, 337, and 339. General RD estimation notes from Table 1 apply. 
Table C3: RD results using alternative bandwidth selectors (1994)

\begin{tabular}{|c|c|c|c|c|}
\hline & Guilty & $\begin{array}{c}\text { Deferred } \\
\text { Adjudication } \\
\text { of Guilt }\end{array}$ & $\begin{array}{c}\text { Total County } \\
\text { Convictions } \\
5 \text { years }\end{array}$ & $\begin{array}{c}\text { Total Quarters } \\
\text { Employed } \\
5 \text { Years }\end{array}$ \\
\hline 1994: MSE1 & $\begin{array}{l}0.366 * * * \\
(0.060)\end{array}$ & $\begin{array}{l}-0.349 * * * \\
(0.058)\end{array}$ & $\begin{array}{l}0.550 * * * \\
(0.185)\end{array}$ & $\begin{array}{l}-0.228 \\
(0.908)\end{array}$ \\
\hline $\begin{array}{l}\text { BW Loc. Poly. (1/r) } \\
\text { BW Bias (1/r) }\end{array}$ & $\begin{array}{l}106 / 106 \\
174 / 174\end{array}$ & $\begin{array}{l}100 / 100 \\
171 / 171\end{array}$ & $\begin{array}{l}118 / 118 \\
215 / 215\end{array}$ & $\begin{array}{l}102 / 102 \\
166 / 166\end{array}$ \\
\hline 1994: MSE2 & $\begin{array}{l}0.353 * * * \\
(0.058)\end{array}$ & $\begin{array}{l}-0.347 * * * \\
(0.061)\end{array}$ & $\begin{array}{l}0.754 * * * \\
(0.237)\end{array}$ & $\begin{array}{l}-0.207 \\
(0.895)\end{array}$ \\
\hline $\begin{array}{l}\text { BW Loc. Poly. (1/r) } \\
\text { BW Bias (1/r) }\end{array}$ & $\begin{array}{c}138 / 90 \\
231 / 160\end{array}$ & $\begin{array}{l}81 / 111 \\
146 / 177\end{array}$ & $\begin{array}{c}68 / 79 \\
125 / 142\end{array}$ & $\begin{array}{c}114 / 94 \\
200 / 153\end{array}$ \\
\hline 1994: MSE3 & $\begin{array}{l}0.361 * * * \\
(0.061)\end{array}$ & $\begin{array}{l}-0.332 * * * \\
(0.063)\end{array}$ & $\begin{array}{l}0.702 * * * \\
(0.231)\end{array}$ & $\begin{array}{l}-0.229 \\
(0.911)\end{array}$ \\
\hline $\begin{array}{l}\text { BW Loc. Poly. (1/r) } \\
\text { BW Bias (1/r) }\end{array}$ & $\begin{array}{c}94 / 94 \\
171 / 171\end{array}$ & $\begin{array}{c}89 / 89 \\
149 / 149\end{array}$ & $\begin{array}{c}84 / 84 \\
137 / 137\end{array}$ & $\begin{array}{c}98 / 98 \\
168 / 168\end{array}$ \\
\hline 1994: CER1 & $\begin{array}{l}0.355 * * * \\
(0.067)\end{array}$ & $\begin{array}{l}-0.314 * * * \\
(0.068)\end{array}$ & $\begin{array}{l}0.653 * * * \\
(0.214)\end{array}$ & $\begin{array}{l}-0.420 \\
(1.003)\end{array}$ \\
\hline $\begin{array}{l}\text { BW Loc. Poly. (1/r) } \\
\text { BW Bias (1/r) }\end{array}$ & $\begin{array}{c}69 \text { / } 69 \\
174 / 174\end{array}$ & $\begin{array}{c}65 / 65 \\
171 / 171\end{array}$ & $\begin{array}{c}77 / 77 \\
215 / 215\end{array}$ & $\begin{array}{c}68 / 68 \\
166 / 166\end{array}$ \\
\hline 1994: CER2 & $\begin{array}{l}0.351 * * * \\
(0.066)\end{array}$ & $\begin{array}{l}-0.312 * * * \\
(0.070)\end{array}$ & $\begin{array}{l}0.814 * * * \\
(0.278)\end{array}$ & $\begin{array}{l}-0.413 \\
(0.998)\end{array}$ \\
\hline $\begin{array}{l}\text { BW Loc. Poly. (1/r) } \\
\text { BW Bias (1/r) }\end{array}$ & $\begin{array}{c}90 / 58 \\
231 / 160\end{array}$ & $\begin{array}{c}53 / 72 \\
146 / 177\end{array}$ & $\begin{array}{c}44 / 51 \\
125 / 142\end{array}$ & $\begin{array}{c}75 / 62 \\
200 / 153\end{array}$ \\
\hline 1994: CER3 & $\begin{array}{l}0.354 * * * \\
(0.071)\end{array}$ & $\begin{array}{l}-0.294 * * * \\
(0.073)\end{array}$ & $\begin{array}{l}0.816 * * * \\
(0.270)\end{array}$ & $\begin{array}{l}-0.482 \\
(1.017)\end{array}$ \\
\hline $\begin{array}{l}\text { BW Loc. Poly. (1/r) } \\
\text { BW Bias (1/r) }\end{array}$ & $\begin{array}{c}61 / 61 \\
171 / 171\end{array}$ & $\begin{array}{c}58 / 58 \\
149 / 149\end{array}$ & $\begin{array}{c}55 / 55 \\
137 / 137\end{array}$ & $\begin{array}{c}65 / 65 \\
168 / 168\end{array}$ \\
\hline
\end{tabular}

$* \mathrm{p}<0.1, * * \mathrm{p}<0.05, * * * \mathrm{p}<0.01$.

Table Notes: This table presents results from local-polynomial RDs varying the bandwidth selection for the September 1, 1994 natural experiment. The bandwidth selectors are coded as follows: MSE1 (one common mean squared error-optimal bandwidth selector for the RD treatment effect estimator); MSE2 (two different mean squared error-optimal bandwidth selectors (below and above the cutoff) for the RD treatment effect estimator); MSE3 (one common mean squared error-optimal bandwidth selector for the sum of regression estimates); CER1 (one common coverage error rate-optimal bandwidth selector for the RD treatment effect estimator); CER2 (two different coverage error rate-optimal bandwidth selectors (below and above the cutoff) for the RD treatment effect estimator); and, CER3 (one common coverage error rate-optimal bandwidth selector for the sum of regression estimates). All other general RD estimation notes from Table 1 apply. 
Table C4: RD results using alternative bandwidth selectors (2007)

\begin{tabular}{lcccc}
\hline Guilty & $\begin{array}{c}\text { Deferred } \\
\text { Adjudication } \\
\text { of Guilt }\end{array}$ & $\begin{array}{c}\text { Total County } \\
\text { Convictions } \\
5 \text { years }\end{array}$ & $\begin{array}{c}\text { Total Quarters } \\
\text { Employed } \\
5 \text { Years }\end{array}$ \\
\hline 2007: MSE1 & $-0.284 * * *$ & $0.223 * * *$ & $-0.622^{* *}$ & $2.490^{* *}$ \\
& $(0.071)$ & $(0.075)$ & $(0.258)$ & $(1.036)$ \\
\hline BW Loc. Poly. (1/r) & $93 / 93$ & $87 / 87$ & $93 / 93$ & $126 / 126$ \\
BW Bias (1/r) & $152 / 152$ & $141 / 141$ & $156 / 156$ & $219 / 219$ \\
\hline \hline
\end{tabular}

\begin{tabular}{lcccc} 
2007: MSE2 & $-0.277 * * *$ & $0.223 * * *$ & $-0.631 * *$ & $2.707 * *$ \\
& $(0.072)$ & $(0.080)$ & $(0.249)$ & $(1.085)$ \\
\hline BW Loc. Poly. (1/r) & $81 / 90$ & $67 / 78$ & $96 / 111$ & $112 / 114$ \\
BW Bias (1/r) & $156 / 154$ & $127 / 139$ & $165 / 178$ & $185 / 209$ \\
\hline \hline
\end{tabular}

\begin{tabular}{lcccc} 
2007: MSE3 & $-0.322 * * *$ & $0.229 * * *$ & $-0.491 * *$ & $2.750^{* *}$ \\
& $(0.061)$ & $(0.064)$ & $(0.214)$ & $(1.120)$ \\
\hline BW Loc. Poly. (1/r) & $116 / 116$ & $99 / 99$ & $131 / 131$ & $114 / 114$ \\
BW Bias (1/r) & $213 / 213$ & $207 / 207$ & $215 / 215$ & $181 / 181$ \\
\hline \hline
\end{tabular}

\begin{tabular}{lcccc} 
2007: CER1 & $-0.272 * * *$ & $0.219 * *$ & $-1.016 * * *$ & $3.037 * * *$ \\
& $(0.083)$ & $(0.089)$ & $(0.295)$ & $(1.167)$ \\
\hline BW Loc. Poly. (1/r) & $61 / 61$ & $57 / 57$ & $60 / 60$ & $84 / 84$ \\
BW Bias (1/r) & $152 / 152$ & $141 / 141$ & $156 / 156$ & $219 / 219$ \\
\hline \hline
\end{tabular}

\begin{tabular}{lcccc} 
2007: CER2 & $-0.262 * * *$ & $0.174 *$ & $-0.924 * * *$ & $3.356^{* * *}$ \\
& $(0.086)$ & $(0.095)$ & $(0.282)$ & $(1.223)$ \\
\hline BW Loc. Poly. (1/r) & $53 / 58$ & $44 / 51$ & $62 / 72$ & $74 / 76$ \\
BW Bias (1/r) & $156 / 154$ & $127 / 139$ & $165 / 178$ & $185 / 209$ \\
\hline \hline
\end{tabular}

\begin{tabular}{lcccc} 
2007: CER3 & $-0.288^{* * *}$ & $0.224 * * *$ & $-0.662^{* * *}$ & $3.352^{* * *}$ \\
& $(0.071)$ & $(0.079)$ & $(0.244)$ & $(1.242)$ \\
\hline BW Loc. Poly. (1/r) & $75 / 75$ & $64 / 64$ & $85 / 85$ & $76 / 76$ \\
BW Bias (1/r) & $213 / 213$ & $207 / 207$ & $215 / 215$ & $181 / 181$ \\
\hline
\end{tabular}

$* \mathrm{p}<0.1, * * \mathrm{p}<0.05, * * * \mathrm{p}<0.01$.

Table Notes: This table presents results from local-polynomial RDs varying the bandwidth selection for the November 7, 2007 natural experiment. The bandwidth selectors are coded as follows: MSE1 (one common mean squared error-optimal bandwidth selector for the RD treatment effect estimator); MSE2 (two different mean squared error-optimal bandwidth selectors (below and above the cutoff) for the RD treatment effect estimator); MSE3 (one common mean squared error-optimal bandwidth selector for the sum of regression estimates); CER1 (one common coverage error rate-optimal bandwidth selector for the RD treatment effect estimator); CER2 (two different coverage error rate-optimal bandwidth selectors (below and above the cutoff) for the RD treatment effect estimator); and, CER3 (one common coverage error rate-optimal bandwidth selector for the sum of regression estimates). All other general RD estimation notes from Table 1 apply. 
Table C5: RD results using alternative variance estimators

\begin{tabular}{|c|c|c|c|c|}
\hline & Guilty & $\begin{array}{c}\text { Deferred } \\
\text { Adjudication } \\
\text { of Guilt }\end{array}$ & $\begin{array}{c}\text { Total County } \\
\text { Convictions } \\
5 \text { years }\end{array}$ & $\begin{array}{c}\text { Total Quarters } \\
\text { Employed } \\
5 \text { Years }\end{array}$ \\
\hline 1994: Day Cluster & $\begin{array}{l}0.363 * * * \\
(0.063)\end{array}$ & $\begin{array}{l}-0.342 * * * \\
(0.059)\end{array}$ & $\begin{array}{l}0.713 * * * \\
(0.205)\end{array}$ & $\begin{array}{c}-0.242 \\
(0.843)\end{array}$ \\
\hline $\begin{array}{l}\text { BW Loc. Poly. (1/r) } \\
\text { BW Bias (1/r) }\end{array}$ & $\begin{array}{c}107 / 97 \\
179 / 176\end{array}$ & $\begin{array}{c}85 / 96 \\
147 / 171\end{array}$ & $\begin{array}{c}80 / 80 \\
137 / 139\end{array}$ & $\begin{array}{c}99 / 94 \\
165 / 164\end{array}$ \\
\hline 1994: Week Cluster & $\begin{array}{l}0.359 * * * \\
(0.057)\end{array}$ & $\begin{array}{l}-0.347 * * * \\
(0.071)\end{array}$ & $\begin{array}{l}0.712 * * * \\
(0.180)\end{array}$ & $\begin{array}{l}-0.241 \\
(0.736)\end{array}$ \\
\hline $\begin{array}{l}\text { BW Loc. Poly. (1/r) } \\
\text { BW Bias (1/r) }\end{array}$ & $\begin{array}{c}104 / 92 \\
169 / 165\end{array}$ & $\begin{array}{l}94 / 106 \\
150 / 173\end{array}$ & $\begin{array}{c}80 / 69 \\
143 / 131\end{array}$ & $\begin{array}{l}94 / 101 \\
168 / 168\end{array}$ \\
\hline 1994: Nearest Neighbor & $\begin{array}{l}0.362 * * * \\
(0.061)\end{array}$ & $\begin{array}{l}-0.345 * * * \\
(0.061)\end{array}$ & $\begin{array}{l}0.704 * * * \\
(0.232)\end{array}$ & $\begin{array}{l}-0.224 \\
(0.909)\end{array}$ \\
\hline $\begin{array}{l}\text { BW Loc. Poly. (1/r) } \\
\text { BW Bias (1/r) }\end{array}$ & $\begin{array}{c}106 / 94 \\
173 / 170\end{array}$ & $\begin{array}{c}89 / 101 \\
150 / 171\end{array}$ & $\begin{array}{c}85 / 85 \\
138 / 144\end{array}$ & $\begin{array}{c}102 / 98 \\
168 / 166\end{array}$ \\
\hline 2007: Day Cluster & $\begin{array}{l}-0.277 * * * \\
(0.064)\end{array}$ & $\begin{array}{l}0.223 * * * \\
(0.064)\end{array}$ & $\begin{array}{l}-0.687 * * \\
(0.273)\end{array}$ & $\begin{array}{l}2.668 * * * \\
(0.994)\end{array}$ \\
\hline $\begin{array}{l}\text { BW Loc. Poly. (1/r) } \\
\text { BW Bias (1/r) }\end{array}$ & $\begin{array}{c}87 / 87 \\
151 / 146\end{array}$ & $\begin{array}{c}82 / 82 \\
134 / 134\end{array}$ & $\begin{array}{l}86 / 101 \\
152 / 160\end{array}$ & $\begin{array}{l}111 / 108 \\
184 / 193\end{array}$ \\
\hline 2007: Week Cluster & $\begin{array}{l}-0.290 * * * \\
(0.064)\end{array}$ & $\begin{array}{l}0.224 * * * \\
(0.047)\end{array}$ & $\begin{array}{l}-1.154 * * * \\
(0.171)\end{array}$ & $\begin{array}{l}2.624 * * * \\
(0.982)\end{array}$ \\
\hline $\begin{array}{l}\text { BW Loc. Poly. (1/r) } \\
\text { BW Bias (1/r) }\end{array}$ & $\begin{array}{c}96 / 96 \\
159 / 153\end{array}$ & $\begin{array}{c}81 / 81 \\
137 / 137\end{array}$ & $\begin{array}{c}46 / 74 \\
105 / 127\end{array}$ & $\begin{array}{c}102 / 96 \\
178 / 161\end{array}$ \\
\hline 2007: Nearest Neighbor & $\begin{array}{l}-0.285^{* * *} \\
(0.071)\end{array}$ & $\begin{array}{l}0.223 * * * \\
(0.076)\end{array}$ & $\begin{array}{l}-0.632 * * \\
(0.247)\end{array}$ & $\begin{array}{l}2.713 * * \\
(1.090)\end{array}$ \\
\hline $\begin{array}{l}\text { BW Loc. Poly. (1/r) } \\
\text { BW Bias (1/r) }\end{array}$ & $\begin{array}{c}94 / 94 \\
156 / 155\end{array}$ & $\begin{array}{c}87 / 87 \\
141 / 141\end{array}$ & $\begin{array}{l}96 / 113 \\
165 / 180\end{array}$ & $\begin{array}{l}114 / 115 \\
185 / 210\end{array}$ \\
\hline
\end{tabular}

$* \mathrm{p}<0.1, * * \mathrm{p}<0.05, * * * \mathrm{p}<0.01$.

Table Notes: This table presents estimates using alternative variance estimators as indicated. All other general RD estimation notes from Table 1 apply. 
Table C6: RD results without conditioning on covariate characteristics

\begin{tabular}{lcccc}
\hline & Guilty & $\begin{array}{c}\text { Deferred } \\
\text { Adjudication } \\
\text { of Guilt }\end{array}$ & $\begin{array}{c}\text { Total County } \\
\text { Convictions } \\
5 \text { years }\end{array}$ & $\begin{array}{c}\text { Total Quarters } \\
\text { Employed } \\
\text { Y Years }\end{array}$ \\
\hline 1994: Post Reform & $0.367^{* * * *}$ & $\begin{array}{c}-0.320^{* * *} \\
(0.063)\end{array}$ & $\begin{array}{c}0.809 * * * \\
(0.259)\end{array}$ & $\begin{array}{c}-0.296 \\
(0.897)\end{array}$ \\
\hline Mean of Dep. Var. (Pre Reform) & 0.34 & 0.52 & 0.79 & 6.60 \\
Observations & 5,193 & 5,193 & 5,193 & 3,936 \\
Order Loc. Poly (p) & 1 & 1 & 1 & 2 \\
Order Bias (q) & 2 & 2 & 2 & $110 / 106$ \\
BW Loc. Poly. (1/r) & $121 / 105$ & $86 / 90$ & $77 / 77$ & $176 / 175$ \\
BW Bias (1/r) & $195 / 182$ & $147 / 160$ & $129 / 134$ & $2.619 * *$ \\
\hline \hline & & & & $(1.115)$ \\
2007: Post Reform & $-0.275^{* * *}$ & $0.215 * * *$ & $-0.560 * *$ & 6.05 \\
& $(0.073)$ & $(0.076)$ & $(0.269)$ & 3,503 \\
\hline Mean of Dep. Var. (Pre Reform) & 0.65 & 0.25 & 1.15 & 1 \\
Observations & 5,524 & 5,524 & 5,524 & 2 \\
Order Loc. Poly (p) & 1 & 1 & 1 & $123 / 117$ \\
Order Bias (q) & 2 & 2 & $94 / 92$ & $198 / 208$ \\
BW Loc. Poly. (1/r) & $90 / 90$ & $86 / 86$ & $160 / 149$ & 208 \\
BW Bias (1/r) & $154 / 147$ & $140 / 140$ & & \\
\hline
\end{tabular}

$* \mathrm{p}<0.1, * * \mathrm{p}<0.05, * * * \mathrm{p}<0.01$.

Table Notes: This table presents estimates without conditioning on any observable characteristics (age, race/ethnicity, gender, prior misdemeanor record). All other general RD estimation notes from Table 1 apply. 
Table C7: RD results without bias correction or robust standard errors

\begin{tabular}{lcccc}
\hline & Guilty & $\begin{array}{c}\text { Deferred } \\
\text { Adjudication } \\
\text { of Guilt }\end{array}$ & $\begin{array}{c}\text { Total County } \\
\text { Convictions } \\
5 \text { years }\end{array}$ & $\begin{array}{c}\text { Total Quarters } \\
\text { Employed } \\
\text { 5 Years }\end{array}$ \\
\hline 1994: Conventional & $\begin{array}{l}0.362^{* * *} \\
(0.052)\end{array}$ & $\begin{array}{c}-0.357^{* * *} \\
(0.051)\end{array}$ & $\begin{array}{c}0.595^{* * *} \\
(0.192)\end{array}$ & $\begin{array}{c}-0.186 \\
(0.768)\end{array}$ \\
\hline Mean of Dep. Var. (Pre Reform) & 0.34 & 0.52 & 0.79 & 6.60 \\
Observations & 5,176 & 5,176 & 5,176 & 3,932 \\
\hline 1994: Bias-corrected & $0.362^{* * *}$ & $-0.344 * * *$ & $0.704 * * *$ & -0.224 \\
& $(0.052)$ & $(0.051)$ & $(0.192)$ & $(0.768)$ \\
\hline Mean of Dep. Var. (Pre Reform) & 0.34 & 0.52 & 0.79 & 6.60 \\
Observations & 5,176 & 5,176 & 5,176 & 3,932 \\
\hline 2007: Conventional & $-0.290^{* * *}$ & $0.226 * * *$ & $-0.592 * * *$ & $2.304 * *$ \\
& $(0.059)$ & $(0.062)$ & $(0.209)$ & $(0.934)$ \\
\hline Mean of Dep. Var. (Pre Reform) & 0.65 & 0.25 & 1.15 & 6.05 \\
Observations & 5,523 & 5,523 & 5,523 & 3,502 \\
\hline 2007: Bias-corrected & $-0.285^{* * *}$ & $0.223 * * *$ & $-0.631 * * *$ & $2.709 * * *$ \\
\hline Mean of Dep. Var. (Pre Reform) & 0.65 & 0.25 & $(0.209)$ & $(0.934)$ \\
\hline Observations & 5,523 & 5,523 & 1.15 & 6.05 \\
\hline
\end{tabular}

$* \mathrm{p}<0.1, * * \mathrm{p}<0.05, * * * \mathrm{p}<0.01$.

Table Notes: This table presents estimates varying the bias correction and robust standard error procedures recommended by Calonico et al. (2016a). "Conventional" estimates omit both bias correction and robust standard errors. "Bias-corrected" estimates omit only robust standard errors. All other general RD estimation notes from Table 1 apply. 
Table C8: RD results after binning running variable by week

\begin{tabular}{lcccc}
\hline & Guilty & $\begin{array}{c}\text { Deferred } \\
\text { Adjudication } \\
\text { of Guilt }\end{array}$ & $\begin{array}{c}\text { Total County } \\
\text { Convictions } \\
5 \text { years }\end{array}$ & $\begin{array}{c}\text { Total Quarters } \\
\text { Employed } \\
\text { 5 Years }\end{array}$ \\
\hline 1994: Post Reform & $0.400^{* * *}$ & $\begin{array}{c}-0.376^{* * *} \\
(0.062)\end{array}$ & $\begin{array}{c}0.648^{* *} \\
(0.259)\end{array}$ & $\begin{array}{c}-0.141 \\
(0.994)\end{array}$ \\
\hline Mean of Dep. Var. (Pre Reform) & 0.34 & 0.52 & 0.79 & 6.60 \\
Observations & 5,145 & 5,145 & 5,145 & 3,908 \\
Order Loc. Poly (p) & 1 & 1 & 1 & 1 \\
Order Bias (q) & 2 & 2 & 2 & $14 / 14$ \\
BW Loc. Poly. (1/r) & $15 / 15$ & $13 / 15$ & $13 / 11$ & $24 / 23$ \\
BW Bias (1/r) & $28 / 26$ & $23 / 25$ & $22 / 21$ & $3.335^{* * *}$ \\
\hline \hline & & & $-0.467 *$ & $(1.171)$ \\
2007: Post Reform & $-0.319 * * *$ & $0.246 * * *$ & $(0.252)$ & 6.04 \\
& $(0.072)$ & $(0.079)$ & 1.15 & 3,487 \\
\hline Mean of Dep. Var. (Pre Reform) & 0.65 & 0.25 & 5,502 & 1 \\
Observations & 5,502 & 5,502 & 1 & 2 \\
Order Loc. Poly (p) & 1 & 1 & 2 & $14 / 15$ \\
Order Bias (q) & 2 & $25 / 14$ & $25 / 27$ \\
BW Loc. Poly. (1/r) & $15 / 14$ & $12 / 12$ & $25 / 25$ & \\
BW Bias (1/r) & $26 / 23$ & $20 / 20$ & & \\
\hline
\end{tabular}

$* \mathrm{p}<0.1, * * \mathrm{p}<0.05, * * * \mathrm{p}<0.01$.

Table Notes: This table presents results from applying the local-polynomial RD methodology to data averaged at the weekly level instead of at the daily level. All other general RD estimation notes from Table 1 apply. 